\title{
Analysis of Energy-Efficiency Investment Decisions by Small and Medium-Sized Manufacturers
}

M. G. Woodruff

J. M. Roop

H. E. Seely
M. R. Muller

T. W. Jones

J. Dowd

May 1996

Prepared for the Office of Policy and the Office of Energy Efficiency and Renewable Energy U.S. Department of Energy under Contract DE-AC06-76RLO 1830

Pacific Northwest National Laboratory Operated for the U.S. Department of Energy by Battelle

DISTRIBUTION OF THIS DOCUMENT IS UNLLMTED

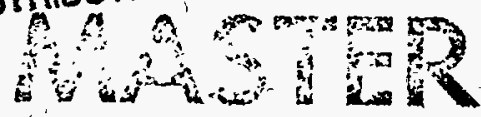




\section{DISCLAIMER}

This report was prepared as an account of work sponsored by an agency of the United States Government. Neither the United States Government nor any agency thereof, nor Battelle Memorial Institute, nor any of their employees; makes any warranty, express or implied, or assumes any legal liability or responsibility for the accuracy, completeness, or usefulness of any information, apparatus, product, or process disclosed, or represents that its use would not infringe privately owned rights. Reference herein to any specific commercial product, process, or service by trade name, trademark, manufacturer, or otherwise does not necessarily constitute or imply its endorsement, recommendation, or favoring by the United States Govemment or any agency thereof, or Battelle Memorial Institute. The views and opinions of authors expressed herein do not necessarily state or reflect those of the United States Government or any agency thereof.

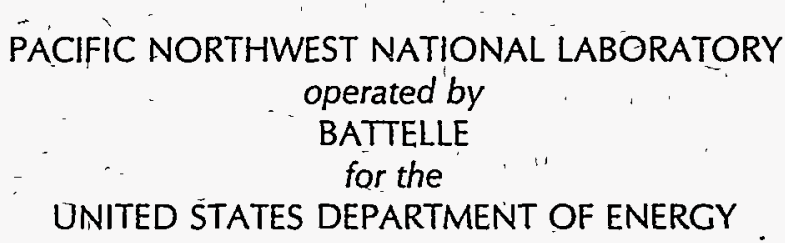

Printed in the United States of America

Available to DOE and DOE contractors from the -

Office of Scientific and Technical Information; P.O. Box 62, Oak Ridge, TN 37831; prices available from (615) $576-8401$.

Available to the public from the National Technical Information Service, U.S. Department of Commerce, 5285 Port Royal Rd., Springfield, VA 22161 
PNNL-11175

UC-1400

\section{Analysis of Energy-Efficiency Investment Decisions by Small and Medium-Size Manufacturers}

M. G. Woodruff

J. M. Roop

H. E. Seely

Pacific Northwest National Laboratory

M. R. Muller

Rutgers University

T. W. Jones

Alliance to Save Energy

J. Dowd

U. S. Department of Energy

May 1996

Prepared for

the Office of Policy and the

Office of Energy Efficiency and Renewable Energy

U.S. Department of Energy

under Contract DE-AC06-76RLO 1830

Pacific Northwest National Laboratory

Richland, Washington 99352 



\section{CONTENTS}

Acknowledgments $\ldots \ldots \ldots \ldots \ldots \ldots \ldots \ldots \ldots \ldots \ldots \ldots \ldots \ldots$ vii

Executive Summary $\ldots \ldots \ldots \ldots \ldots \ldots \ldots \ldots \ldots \ldots \ldots \ldots \ldots \ldots \ldots$

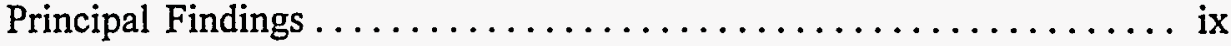

Energy Assessments $\ldots \ldots \ldots \ldots \ldots \ldots \ldots \ldots \ldots \ldots \ldots \ldots$ ix

Implementation of Recommendations . . . . . . . . . . . . . .

Payback Periods and Discount Rates ............... xii

Factors Influencing Investment Behavior............ xii

Recommendations $\ldots \ldots \ldots \ldots \ldots \ldots \ldots \ldots \ldots \ldots \ldots \ldots \ldots \ldots \ldots \ldots \ldots \ldots \ldots \ldots$

1. Introduction $\ldots \ldots \ldots \ldots \ldots \ldots \ldots \ldots \ldots \ldots \ldots \ldots \ldots \ldots$

2. Background $\ldots \ldots \ldots \ldots \ldots \ldots \ldots \ldots \ldots \ldots \ldots \ldots \ldots \ldots \ldots$

Program Description $\ldots \ldots \ldots \ldots \ldots \ldots \ldots \ldots \ldots \ldots \ldots \ldots \ldots, \ldots \ldots \ldots$

Client Profiles.$\ldots \ldots \ldots \ldots \ldots \ldots \ldots \ldots \ldots \ldots \ldots \ldots \ldots$

3. Assessment Recommendations and Implementation Rates $\ldots \ldots \ldots 11$

Analysis of Assessment Recommendations . . . . . . . . . . . . 11

Analysis of Implementation Rates and Energy

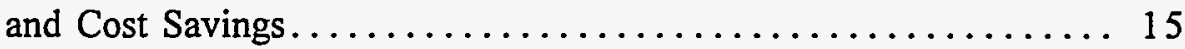

Variation by Type of Assessment Recommendation.......... 16

Variation by Employment Size Classes .............. 20

Variation by Sales Size Classes .................... 22

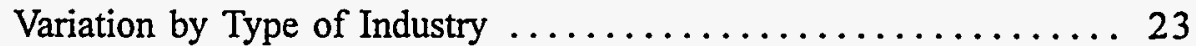

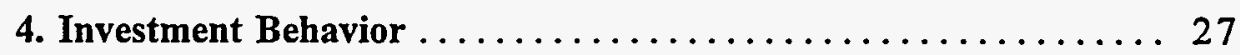

Payback Period and Implicit Discount Rate Analysis.......... 27

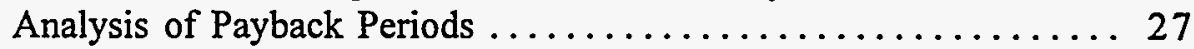

Implicit Discount Rates ........................ 34

Why Some Energy Efficiency Measures Are Not Implemented..... 35

Analysis of Rejection Codes in the EADC Database $\ldots \ldots \ldots \ldots \ldots 35$

1991 EADC Callback Interviews . . . . . . . . . . . . . . . . . . . . . 38

1994 EADC Client Survey of 104 Companies. . . . . . . . . . . . . . . 39

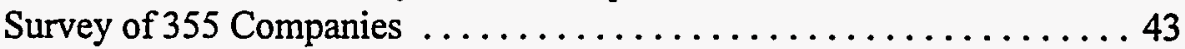

Observations From Industry Roundtables $\ldots \ldots \ldots \ldots \ldots \ldots \ldots$

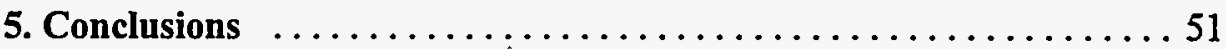

Findings and Observations . ....................... 51

A Typical Energy Assessment ..................... 51

Longevity of Implemented Savings $\ldots \ldots \ldots \ldots \ldots \ldots \ldots \ldots \ldots \ldots$

Implementation Experience at Smaller Versus Larger Plants.$\ldots \ldots \ldots 53$

Payback Period and Discount Rate Results . . . . . . . . . . . . 53

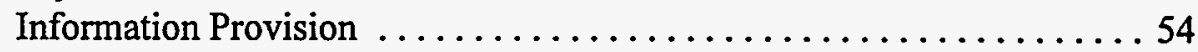


Recommendations ....................... 55

Helping Small Companies Access and Evaluate Energy-Efficiency Information ............................ 55

Enabling Investments Through Technical and Financing Assistance ........................... 55

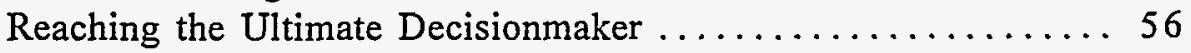

Fostering Energy-Efficiency Networks .............. 56

Expanding the Technical Resources Available to the IACs ...... 57

Enhancing Assessment Data Collection............... 58

Appendix A. Description of the Energy Assessment Process . . . . . 59

The Energy Assessment Process . . . . . . . . . . . . . . . . 59

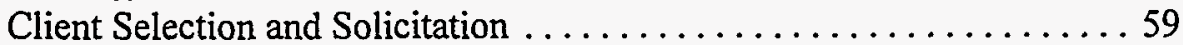

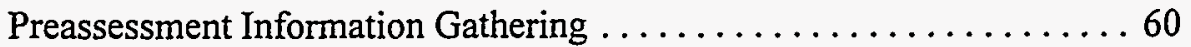

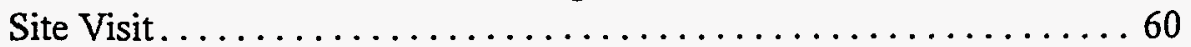

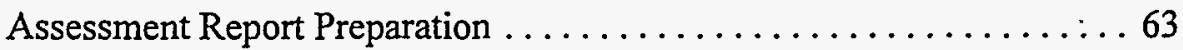

Implementation. . . . . . .

Appendix B. Benefits of the IAC Program $\ldots \ldots \ldots \ldots \ldots \ldots \ldots 6$

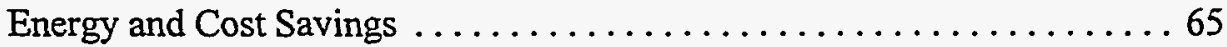

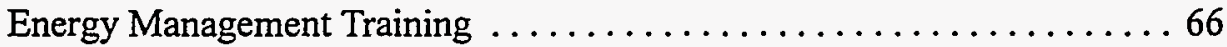

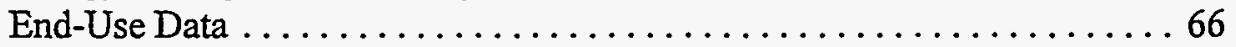

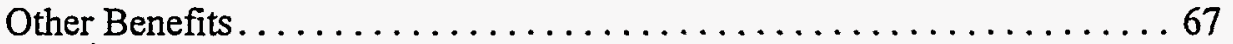

Appendix C. University Participation in the IAC Program $\ldots \ldots \ldots 69$

Appendix D. Rejection Code Results $\ldots \ldots \ldots \ldots \ldots \ldots \ldots \ldots \ldots$

Appendix E. Methodology for Payback Period

and Implicit Discount Rate Analysis $\ldots \ldots \ldots \ldots \ldots \ldots \ldots \ldots \ldots$

Database Analysis........................ 73

Determining Implicit Discount Rates From Payback Periods . . . . . . . 74

References and Bibliography $\ldots \ldots \ldots \ldots \ldots \ldots \ldots \ldots \ldots \ldots 77$ 
Tables

ES-1. Ranking of Measures by Frequency ................. xi

2-1. Two-Digit Manufacturing Standard Industrial Classification (SIC) Codes . . . . . . . . . . . . . . . . . 7

3-1. Classes of Assessment Recommendations ............ 13

3-2. Implementation Rate by Employment Size Class ......... 21

3-3. Implementation Rate by Sales Size Class ............ 23

3-4. Variation in Implementation Rate, Energy Savings, and Cost Savings by Two-Digit SIC Code ............. 25

4-1. Two-Digit Assessment Recommendation Categories......... 28

4-2. Quartile-Based Statistics on Implementation Rates, Costs, and Payback Periods by Two-Digit ARC............. 29

4-3. Number of Recommendations With Payback Periods in Given Ranges........................ 31

4-4. Number of Recommendations With Implementation Costs

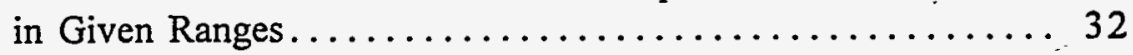

4-5. Variation of Plant Characteristics With Average Assessment Payback Period for Implemented Measures....... 33

4-6. Distribution of Recommended Measures Among Five Payback Period Ranges .................... 34

4-7. Selected EADC Database Rejection Codes............. 36

4-8. Distribution of Recommendations by Reason for Rejection.... 37

4-9. Response to Question on Large Investment .............. 40

$4-10$. Reasons for Nonimplementation ................ 44

4-11. Reasons for Nonimplementation of Energy-Efficiency Measures, by Reader of Report (Energy Savings Basis) ....... 45

4-12. Reasons for Nonimplementation of Energy-Efficiency Measures, by Reader of Report (Cost Savings Basis) ........ 46

$5-1$. Ranking of Measures by Frequency ............... 52

C-1. University Participation in the IAC Program ...........69

D-1. EADC Database Rejection Codes ............... 71

D-2. Distribution of Recommendations Among Rejection Codes ... 72

E-1. Implicit Real Discount Rates as a Function of Payback Period and Investment Lifetime ............... 76

Figures

2-1. Service Territories Covered by Current Industrial Assessment Centers .............................. 4

2-2. . Distribution of Energy Assessments by Two-Digit SIC Codes . . . . 6

2-3. Number of Energy Assessments by Industry and Region ..... 8

2-4. Number of Energy Assessments by Sales Size Class ....... 8

2-5. Number of Energy Assessments by Employment Size Class ..... 9

2-6. Number of Energy Assessments by Two-Digit SIC Code and Employment Size Class ................... 9

2-7. Number of Energy Assessments by Two-Digit SIC Code and Sales Size Class....................... 10 
3-1. Total Number of Assessment Recommendations by Two-Digit SIC Code .................... 11

3-2. Number of Assessment Recommendations by Two-Digit SIC Code and Sales Size Class ................... 12

3-3. Number of Assessment Recommendations by Two-Digit SIC Code and Employment Size Class ............. 12

3-4. Number of Recommendations by Class of Assessment Recommendation....................... 14

3-5. Number of Recommended and Implemented ARs by Class of Assessment Recommendation ........... 17

3-6. Implemented Energy Savings by Class of Assessment Recommendation...................... 18

3-7. Implemented Cost Savings by Class of Assessment Recommendation....................... 19

3-8. Recommended and Implemented Assessment Recommendations by Employment Size............ 20

3-9. Implemented Energy Savings by Employment Size Class ..... 21

3-10. Implemented Cost Savings by Employment Size Class ...... 22

3-11. Recommended and Implemented Assessment Recommendations by Sales Size .............. 23

3-12. Implemented Energy Savings by Sales Size Class $\ldots \ldots \ldots \ldots 24$

3-13. Implemented Cost Savings by Sales Size Class .......... 24

4-1. Implementation Rate Versus Implementation Cost ........ 30

4-2. Implementation Rate Versus Payback Period .......... 30 


\section{ACKNOWLEDGMENTS}

The authors wish to express gratitude to the following reviewers for their input: Charles Glaser of the U.S. Department of Energy; Warren M. Heffington of Texas A\&M University; George Wheeler of Oregon State University; Larry Ambs of the University of Massachusetts; Scott Dunning of the University of Maine; Dr. F. William Kirsch and William J. Clark of the Industrial Technology and Energy Management Division, University City Science Center; Michaela M. Abraham of Oak Ridge National Laboratory; and Neal Elliott of the American Council for an Energy-Efficient Economy.

Thanks also to Dr. F. William Kirsch and William J. Clark for allowing findings from their client interview study to be incorporated into this report. 



\section{EXECUTIVE SUMMARY}

This report highlights the results of a comprehensive analysis of investment decisions regarding energy-efficiency measures at small and medium-sized manufacturing plants. The analysis is based primarily on the experiences of companies participating in the U.S. Department of Energy's Industrial Assessment Center (IAC) program. The IAC program (formerly called the Energy Analysis and Diagnostic Center (EADC) program) is a network of universitybased centers that provides energy and waste assessments to small and mediumsized manufacturing plants.

The purposes of this report are to do the following:

- Examine what the data collected by the program reveal about patterns of implementation of recommended energy-efficiency measures

- Evaluate how various factors, such as the type of industry, the characteristics of the manufacturing plants, or the cost of recommended measures, appear to affect implementation rates

- Examire reasons why recommended energy-saving measures are accepted or rejected

The report draws on a detailed analysis of the DOE Industrial Assessment Database (also referred to as the "EADC database") and on the findings of four other studies. These studies involved efforts to contact companies that had received an energy assessment to (1) discuss in depth the reasons that measures are accepted or rejected, (2) investigate the extent to which implemented measures are maintained over time, and (3) investigate various investment issues faced by small and medium-sized manufacturing companies.

\section{Principal Findings}

\section{Energy Assessments}

Energy assessments are performed most frequently in the fabricated metal products (Standard Industrial Classification, or SIC, code 34) and food and kindred products (SIC 20) industries, both of which have a high concentration of small and medium-sized plants. Assessments are performed least frequently in the leather and leather products (SIC 31) and petroleum refining (SIC 29) 
industries. No assessments have been performed in the tobacco industry (SIC 21).

The program is reaching even the smaller establishments within its client base of small and medium-sized manufacturing plants. On average, a plant receiving an assessment has about 160 employees, on the order of $\$ 21$ million in annual sales, and $\$ 364,000$ in annual energy expenditures. Roughly twothirds of the energy assessments have been conducted at plants with less than $\$ 20$ million in annual sales and fewer than 200 employees. The plants most frequently receiving assessments have under $\$ 10$ million in annual sales and fewer than 100 employees.

On average, a manufacturing plant will save about 4.4 billion Btu of energy per year as a result of implementing energy-saving recommendations and will reduce its energy costs by about 10 percent. A plant typically pays for these measures within 2 years of the change.

\section{Implementation of Recommendations}

Through 1992, on average, plants implemented 50 to 61 percent of the assessment recommendations (ARs) they received. ${ }^{l}$ An AR is considered implemented when the plant reports that it has actually implemented it or that it plans to do so within 2 years of the assessment.

Table ES-1 summarizes the observations from the EADC database on the top recommended and implemented measures and those that save the most energy and money.

The types of recommendations least likely to be made apply to drying, heat treatment, and cogeneration. Measures such as cogeneration are infrequently implemented. High first cost and the complexity of such projects might account for the low implementation rate of this recommendation.

Implementation rates by two-digit SIC code range from about 56 percent to more than 73 percent. The lowest implementation rates are in the pulp and paper (SIC 26) and primary metals (SIC 33) industries, both energy-intensive industries. The highest implementation rate is in petroleum and coal products (SIC 29).

\footnotetext{
IThrough 1992, more than 50 percent of all ARs in the EADC database were implemented. This value increases to about 61 percent when those AR records are dropped that have zeroes or blanks in the implementation status field. (This field should contain an integer value between 1 and 5.)
} 
Table ES-1. Ranking of Measures by Frequency

\begin{tabular}{|c|c|c|c|}
\hline $\begin{array}{l}\text { Most Frequently } \\
\text { Recommended Measures }\end{array}$ & $\begin{array}{c}\text { Measures with } \\
\text { the Highest } \\
\text { Implementation Rate }\end{array}$ & $\begin{array}{l}\text { Measures Saving } \\
\text { the Most Energy }\end{array}$ & $\begin{array}{l}\text { Measures Saving } \\
\text { the Most Money }\end{array}$ \\
\hline Lighting & Steam Systems & $\begin{array}{l}\text { Heat Recovery } \\
\text { and Containment }\end{array}$ & $\begin{array}{l}\text { HVAC Systems and } \\
\text { Building Envelope } \\
\text { Changes }\end{array}$ \\
\hline $\begin{array}{l}\text { HVAC Systems and } \\
\text { Building Envelope } \\
\text { Changes }\end{array}$ & Boilers & Boilers & $\begin{array}{l}\text { Heat Recovery } \\
\text { and Containment }\end{array}$ \\
\hline $\begin{array}{l}\text { Heat Recovery } \\
\text { and Containment }\end{array}$ & Air Compressors & $\begin{array}{l}\text { HVAC Systems and } \\
\text { Building Envelope } \\
\text { Changes }\end{array}$ & Lighting \\
\hline Air Compressors & Lighting & Operational Changes & Boilers \\
\hline Motors & Motors & Steam Systems & Operational Changes \\
\hline Operational changes & Operational Changes & Lighting & Motors \\
\hline
\end{tabular}

Note: Only the measures ranked first through sixth (in that order) are listed in each column.

Smaller establishments receive a higher number of assessments and, hence, a higher number of ARs than larger plants. However, implementation rates are roughly the same for all sizes of plants, as are the number of recommendations and implementations per assessment. In addition, there appears to be little or no correlation between implementation rates and energy and cost savings. The cost savings, however, do appear to bear some relationship to the energy savings.

Almost 9.5 trillion Btu of energy have been saved over the period from 1980 to 1992, and more than 3 trillion Btu of these savings have occurred just within plants with 100 to 199 employees. Similarly, more than $\$ 70$ million have been saved over the same period, and almost a third of these savings have occurred in the same size class of plant.

Two of the studies reviewed for this report confirm that the savings originally achieved via implementation of ARs persist. More than 80 percent of the implemented energy savings continue to be achieved up to 7 years after an assessment. In addition, 12 percent of the recommen thens there not originally implemented were eventually adopted, sucis that the 
implementation rates reported initially by the IAC program may understate the actual savings. Moreover, the assessments continued to influence companies' behavior. For example, some companies reported that, as a result of the energy assessment, energy-efficient lighting was installed in a new facility that was constructed after the assessment.

\section{Payback Periods and Discount Rates}

Most small and medium-sized plants participating in the IAC program will invest in energy-efficiency measures only if their initial capital cost can be paid back in operational savings within 2 years. This finding is consistent with the other studies reviewed in this report, which indicates that a 2-year payback period is the typical investment threshold for small and medium-sized manufacturing plants. In fact, the most frequently recommended and implemented measures had payback periods of 1 year or less. (The average payback period was also about 1 year, both for implemented ARs and for the full set of recommendations.) Contrary to expectations, implementation rates appear to drop off little, if any, with increasing payback period. Moreover, the average payback period associated with implemented measures does not appear to increase with plant size or annual energy cost.

For most ARs, a payback period of up to 2 years implies an implicit (real) discount rate of about 50 percent. This is significantly higher than the values typically used to characterize industrial investment decisions in energyeconomic models. The majority of companies are modeled using a discount rate of 25 percent, a value intended to characterize the investment behavior of less flexible, more capital-constrained companies. The findings of this study indicate that another tier of companies exists-the small and medium-sized manufacturing companies-for which a discount rate of about 50 percent or more is probably more appropriate.

\section{Factors Influencing Investment Behavior}

Based on the detailed analysis of the EADC database, first cost appears somewhat more important than payback period in determining whether a measure will be implemented. The implementation rate appears to decrease as both implementation cost and payback period increase, as would be expected. However, the relationship is more pronounced for implementation cost. This 
finding makes sense in light of the plant sizes targeted by the IAC program, as small and medium-sized companies are likely to be more capital-constrained than larger companies and thus less able to invest in even those higher cost measures that have very short payback periods.

Three recent studies-two surveys of companies that had received an IAC audit and a set of roundtable discussions with small and medium-sized companies-also explored financial and other factors that affect investment decisionmaking at small and medium-sized manufacturing plants. In addition, an analysis of the rejection codes contained in the EADC database was carried out for this report. These four analyses agree that financial concerns are important in determining whether an energy-saving recommendation will be implemented. The ARs rejected tend to be the highest cost measures, with the average cost of measures rejected for financial reasons 10 times the average cost of measures rejected for other reasons.

In fact, one of these studies reveals that first cost appears to be a major factor in decisionmaking regardless of investment size, even more important than the payback period (as was found in the analysis of the EADC database). A recommendation costing more than $\$ 5,000$ was typically considered a "large investment" regardless of payback period. Even when a high-cost measure was not considered a "major financial undertaking," companies still felt that cost was the major issue in deciding whether to implement the measure.

Capital investment decisions appear to reflect plant size rather than energy intensity. That is, plants that reported a "large investment" threshold of $\$ 20,000$ averaged twice the sales of plants whose threshold was $\$ 1,000$. However, average energy expenditures are about the same across various investment threshold categories.

Generally, what companies consider to be a large investment varies with the hierarchical position of the decisionmaker. Involvement of plant-level personnel in the decision process appears to increase the focus on the benefits of investing in higher cost measures. The typical reasons for rejecting energyefficiency recommendations appears to vary with the hierarchical position of the decisionmaker.

Concerns about technical issues or impacts on production are frequently cited as reasons why measures to improve energy efficiency are rarely undertaken for the potential cost savings alone. 


\section{Recommendations}

Several policy options for enhancing the support that the Department of Energy and others provide to small and medium-sized manufacturing companies are recommended based on the analysis presented in this report and the findings of the studies reviewed herein. Some of these options apply specifically to the IAC program, while others are more general.

- Accessing and Evaluating Energy-Efficiency Information. Proactive information and cooperative demonstration programs should be instituted to help smaller companies make wise investment decisions. For example, local utilities, State energy offices, and regional Department of Energy offices should work together to provide accurate cost and performance information on energy-efficient process technologies and to demonstrate such technologies. Utilities should expand their efforts to provide small companies with assistance, particularly with enhanced metering and submetering programs.

- Enabling Investment Through Technical and Financial Assistance. Smaller companies need greater access to higher levels of energy-efficiency expertise. States should establish energy manager pools to share "hands on" assistance for identifying and implementing energy-efficiency improvements. In addition, energy assessment reports should include information on sources of financing, and the Department of Energy or local utilities should conduct workshops to educate industrial decisionmakers on energy service companies and vendor financing opportunities.

- Reaching the Ultimate Decisionmaker. Each energy assessment team should try to reach the ultimate decisionmaker (for example, plant manager versus higher management) for the assessment recommendations and provide different presentations to different company representatives. Assessment teams also should inquire about the need for followup technical evaluation services from the IAC or a third party.

- Fostering Energy-Efficiency Networks. Smaller companies need more opportunities to exchange information on energy-efficiency projects. The - IACs or others should develop individual and regional programs to increase peer-to-peer exchanges within industry by (1) encouraging participation in local energy-related associations, (2) developing energy engineer program groups where they do not exist, and (3) fostering industry-specific local 
energy engineering groups. Also, regional clearinghouses for energy efficiency should be established to serve as information clearinghouses on energy-efficient technologies, to provide a single point of contact to locate relevant experts, and to serve as regional technology demonstration and training sites.

- Expanding the Technical Resources Available to the IACs. The energy assessment teams should be provided with enhanced tools and assessment aids. These include industry-specific guides containing industry information and energy-efficiency ideas, including potential process improvements. In addition, a computer tool should be developed that contains industryspecific information such that it can walk an assessment team through a typical plant within a given SIC code. The IAC directors and teams should be asked what additional tools would be useful to them.

- Enhancing Assessment Data Collection. To facilitate analysis using the EADC database together with other data sources, the energy assessment teams should, if possible, identify for each assessment any reports to the Census Bureau that an establishment has filed in the recent past. 



\section{INTRODUCTION}

Small and medium-sized manufacturing plants (those with fewer than 500 employees) represent more than 98 percent of the 374,000 establishments in the U.S. manufacturing industry, 64 percent of employees in the total manufacturing labor force, and more than 42 percent of total manufacturing energy consumption. ${ }^{\prime}$ Their energy bill in 1991 was about $\$ 31$ billion, roughly one-half of the total U.S. manufacturing sector's energy expenditures.

The Industrial Assessment Center (IAC) program (formerly called the Energy Analysis and Diagnostic Center (EADC) program) of the U.S. Department of Energy (DOE) has been in operation since 1976. The program comprises a network of university-based centers that provide energy assessments for small and medium-sized manufacturing plants. The program has become the object of increased attention as a mechanism for improving the energy efficiency and productivity of small and medium-sized manufacturing plants and for reducing U.S. greenhouse gas emissions (Clinton and Gore, 1993). In 1994, the program mission was expanded with the addition of the "industrial assessment"; this expanded service examines waste streams, energy use, and productivity.

Information on the energy-saving measures recommended during the assessments and the plants' response to them is contained in the DOE Industrial Assessment Database (also referred to as the "EADC database") housed at the Office of Industrial Productivity and Energy Assessment at Rutgers University. This database is available to the public at no cost via computer modem or Internet access. ${ }^{2}$

The purposes of this report are the following:

- To examine what the data collected by the IAC program reveal about patterns of implementation of recommended energy-efficiency measures

\footnotetext{
${ }^{\prime}$ Manufacturing establishments are usually defined as plants, factories, facilities, or mills. In this report, plants and establishments are used interchangeably. The report further distinguishes between plants and companies. Manufacturing companies may comprise a single establishment or multiple establishments. Findings from the EADC databases are applicable to plants.

${ }^{2}$ See Appendix B for information on how to access the database.
} 
- To evaluate how various factors, such as the type of industry, the characteristics of manufacturing plants, or the cost of recommended measures, appear to affect implementation rates

- To examine reasons why recommended energy-saving measures are accepted or rejected

The report draws on a detailed analysis of the EADC database and on findings from other analyses, which involved efforts to contact companies that received an assessment to (1) discuss in depth the reasons why measures are accepted or rejected, (2) investigate the extent to which implemented measures are maintained over time, and (3) investigate various investment issues faced by small and medium-sized companies.

The analyses of EADC data discussed in this report were conducted using data that have been aggregated over time. Year-to-year variations in the data and analysis results may exist, in part, as a result of changes in energy prices and other economic factors, as well as changes over time in the IAC program. However, this report is concerned with the aggregate experience of the program since its inception.

The intended audience for the report includes State energy offices, utilities, energy analysts, and others interested in the factors that influence decisions to implement energy-efficiency measures in small and medium-sized companies. Manufacturing companies that are not currently participating in the IAC program may also benefit from the report's findings. In addition, the information in this report informs the Department of Energy's continuing effort to encourage U.S. industries to invest in energy-efficiency measures.

The report is organized as follows: Chapter 2 describes the IAC program and its client customers. Chapter 3 presents an assessment of the recommendations made and the implementation results. Chapter 4 discusses the factors that influence implementation rates and examines investment behavior in detail, drawing on the EADC database itself and on recent efforts to engage in discussions with company representatives. Chapter 5 summarizes the key observations and recommendations that flow from the analysis contained in this report. The appendices provide more details on the IAC program, the energy assessment process, and various aspects of the data analysis methodology. 


\section{BACKGROUND}

The Industrial Assessment Center (IAC) program provides assessments of energy use characteristics and potential energy-saving measures for small and medium-sized manufacturing plants across the United States. A fundamental aim of this program is to increase efficiency in the consumption of energy by the manufacturing plants served by the IACs. Assessments are available to plants located within approximately 150 miles of a center.

This chapter provides background information on the IAC program and its client companies. Additional details on the program's energy-assessment. process and program benefits can be found in Appendices A and B, respectively.

\section{Program Description}

The Federal Government has been funding industrial energy assessments for small and medium-sized manufacturing plants under the auspices of the IAC program since 1976. This service, which is provided to plants at no charge, is funded through the Department of Energy's Office of Industrial Technologies. Energy assessments are performed by teams of faculty and students from engineering schools at universities. Students participate in every aspect of the program, from selecting clients to preparing implementation reports. Normally, each assessment team conducts an extensive, data-gathering preassessment and then performs a 1-day site visit at an industrial plant. Following the site visit, the assessment team prepares a report for the plant that includes information about the plant's energy use, processes, and other operations. In addition, each report includes several assessment recommendations (ARs) that contain sufficient technical and cost detail to compute the anticipated savings, implementation costs, and simple payback period for each AR.

The program began with four universities. There are currently 30 universities operating IACs around the United States. Figure 2-1 shows the service territories for the current centers, located to serve manufacturing plants across the Nation.

During a given year, an IAC is expected to carry out 30 energy assessments, though centers operating in their first year are expected to do only 15 assessments. Currently, 900 energy assessments are performed each year. 


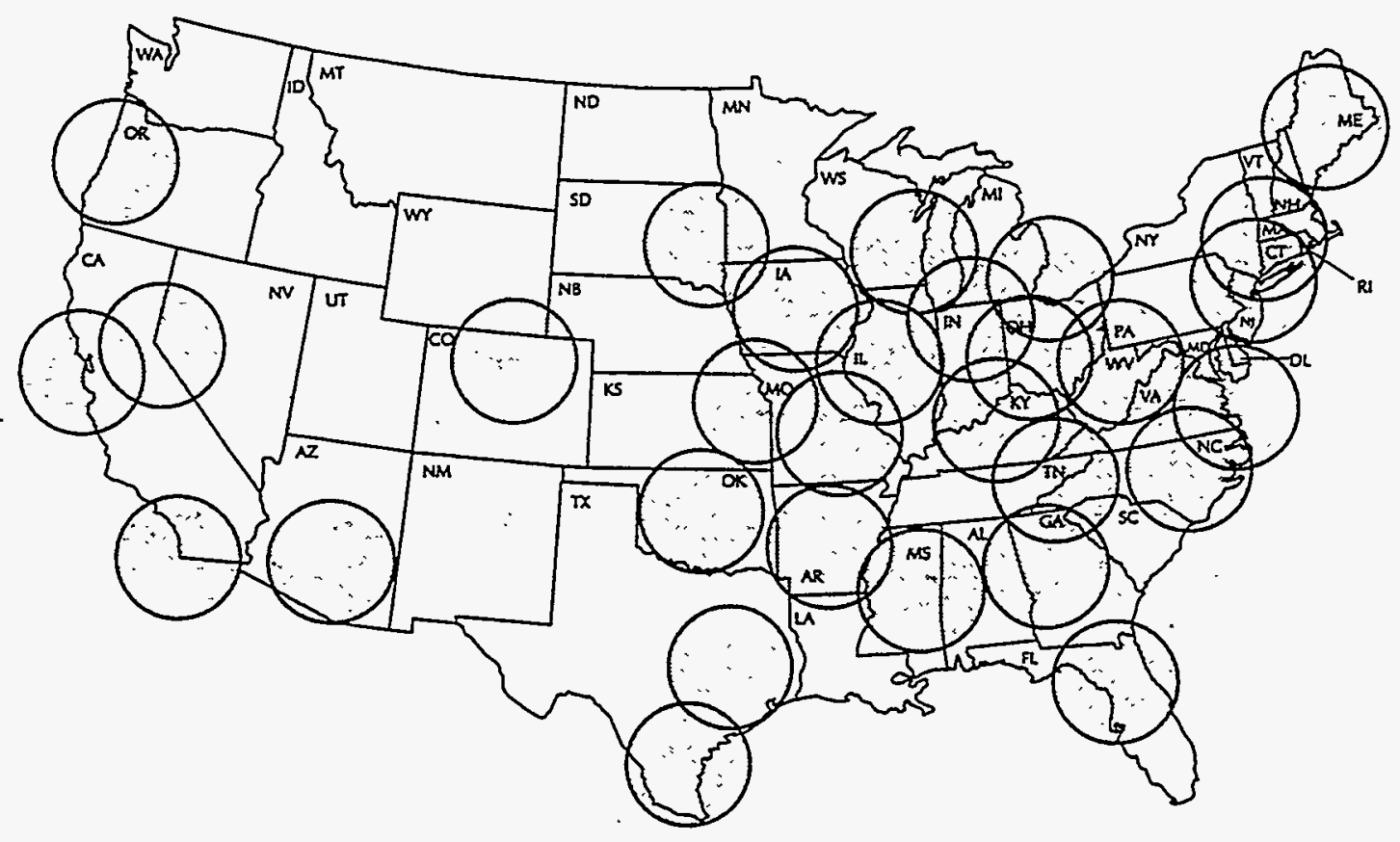

Figure 2-1. Service Territories Covered by Current Industrial Assessment Centers

Field management of the program is divided into two national regions and is carried out at two sites: the University City Science Center in Philadelphia, Pennsylvania, which manages IACs in the western United States, and the State University of New Jersey at Rutgers, which manages IACs in the eastern United States. Each field manager oversees the operations of half the centers. In addition, Rutgers University. is charged with the responsibility of maintaining data generated by assessments carried out by all of the centers. ${ }^{l}$

From its inception in 1976 through the close of 1994, the IAC program-

- Conducted more than 5,100 energy assessments

- Generated cumulative dollar savings of more than $\$ 517$ million

\footnotetext{
${ }^{I}$ As indicated in Table C-1, Rutgers University operated a center from 1986 to 1992 . In October 1992, Rutgers began its field management duties for the program and ceased operation of its center.
} 
- Implemented cumulative energy savings of more than 94 trillion British thermal units (Btu)

- Avoided the emission of nearly 200,000 metric tons of carbon-equivalent

These results were achieved at a total (cumulative) Federal cost of $\$ 27$ million.

\section{Client Profiles}

The IAC program is directed exclusively at the small and medium-sized plants. ${ }^{2}$ Large manufacturing establishments are expected to be able to fund such studies independently and so are excluded from the program. The IAC program is specific about which plants qualify for its assessments. An IAC assessment is available to any eligible manufacturing plant whose products fall within the Standard Industrial Classification (SIC) codes 20 through 39, that is located within 150 miles of a host campus, and that meets the following criteria: ${ }^{3}$

- Has gross annual sales of $\$ 75$ million or less

- Has a total annual energy bill of $\$ 1.75$ million or less

- Has no more than 500 employees at the plant site

- Does not have technical staff whose primary duty is energy analysis

Figure 2-2 shows the distribution of the energy assessments among the manufacturing SIC codes listed in Table 2-1. ${ }^{4}$ The distribution is not uniform. This is to be expected, because certain industries, such as food and kindred products (SIC 20) and fabricated metal products (SIC 34), have a much higher presence in small and medium-sized manufacturing operations than industries such as pulp and paper (SIC 26) and petroleum refining (SIC 29).

\footnotetext{
${ }^{2}$ Because participating small and medium-sized plants are located within a 150 -mile radius of IAC universities and their participation in the program is through self-selection, the industries participating in the IAC program may not be representative of the entire population of small and medium-sized plants in the United States.

${ }^{3}$ These criteria were revised in the late 1980 s. Before then, the limits on annual sales and annual energy costs were $\$ 50$ million and $\$ 1.5$ million, respectively.

${ }^{4}$ The figures and numbers reported in the graphs and tables show only plants audited during the period 1981 through 1992 and for which a reasonable estimate of assessment recommendations adopted by plants is available. During this period, there were 3,914 energy assessments available for analysis in the EADC database (after deleting assessments that are missing key data).
} 


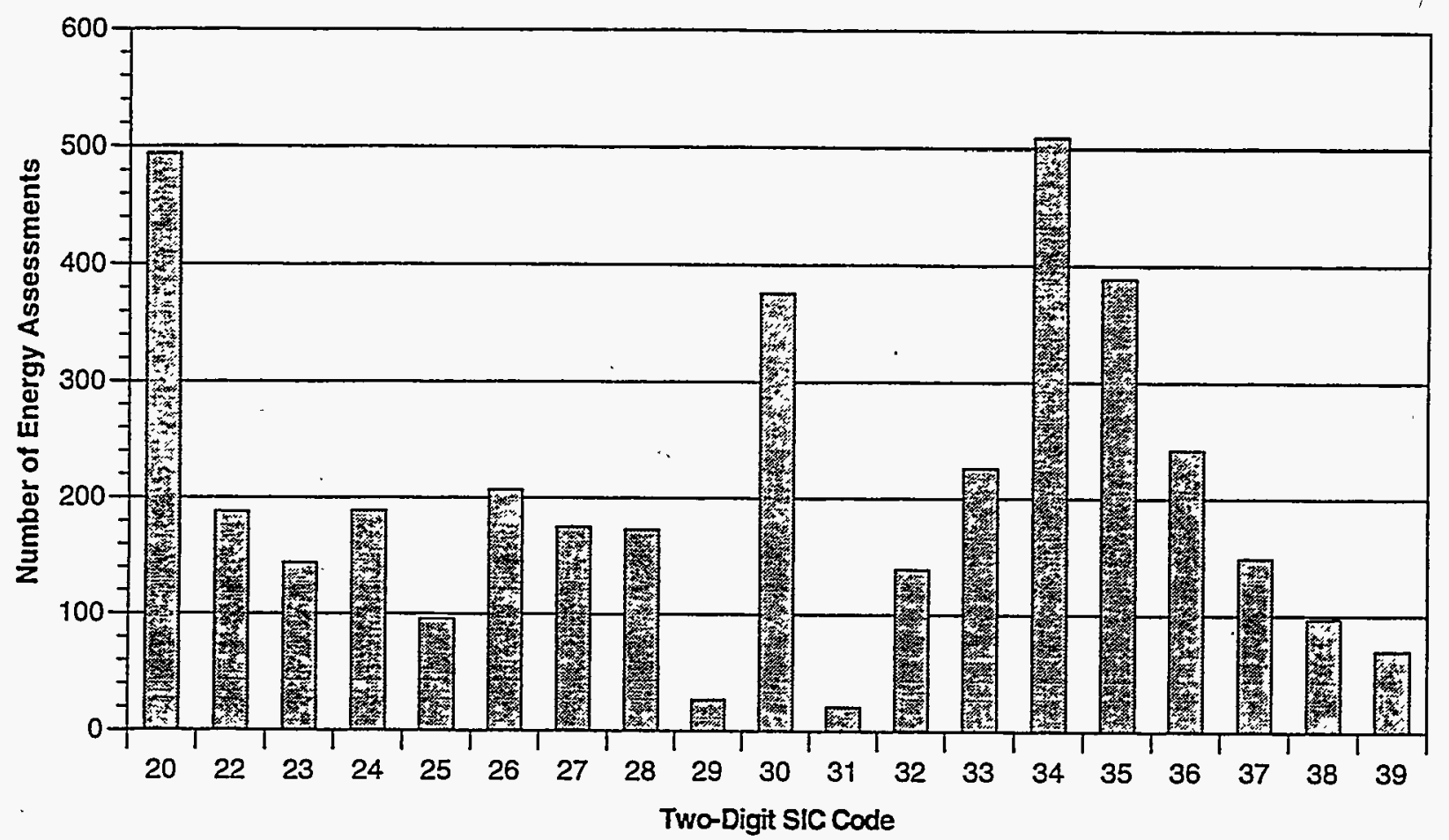

Figure 2-2. Distribution of Energy Assessments by Two-Digit SIC Codes

The four manufacturing industries that have received energy assessments most frequently are fabricated metal products (SIC 34), food and kindred products (SIC 20), industrial machinery and equipment (SIC 35), and rubber and miscellaneous plastic products (SIC 30). The four industries that have received energy assessments the least frequently are leather and leather products (SIC 31), petroleum refining (SIC 29), miscellaneous manufacturing (SIC 39), and furniture and fixtures (SIC 25). In general, these frequency patterns occur no matter what region of the country one is in, as shown in Figure 2-3. No assessments have been made in the tobacco industry (SIC 21).

Figures $2-4$ and 2-5 show the distribution of assessments by plant size, using gross sales and number of employees as measures of size. On average, a plant receiving an assessment has about 160 employees, on the order of $\$ 21$ million in annual gross sales, and $\$ 364,000$ in annual energy expenditures. The plants most frequently receiving energy assessments have under $\$ 10$ million in sales. More than 1,400 assessments were conducted within this size range through 1992. Plants with sales in the $\$ 10$ million to $\$ 20$ million size range are next, 
Table 2-1. Two-Digit Manufacturing Standard Industrial Classification (SIC) Codes

\begin{tabular}{ll}
\hline Two-Digit SIC Code & \multicolumn{1}{c}{ Description } \\
\hline 20 & Food and Kindred Products \\
21 & Tobacco Products \\
22 & Textile Mill Products \\
23 & Apparel and Other Textile Products \\
24 & Lumber and Wood Products \\
25 & Furniture and Fixtures \\
26 & Paper and Allied Products \\
27 & Printing and Publishing \\
28 & Chemicals and Allied Products \\
29 & Petroleum and Coal Products \\
30 & Rubber and Miscellaneous Plastics Products \\
31 & Leather and Leather Products \\
32 & Stone, Clay, and Glass Products \\
33 & Primary Metal Industries \\
34 & Fabricated Metal Products \\
35 & Industrial Machinery and Equipment \\
36 & Electronic and Other Electric Equipment \\
37 & Transportation Equipment \\
38 & Instruments and Related Products \\
39 & Miscellaneous Manufacturing \\
\hline & \\
\hline
\end{tabular}

with more than 1,000 assessments through 1992 . These figures match very closely the tally of assessments if employment is used as a measure of size, where employment is measured in increments of 100 employees (Figure 2-5). Most of the assessments are for plants with fewer than 100 and between 100 and 199 employees, although there are a substantial number of assessments for larger plants.

Figure 2-6 shows the number of energy assessments for each of the two-digit SIC categories with each bar broken into segments that indicate the employment size classes served by the assessments for that SIC. Figure 2-7 shows the same breakdown by sales size classes. 


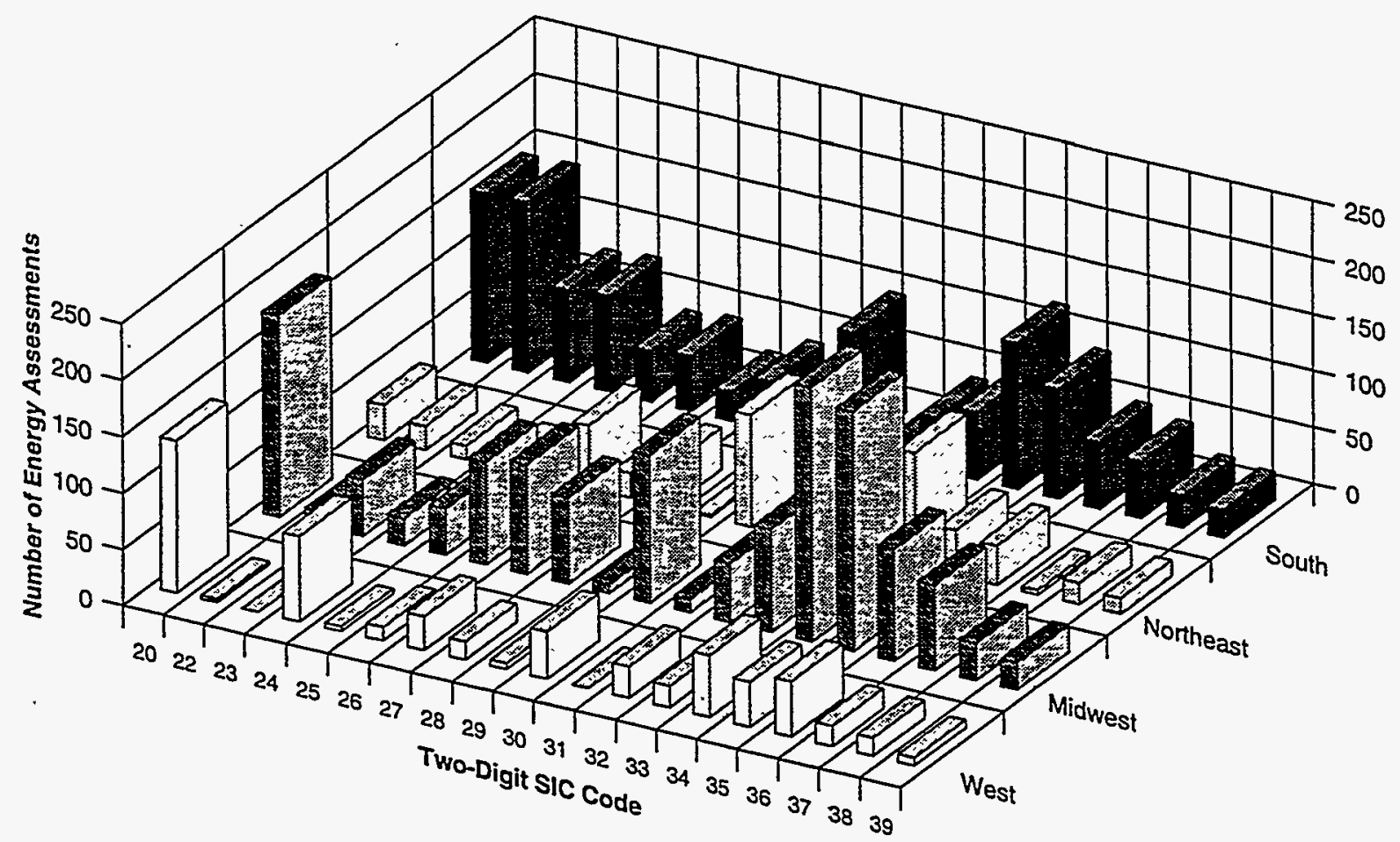

Figure 2-3. Number of Energy Assessments by Industry and Region

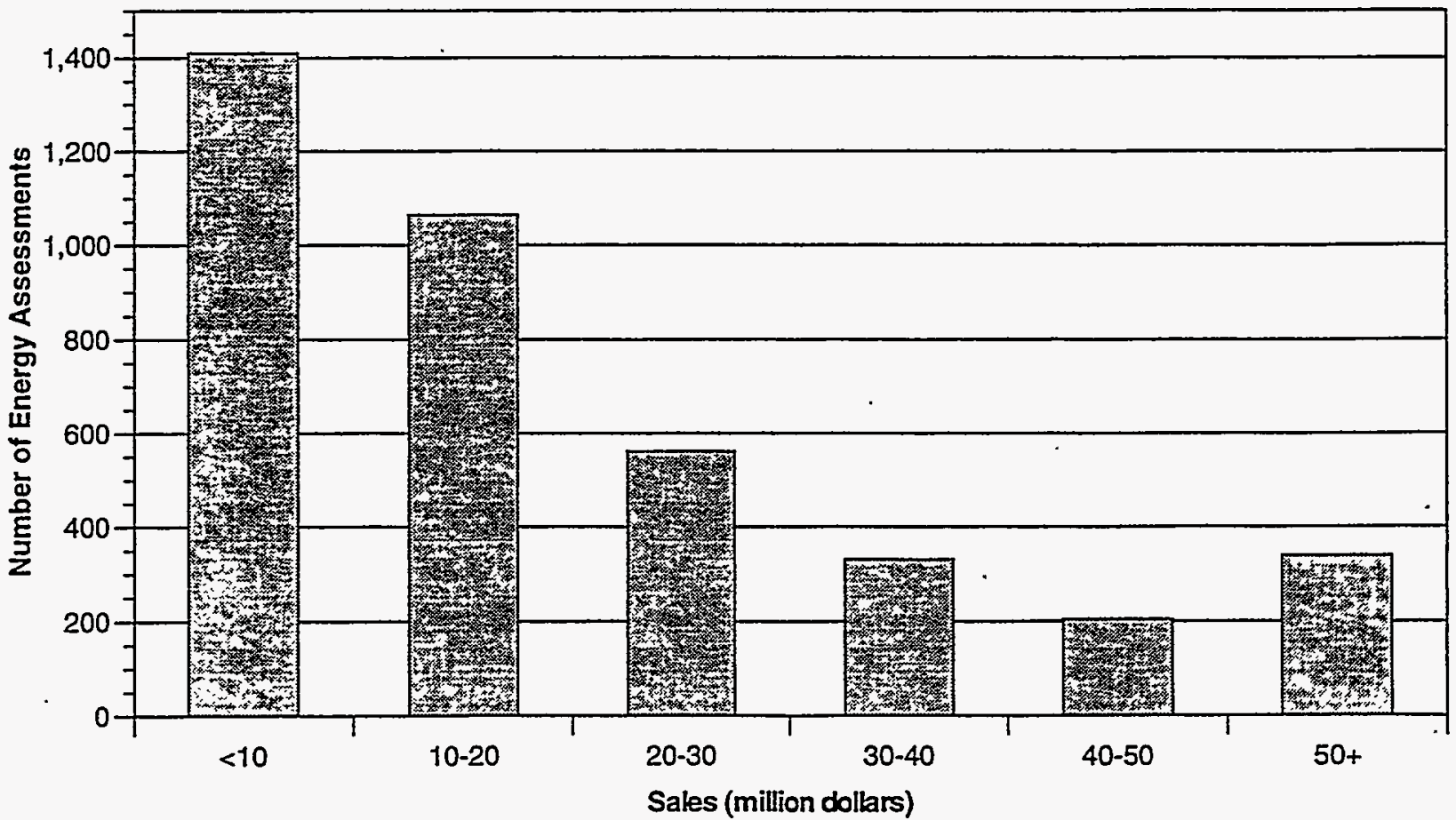

Figure 2-4. Number of Energy Assessments by Sales Size Class 


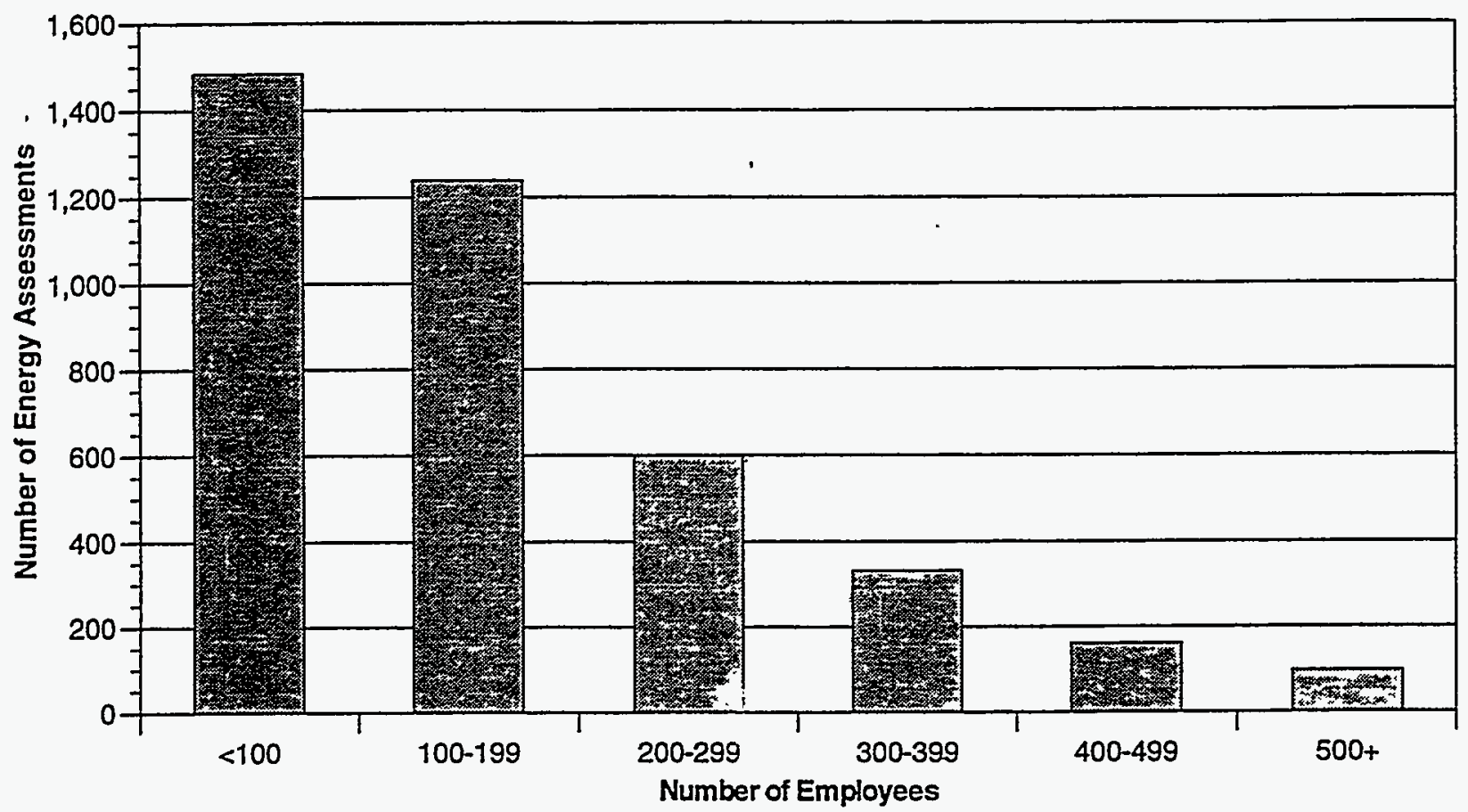

Figure 2-5. Number of Energy Assessments by Employment Size Class

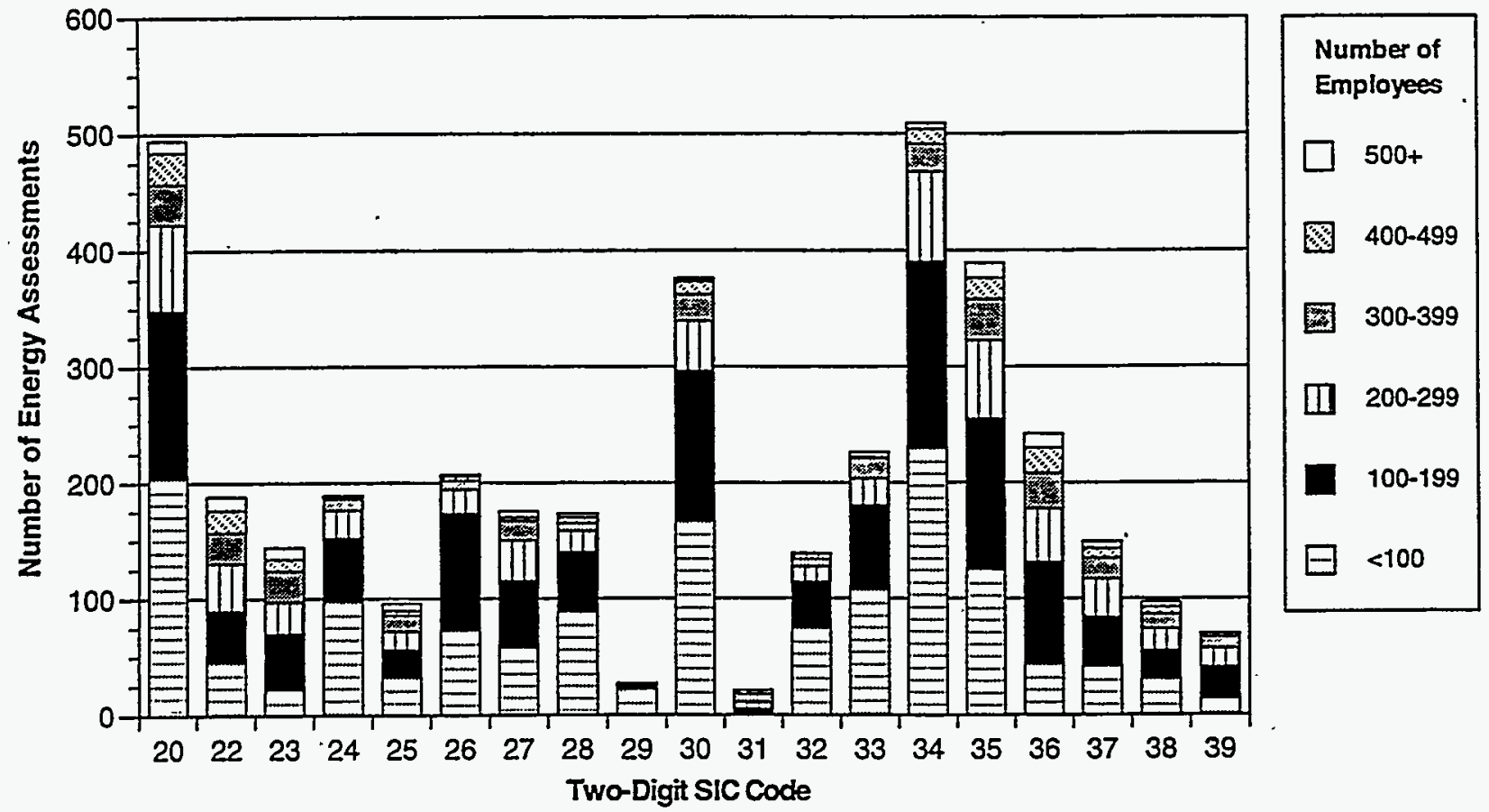

Figure 2-6. Number of Energy Assessments by Two-Digit SIC Code and Employment Size Class 


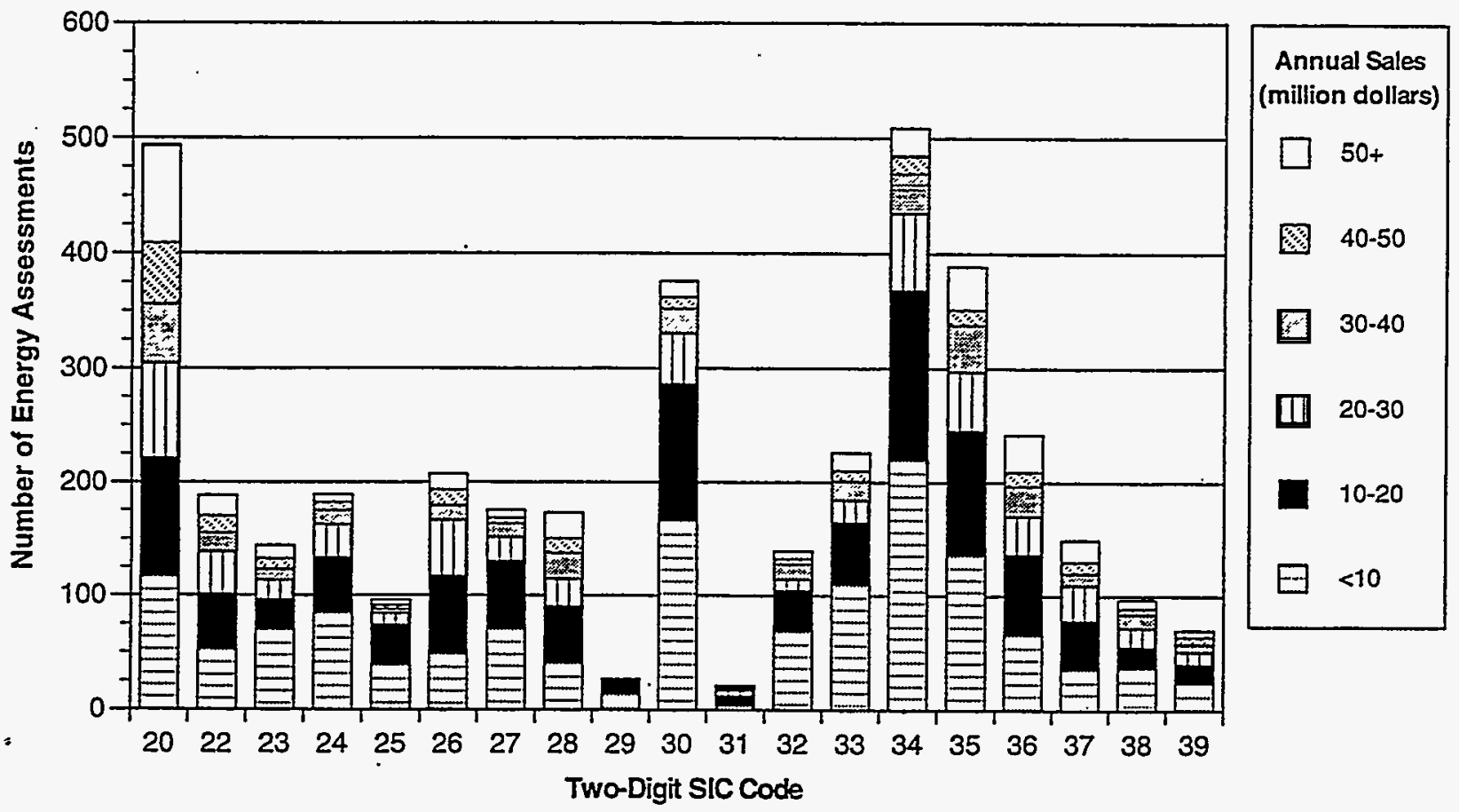

Figure 2-7. Number of Energy Assessments by Two-Digit SIC Code and Sales Size Class 


\section{ASSESSMENT RECOMMENDATIONS AND IMPLEMENTATION RATES}

\section{Analysis of Assessment Recommendations}

Each energy assessment yields a set of recommendations for ways to improve energy use within a plant. Figure 3-1 shows the distribution of the number of assessment recommendations (ARs) by two-digit Standard Industrial Classification (SIC) code for the period from 1981 through 1992. As expected, the number of ARs mirrors the number of energy assessments by SIC code (shown in Figure 2-2). Figure 3-2 further breaks down the total number of ARs by plant size, where the size is defined by the level of sales. In many cases, industries show a much higher total number of ARs for plants with below $\$ 20$ million in sales, and in SICs 20, 30, 34, and 35. Figure 3-3 shows the comparable distribution based on employment size classes, with most of the ARs occurring for plants with fewer than 200 employees (that is, the first 2 size classes). The average number of recommendations given per assessment is roughly the same (about six) for all sales and employment size classes.

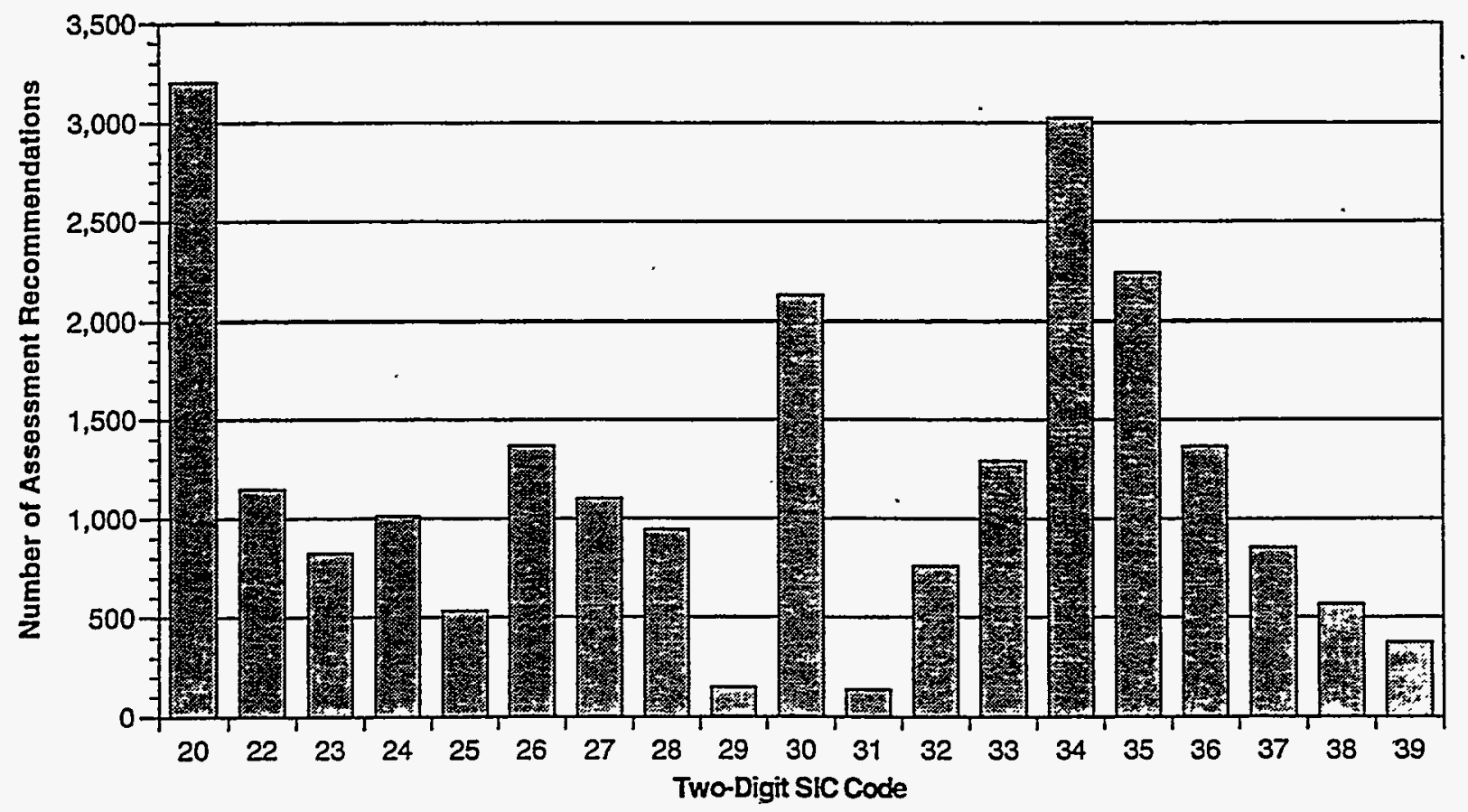

Figure 3-1. Total Number of Assessment Recommendations by Two-Digit SIC Code 


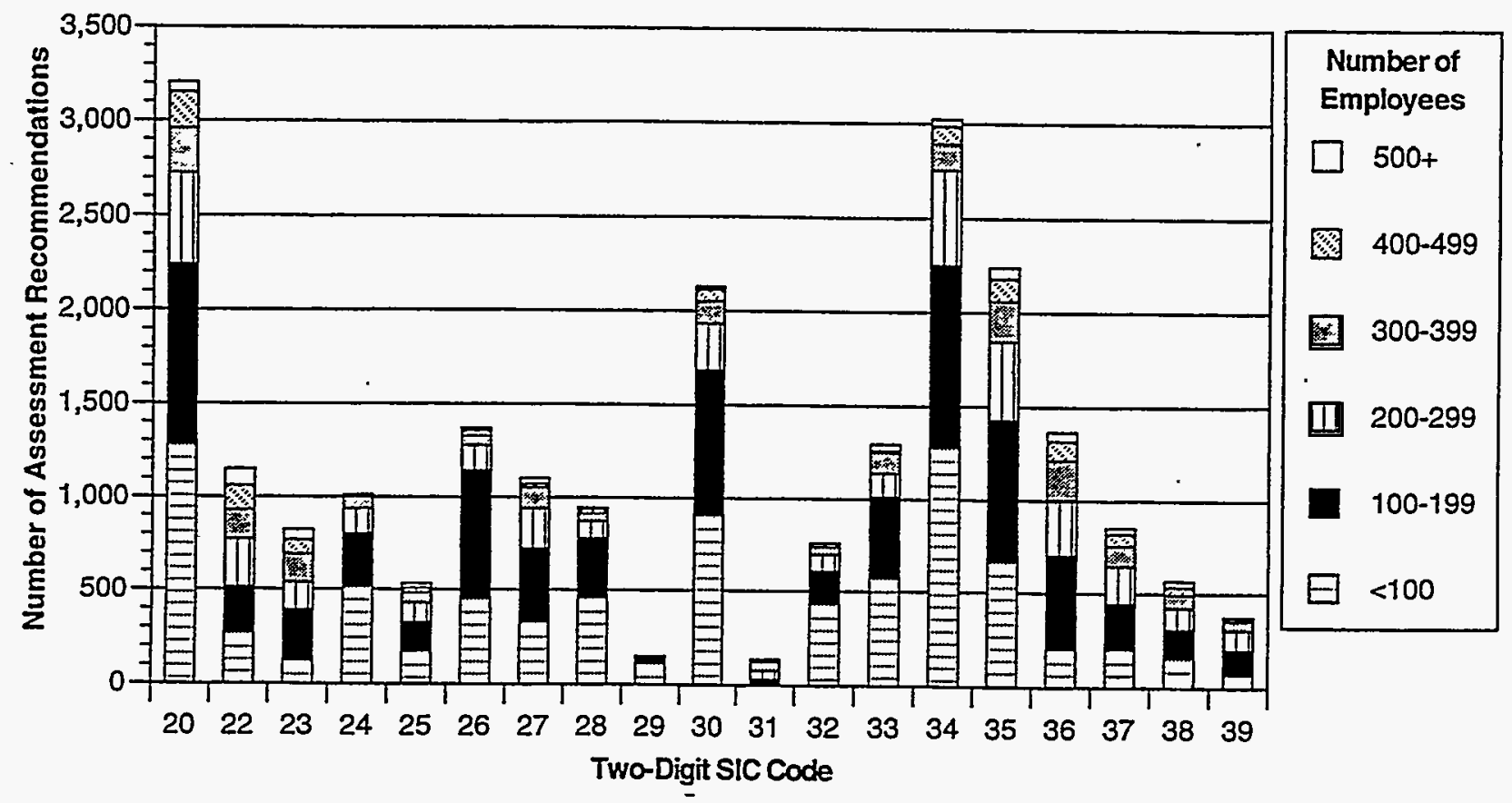

Figure 3-2. Number of Assessment Recommendations by Two-Digit SIC Code and Sales Size Class

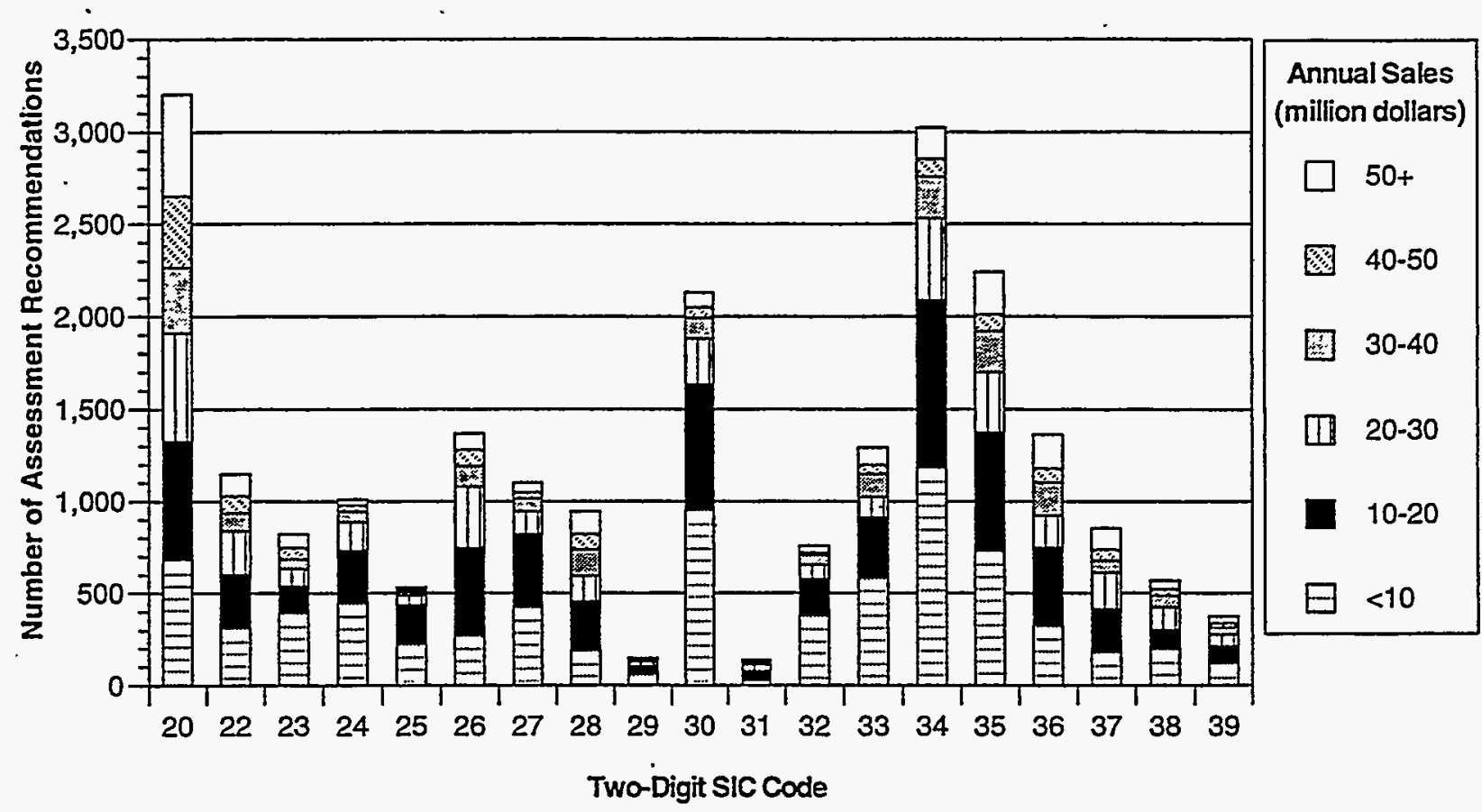

Figure 3-3. Number of Assessment Recommendations by Two-Digit SIC Code and Employment Size Class 
Assessment recommendations can be classified in a number of ways: by the technology (such as motors and boilers); according to whether they are equipment changes, changes in operating and maintenance procedures, or process changes; or by the nature of the recommendation, such as fuel switching. The Office of Industrial Productivity and Energy Assessment at Rutgers University has developed a classification system for recommendations that is delineated by assessment recommendation codes (ARCs) ${ }^{l}$ (Muller et al., 1994). For the purposes of the analysis in this section, Table 3-1 groups the ARs into

IThe ARC classification consists of a four-digit code. Two- and three-digit codes are used to categorize groups of ARs. For example, $A R C 4$ is Motor Systems (ARC 4 appears as 2.4 in the ARC manual, where the first digit denotes "energy assessment"), $A R C 41$ is within $A R C 4$ and is Motors, $A R C 412$ is within ARC 41 and represents Hardware, and finally $A R C 4123$ is within ARC 412 and denotes Use Multiple Speed Motors or Adjustable Speed Drive (ASD) for Variable Pump, Blower, and Compressor Loads.

Table 3-1. Classes of Assessment Recommendations

\begin{tabular}{lr}
\hline Characteristics & $\begin{array}{r}\text { Corresponding Two-Digit } \\
\text { Assessment Recommendation } \\
\text { Code (ARC) Classifications }\end{array}$ \\
\hline Furnaces & ARC 11 \\
Boilers & ARC 12, 13 \\
Fuel Switching & ARC 14 \\
Steam & ARC 21 \\
Heating and Heat Treatment & ARC 22, 23 \\
Heat Recovery and Containment & ARC 24, 25 \\
Cooling & ARC 26 \\
Drying & ARC 27 \\
Electric Power & ARC 31, 32, 33, 35 \\
Cogeneration & ARC 34 \\
Motors & ARC 41 \\
Air Compressors & ARC 42 \\
Other Motor Equipment & ARC 43 \\
Operational Changes & ARC 51, 61, 62 \\
Lighting & ARC 71 \\
HVAC and Building Envelope & ARC 72, 73, 74 \\
Other and Administrative (includes solar energy) & ARC 81, 82, 91 \\
&
\end{tabular}

Note: Table 4-1 lists the individual two-digit ARC classes. 
17 categories. The findings in the remainder of this section are discussed in terms of these $17 \mathrm{AR}$ categories.

Figure 3-4 shows the number of recommendations organized as in

Table 3-1. The most frequently recommended measures in order of occurrence are the following:

- Lighting and building envelope

- Heating, ventilation, and air-conditioning (HVAC) systems (including equipment changes and building envelope measures)

- Heat recovery and containment

- Air compressors

- Motors

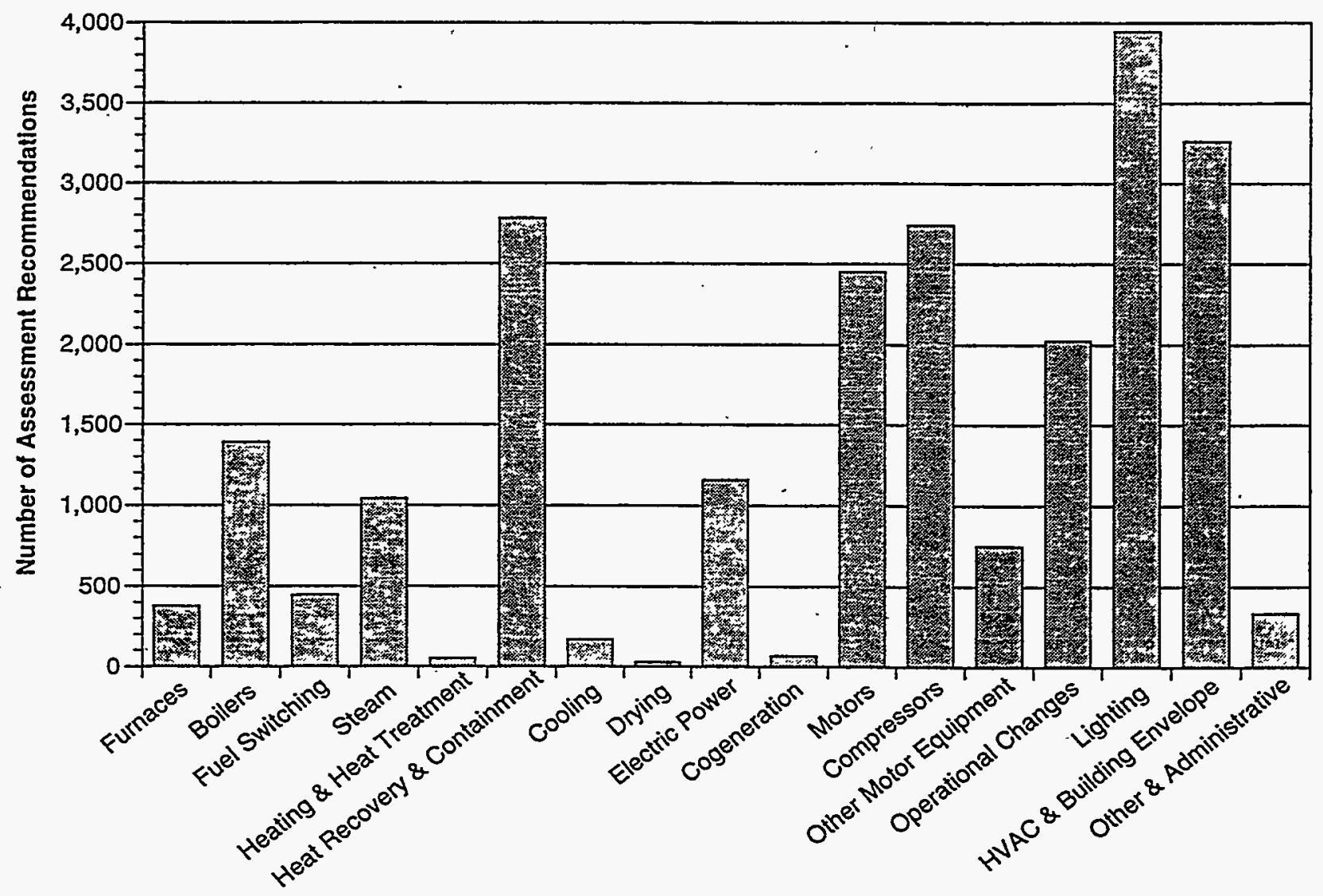

Assessment Recommendation Class

Figure 3-4. Number of Recommendations by Class of Assessment Recommendation 
- Operational changes

- Boilers

- Electric power (including demand management and cogeneration)

- Steam systems (including trap maintenance, condensate return, and leak elimination)

Although lighting and HVAC recommendations are frequent, they apply to only a small part of energy use in the more energy-intensive industries. The next most frequent recommendations (heat recovery and containment, compressors, and motors) address the heart of energy use in manufacturing. The types of recommendations least likely to be made apply to drying, heat treatment, and cogeneration.

Not all recommendations are implemented. The rate at which recommendations are implemented varies depending on the type of recommendation and the characteristics of the plant. The remainder of this section presents information on implementation rates and implemented energy and cost savings, and on how these results vary by type of recommendation, sales and employment, and type of industry.

\section{Analysis of Implementation Rates and Energy and Cost Savings}

Through 1992, more than 50 percent of all ARs were implemented. This number increases to about 61 percent when those AR records that have zeros or blanks in the implementation status field are dropped from the EADC database. For the graphics and tables shown in this section, these ARs have been deleted. These AR records could represent database errors or plants that have been very recently assessed. In the analysis, ARs are considered "implemented" when a plant makes an initial decision to implement an AR or plans to implement the AR within 2 years of the date of the energy assessment. The following is the implementation status defined in the EADC database:

Status $=1:$ AR was completely implemented during the same calendar year as the assessment report.

Status $=2: \quad A R$ will be completely implemented during the same calendar year the assessment occurred. 
Status $=3:$ AR will be completely implemented by the end of the first calendar year subsequent to the assessment.

Status $=4:$ AR will be completely implemented by the end of the second calendar year subsequent to the assessment.

Status = 5: AR will not be implemented or will be implemented after the second calendar year subsequent to the assessment.

The implementation rates reported in this analysis are a reliable estimate of actual investments made by small and medium-sized plants participating in the IAC program. Data obtained from 4 to 7 years following assessments indicate that about 90 percent of the originally estimated energy savings are still being achieved (Wilfert et al., 1991). The 10-percent difference in energy-savings estimates is due to several factors: (1) the initial decision to implement some measures was never followed up, (2) several measures were implemented, then later withdrawn from operation, and (3) a few measures were implemented later than originally estimated.

\section{Variation by Type of Assessment Recommendation}

Figure 3-5 shows the number of recommendations and the number of these recommendations that were implemented for the 17 types of recommendations listed in Table 3-1. The AR classes with the highest implementation rates are the following:

- Steam systems

- Boilers

- Air compressors

- Lighting

- Motors

- Operational changes

The highest implementation rates occur where the bulk of the energy use occurs in industry: in boilers, steam, and motors and compressors. The most frequently recommended actions, lighting changes, are also high on the list of implemented measures, as are "operational changes." The least likely recommendations to be implemented have to do with fuel switching and cogeneration. The low implementation rates for fuel switching and cogeneration should 


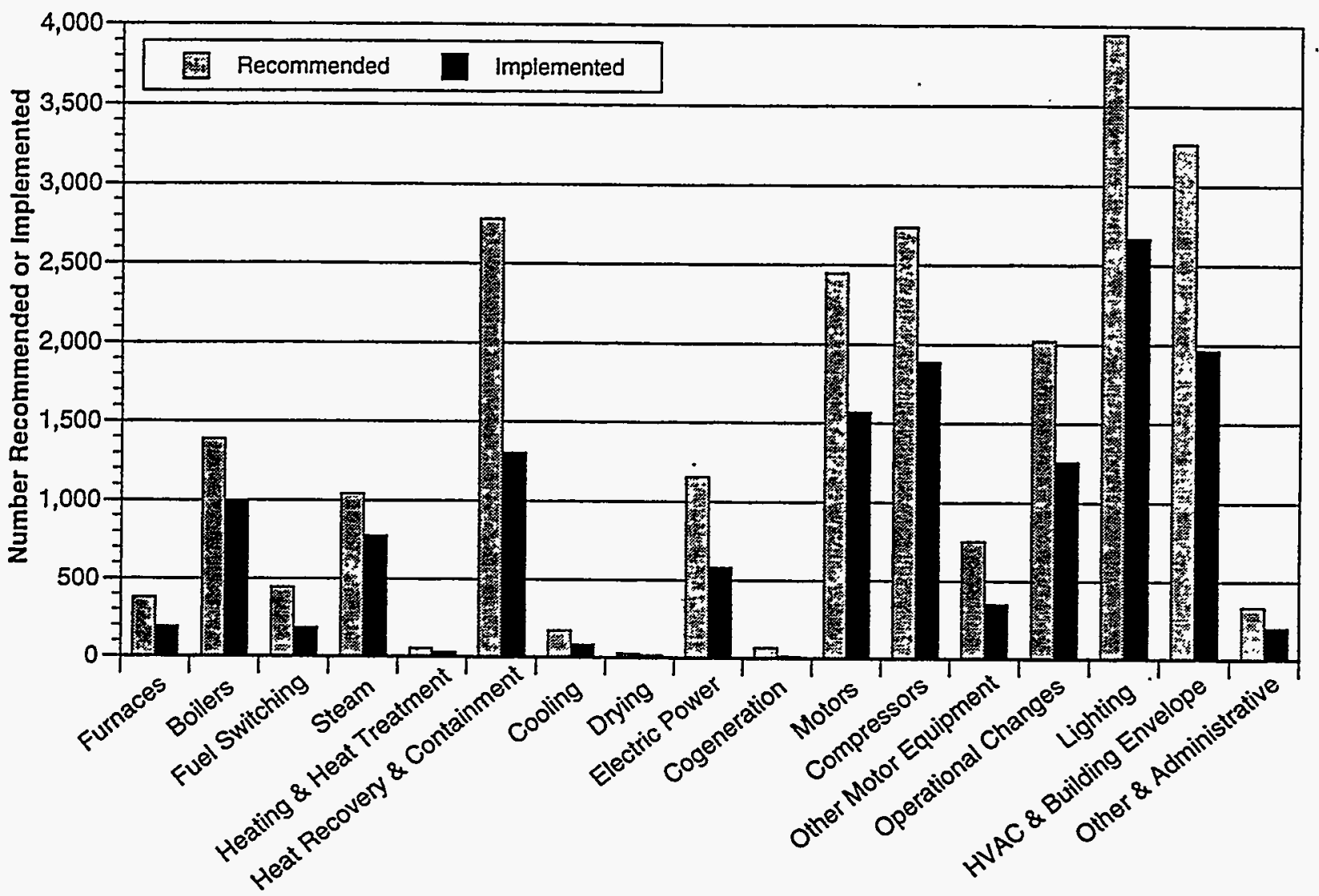

Assessment Recommendation Class

Figure 3-5. Number of Recommended and Implemented ARs by Class of Assessment Recommendation

be no great surprise, because the adoption of these alternatives is a complicated issue, dependent on utility programs and other considerations.

The total implemented energy savings associated with these AR categories are shown in Figure 3-6. Most energy savings are associated with the following ARs:

- Heat recovery and containment

- Boilers

- HVAC systems and building envelope changes

- Operational changes

- Steam systems

- Lighting 


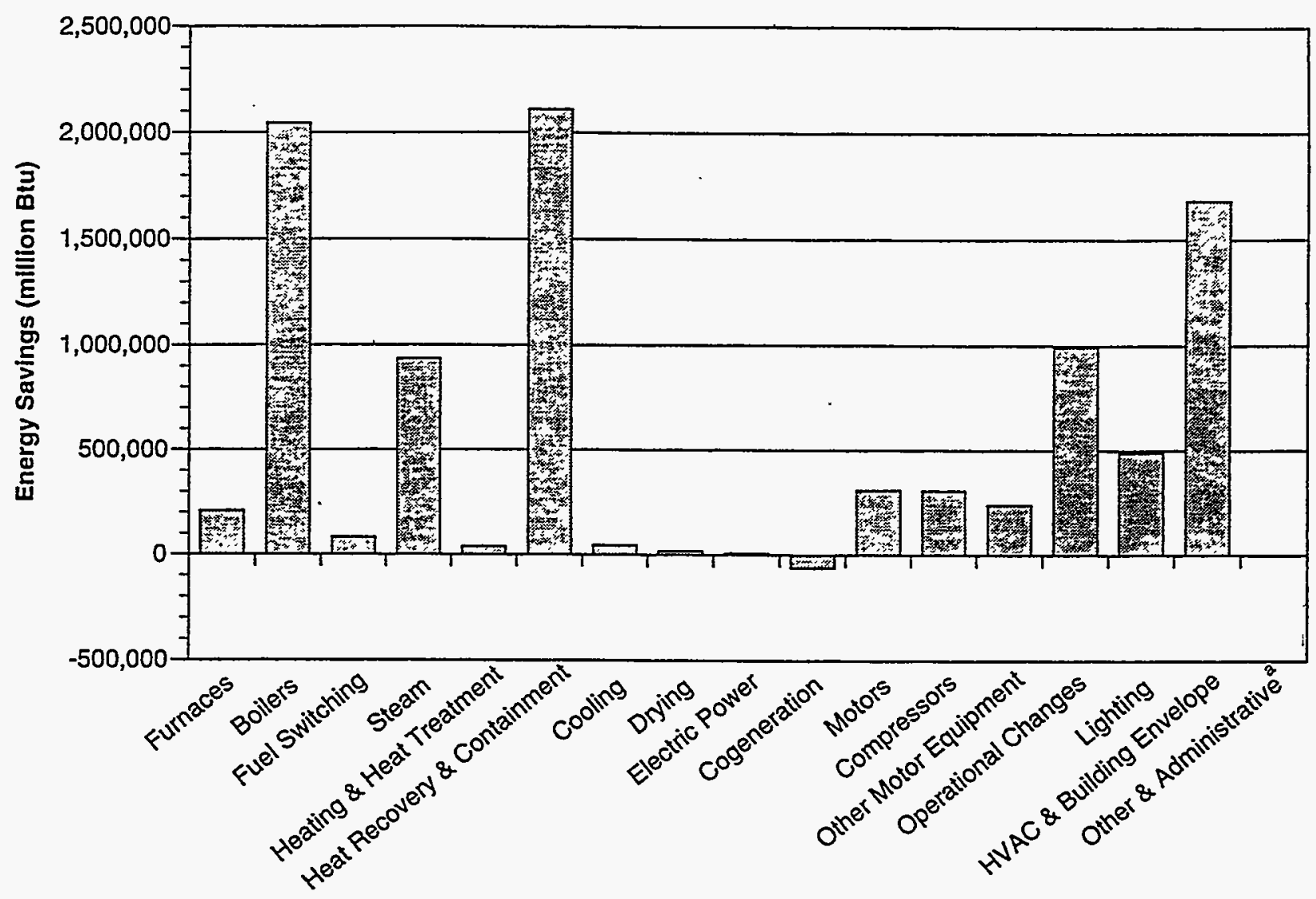

Assessment Recommendation Class

aThe value for energy savings in the "Other and Administrative" category is 479 million Btu.

Figure 3-6. Implemented Energy Savings by Class of Assessment Recommendation

The ordering of the six most recommended energy savings options differs from the ordering by most frequently implemented AR: heat recovery and containment and boilers score highest, with HVAC and operational changes next, followed by steam system and buildings and grounds recommendations. The savings fall off dramatically after that, with cogeneration actually adding energy use. Why these cogeneration recommendations are made is evident in Figure $3-7$, where the implemented cost savings by recommendation class are shown. 


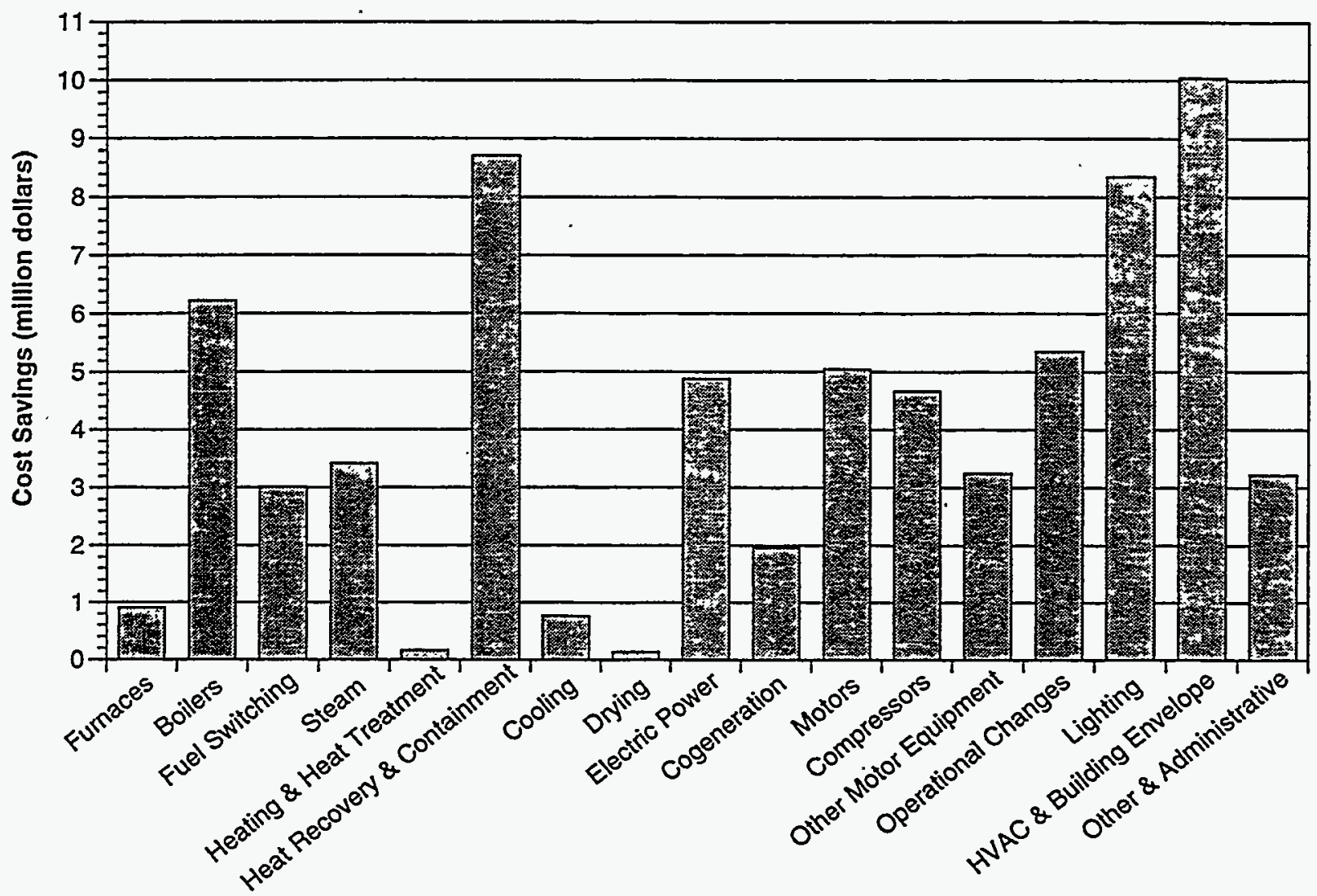

Assessment Recommendation Class

Figure 3-7. Implemented Cost Savings by Class of Assessment Recommendation

Most cost savings are associated with the following:

- HVAC systems and building envelope changes

- Heat recovery and containment

- Lighting

- Boilers

- Operational changes

- Motors

Of the six top money-saving recommendations, five are among the most frequently recommended. But cogeneration, the third biggest potential money saver when all recommendations (not just those that were implemented) are 
considered, can save a plant quite a lot of money even though it increases energy use for the plant. ${ }^{2}$

\section{Variation by Employment Size Classes}

Figure 3-8 shows both total recommendations and implemented recommendations by employment size class. The smaller plant receives the bulk of the assessments and, hence, the recommendations. The number of ARs correlates closely with the number of energy assessments (audits) performed by size class (Figure 2-5). The average number of implementations per assessment is roughly constant (about four) across employment size classes. Implementation rates also vary little by employment size classes, as shown in Table 3-2.

\footnotetext{
${ }^{2} \mathrm{~A}$ recommendation to cogenerate will increase fuel use to the plant, but will typically reduce energy use for the system. Purchased electricity has a thermal energy value of $3,412 \mathrm{Btu} / \mathrm{kWh}$, even though a utility typically has to use 10,500 Btu to generate and transmit that $\mathrm{kWh}$ to the plant. If the plant can generate that $\mathrm{kWh}$ using only 5,000 to $6,000 \mathrm{Btu} / \mathrm{kWh}$, which is typical, then the system saves energy and the plant saves money, because the electricity cost per $\mathrm{kWh}$ reflects the 10,500 Btu of fuel used to produce it. The decision to cogenerate may be influenced by the capacity situation of the local utility: if constrained by too little capacity, the utility may provide incentives for the plant to generate part of its required power needs.
}

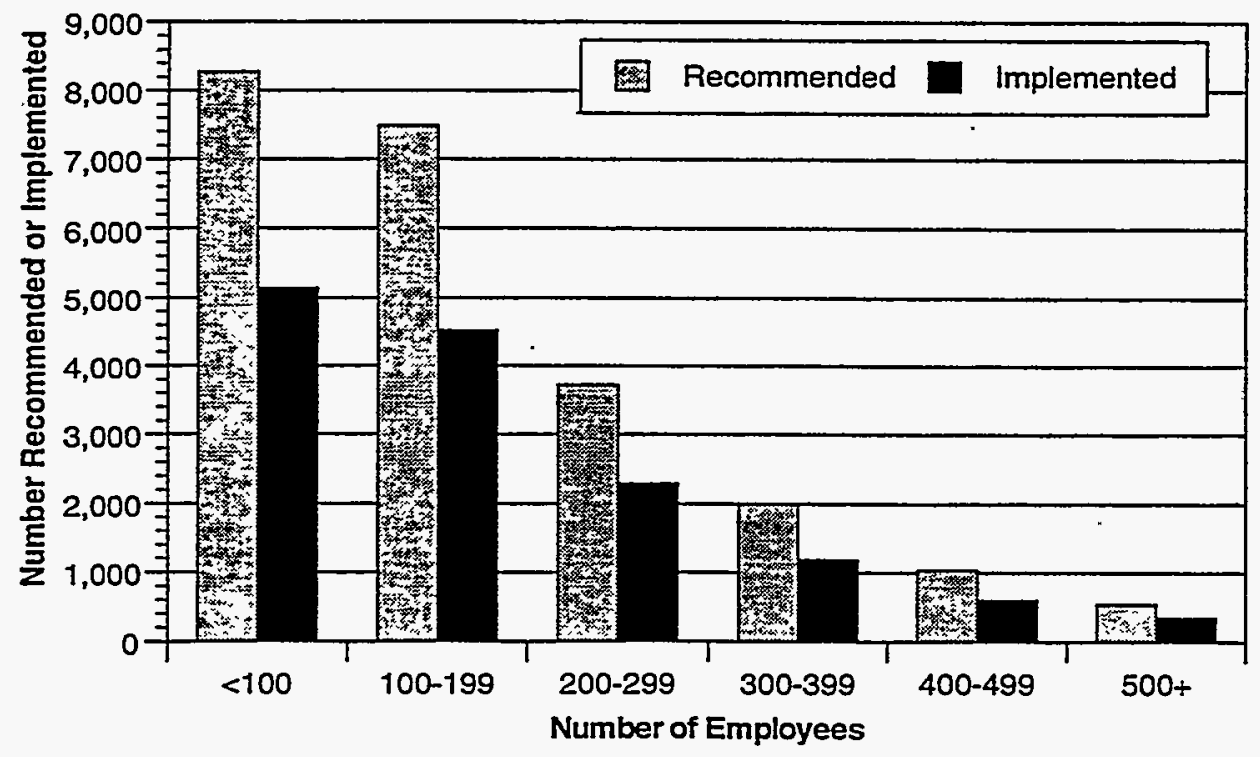

Figure 3-8. Recommended and Implemented Assessment Recommendations by Employment Size 
Table 3-2. Implementation Rate by Employment Size Class

\begin{tabular}{lc} 
Number of Employees & Implementation Rate (percent) \\
\hline Fewer than 100 & 62.2 \\
$100-199$ & 60.3 \\
$200-299$ & 61.6 \\
$300-399$ & 59.3 \\
$400-499$ & 57.8 \\
$500+$ & 64.3
\end{tabular}

The energy saved as a result of these implemented recommendations is shown in Figure 3-9, with cost savings shown in Figure 3-10. More than 3 trillion British thermal units (Btu) of energy have been saved over the period 1980 to 1992 just within plants with 100 to 199 employees. About 2 trillion Btu have been saved in each of 2 other size classes-fewer than 100 and 200 to 299 employees. The cost savings for these size categories correlate fairly well with these energy savings.

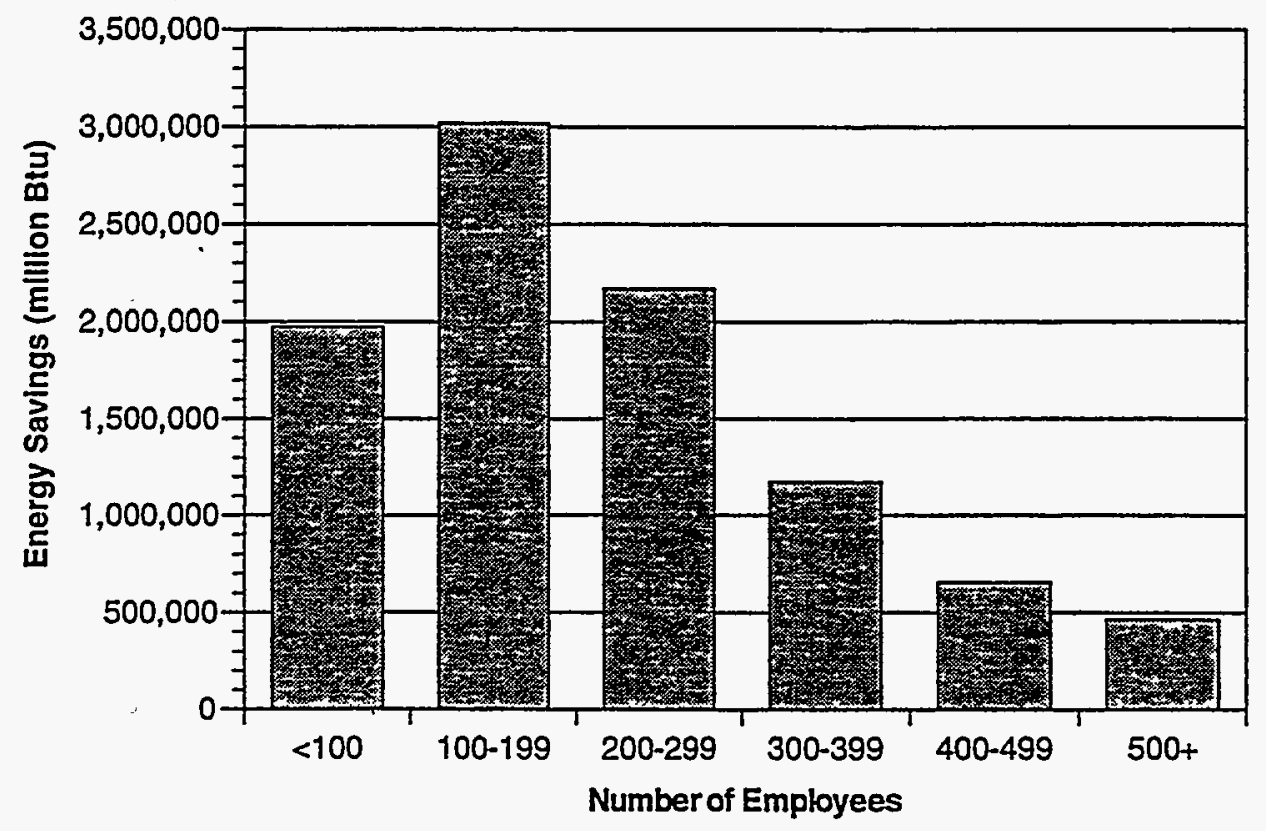

Figure 3-9. Implemented Energy Savings by Employment Size Class 


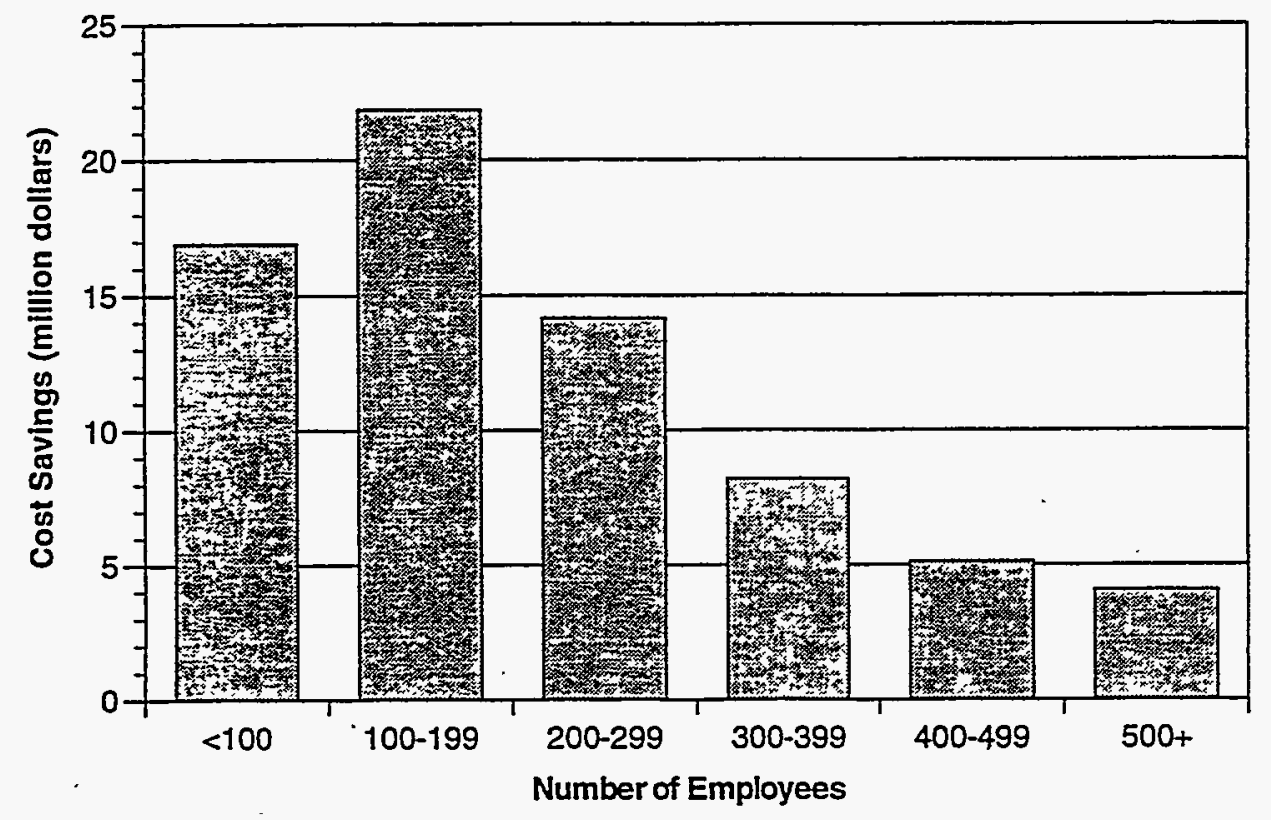

Figure 3-10. Implemented Cost Savings by Employment Size Class

\section{Variation by Sales Size Classes}

Figure $3-11$ shows both recommended and implemented ARs by sales size classes, with size classes defined by increments of $\$ 10$ million. There is a smooth reduction in the number of implemented ARs as the sales size of the plant increases, beginning with more than 4,800 implemented ARs for plants under $\$ 10$ million in sales and declining to less than 1,000 implemented ARs for plants with $\$ 40$ million to $\$ 50$ million in sales. However, as with employment size classes, there is very little difference in implementation rates among sales size classes, as shown in Table 3-3. The average number of implementations per assessment is roughly constant (about four) across sales size classes.

Using sales as the metric for plant size, the analysis shows that the decline in energy and cost savings, shown in Figures 3-12 and 3-13, does not follow quite the same size-class variations as it did with employment size classes. While the smaller sales size classes (that is, less than $\$ 10$ million, $\$ 10$ million to $\$ 20$ million, and $\$ 20$ million to $\$ 30$ million) save the most energy and have the highest cost savings, plants with sales of $\$ 50$ million or greater have higher cost and energy savings than plants in the $\$ 30$-million-to- $\$ 40$ million and $\$ 40$-million-to- $\$ 50$ million sales categories. 


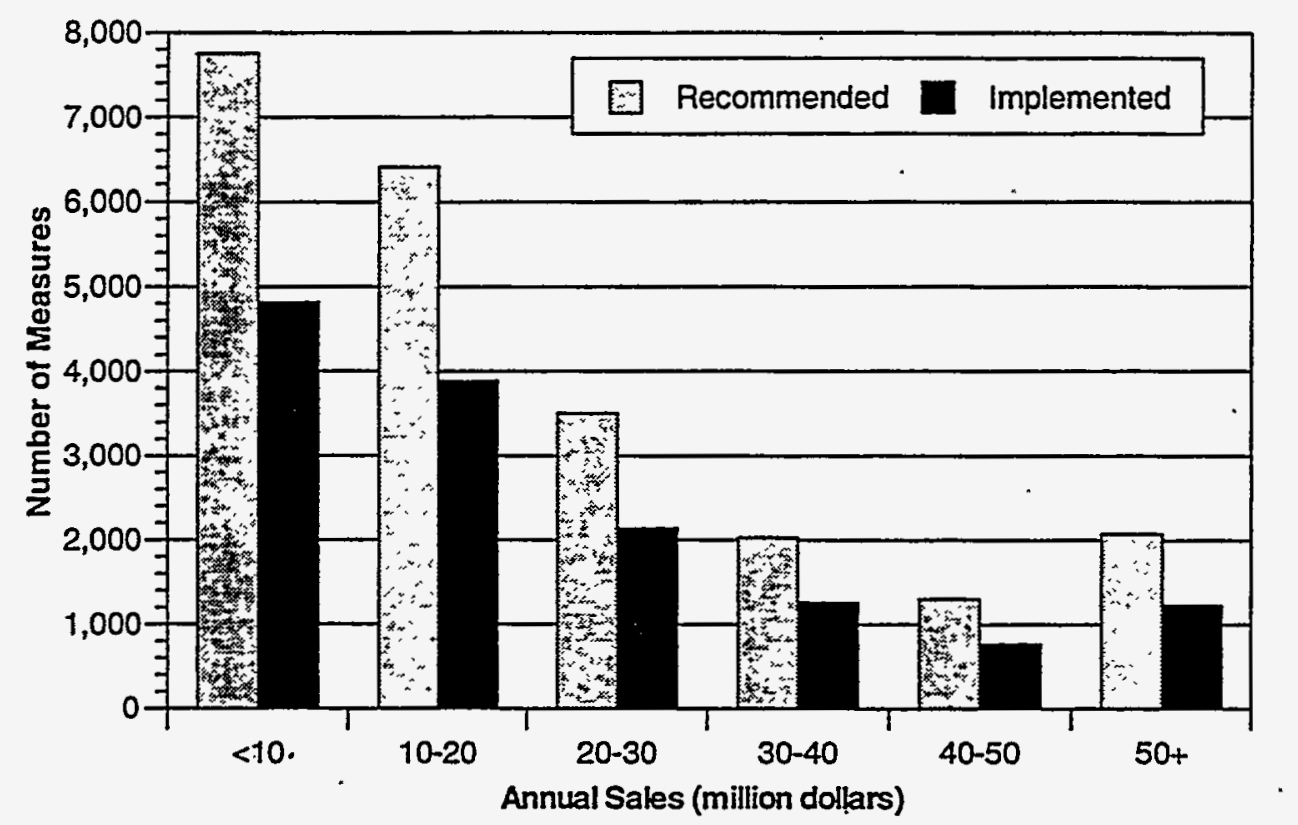

Figure 3-11. Recommended and Implemented Assessment Recommendations by Sales Size

Table 3-3. Implementation Rate by Sales Size Class

Annual Sales (million dollars) Implementation Rate (percent)

Less than 10

$10-20$

20-30

$30-40$

$40-50$

$50+$
62.1

60.6

60.9

62.2

59.2

59.3

\section{Variation by Type of Industry}

Implementation rates by SIC code organized from highest to lowest rates are reported in Table 3-4. Table 3-4 also summarizes variations in implemented energy and cost savings organized from highest to lowest savings. There is more variation by SIC code than appeared for either sales size class or employment 


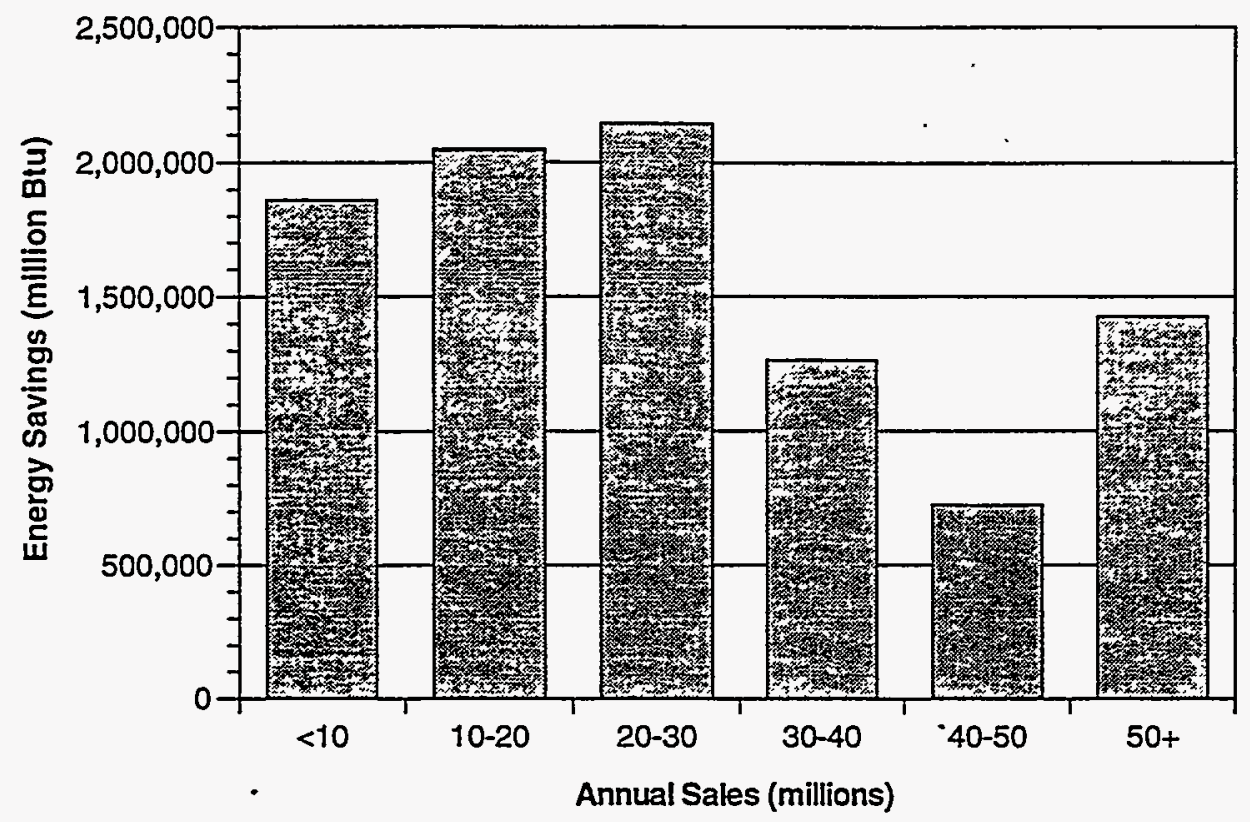

Figure 3-12. Implemented Energy Savings by Sales Size Class

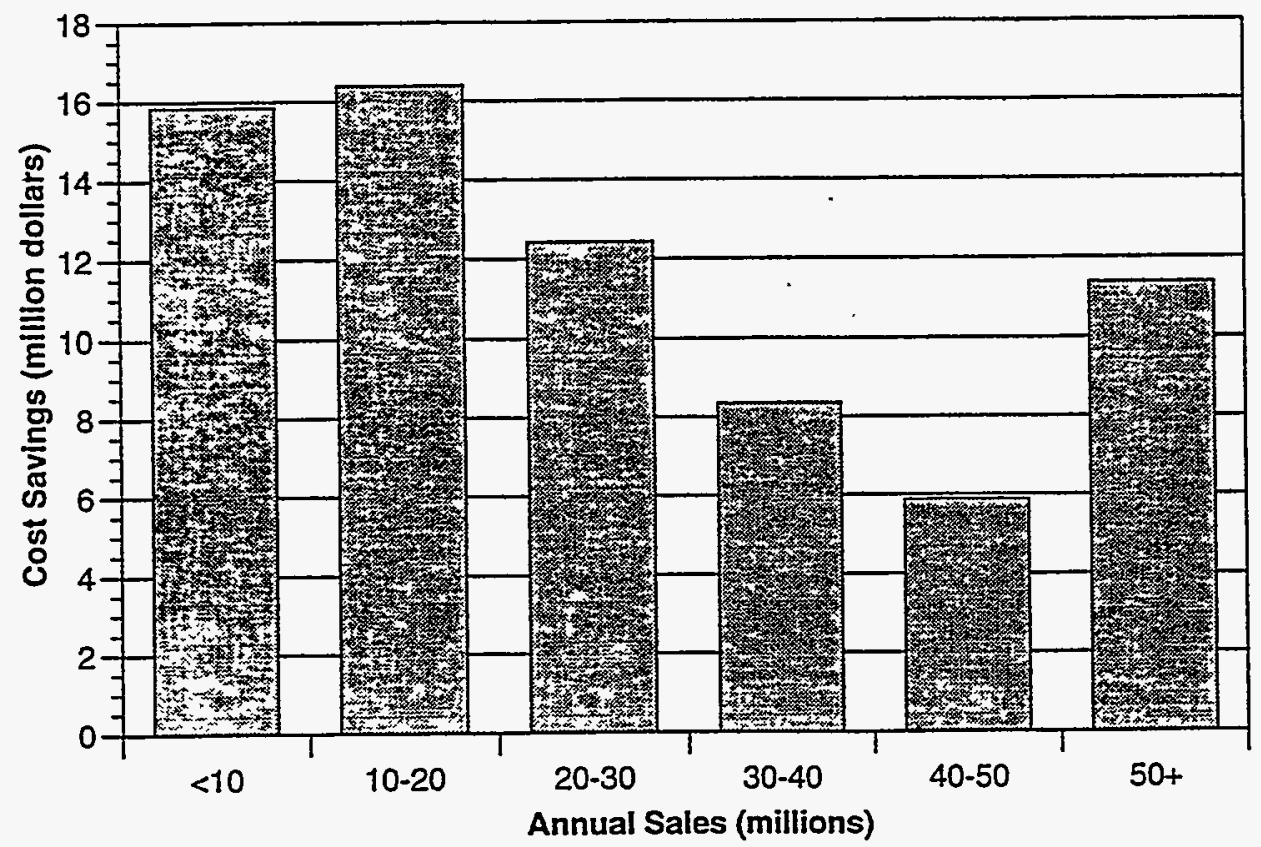

Figure 3-13. Implemented Cost Savings by Sales Size Class 
Table 3-4. Variation in Implementation Rate, Energy Savings, and Cost Savings by Two-Digit SIC Code

\begin{tabular}{|c|c|c|c|c|c|}
\hline \multicolumn{2}{|c|}{ Type of Industry } & \multicolumn{2}{|c|}{$\begin{array}{l}\text { Implemented } \\
\text { Energy Savings }\end{array}$} & \multicolumn{2}{|c|}{$\begin{array}{l}\text { Implemented } \\
\text { Cost Savings }\end{array}$} \\
\hline $\begin{array}{l}\text { Implementation } \\
\text { Rate (percent) }\end{array}$ & $\begin{array}{c}\text { SIC } \\
\text { Code }\end{array}$ & $\begin{array}{c}\text { Savings } \\
\text { (billion Btu) }\end{array}$ & $\begin{array}{l}\text { SIC } \\
\text { Code }\end{array}$ & $\begin{array}{l}\text { Savings } \\
\text { (\$ millions) }\end{array}$ & $\begin{array}{l}\text { SIC } \\
\text { Code }\end{array}$ \\
\hline 73.3 & 29 & 1,628 & 20 & 8.6 & 34 \\
\hline 66.8 & 39 & 1,220 & 22 & 8.4 & 20 \\
\hline 66.8 & 37 & 887 & 34 & 7.4 & 22 \\
\hline 66.5 & 25 & 690 & 24 & 5.8 & 30 \\
\hline 66.2 & 23 & 686 & 26 & 5.6 & 33 \\
\hline 64.5 & 22 & 670 & 32 & 5.3 & 35 \\
\hline 63.3 & 28 & 611. & 33 & 4.3 & 24 \\
\hline 62.5 & 24 & 579 & 35 & 4.0 & 28 \\
\hline 62.4 & 34 & 509 & 30 & 3.9 & 32 \\
\hline 62.2 & 35 & 452 & 28 & 3.4 & 26 \\
\hline 61.9 & 31 & 298 & 37 & 3.1 & 36 \\
\hline 61.8 & 32 & 280 & 36 & 2.5 & 37 \\
\hline 60.2 & 30 & 190 & 25 & 1.8 & 27 \\
\hline 59.3 & 20 & 178 & 27 & 1.4 & 25 \\
\hline 58.8 & 27 & 163 & 29 & 1.3 & 23 \\
\hline 58.4 & 36 & 129 & 23 & 1.0 & 38 \\
\hline 56.8 & 38 & 118 & 39 & 1.0 & 39 \\
\hline 55.9 & 33 & 101 & 38 & 0.9 & 29 \\
\hline 55.7 & 26 & 65 & 31 & 0.4 & 31 \\
\hline
\end{tabular}

size class, although there is less variation here than by AR category. The lowest implementation rates are in pulp and paper (SIC 26), primary metals (SIC 33), and instruments and scientific equipment (SIC 38). The highest implementation rate, well over 70 percent, is in petroleum refining and coal products (SIC 29), with five other SIC codes, none of which use large amounts of energy, at or above 65 percent-miscellaneous manufacturing industries (SIC 39), transportation equipment (SIC 37), furniture and fixtures (SIC 25), apparel and other textile products (SIC 23), and textile mill products (SIC 22). 
As shown in Table 3-4, there appears to be little or no correlation between implementation rates and energy and cost savings. The industry with the most energy savings, food processing (SIC 20), is average in terms of implementation rate, as are the other two major energy-saving industries, textiles (SIC 22) and fabricated metal products (SIC 34). The cost savings bear some relationship to the energy savings-SIC codes 20,22 , and 34 have the most cost savings. 


\section{INVESTMENT BEHAVIOR}

This chapter examines the investment behavior of small and medium-sized companies. First, evidence from the EADC database on plant decisions to implement energy-saving measures is examined (investment patterns are examined for the database as a whole, with records aggregated across industries and time periods). Second, the findings of several studies that investigated why recommended measures are not implemented are described.

\section{Payback Period and Implicit Discount Rate}

\section{Analysis}

\section{Analysis of Payback Periods}

The EADC database contains an "implementation status" field. Based on an interview with each manufacturing plant 6 months to 2 years following its assessment, an implementation status code is assigned to each assessment recommendation (AR). A code of 1 through 4 indicates that the plant has implemented the AR or plans to do so within 2 years of the assessment, whereas a code of 5 is entered if the AR will not be implemented. Some AR records contain "implementation status" fields that are blank or contain zeros. Because the implementation status of these records is unclear or pending, they were excluded from this analysis. For the detailed analysis of payback periods and implementation rates described in this section, only AR records coded with an implementation status of $1,2,3,4$, or 5 are used. A description of the methodology used for the implicit payback period and discount rate analysis is provided in Appendix E. In addition, the analysis and findings in this section are organized by two-digit assessment recommendation groups listed in *

Table 4-1. Table 3-1 indicates how the two-digit assessment recommendation code (ARC) categories in Table 4-1 correspond to the AR categories used in Chapter 3.

Table 4-2 presents data on implementation rates, average costs, and average payback periods by two-digit AR group. The data are organized from highest to lowest implementation rate and divided into quartiles, where each quartile contains approximately one-fourth of the two-digit AR groups. (The findings of this analysis are essentially the same when the quartiles are constructed by including one-fourth of the ARs in each quartile.) 
Table 4-1. Two-Digit Assessment Recommendation Categories

Combustion
ARC 11 Furnaces, Ovens, and Directly Fired
Operations

ARC 12 Boilers

ARC 13 Combustion of Waste Products

ARC 14 Fuel Switching

Thermal Systems

ARC 21 Steam

ARC 22 Heating

ARC 23 Heat Treating

ARC 24 Heat Recovery

ARC 25 Heat Containment

ARC 26 Cooling

ARC 27 Drying

Electrical Power

ARC 31 Demand Management

ARC 32 Power Factor

ARC 33 Generation of Power

ARC 34 Cogeneration

ARC 35 Transmission
Motor Systems

ARC 41 Motors

ARC 42 Air Compressors

ARC 43 Othẹ Equipment

Industrial Design

ARC 51 Systems

Operations

ARC 61 Maintenance

ARC 62 Equipment Control

Building and Grounds

ARC 71 Lighting

ARC 72 Space Conditioning

ARC 73 Ventilation

ARC 74 Building Envelope

Ancillary Costs

ARC 81 Administrative

ARC 82 Shipping, Distribution, and Transportation

\section{Alternate Energy Use}

ARC 91 Solar

Table 4-2 indicates that, in general, the implementation rate decreases as both implementation cost and payback period increase, as would be expected. However, the relationship is more pronounced for implementation cost, as shown in Figures 4-1 and 4-2. In fact, contrary to expectations, implementation rates appear to drop off little, if any, as payback period increases.

Tables 4-3 and 4-4 explore these relationships further. As indicated in Table 4-3, which shows the distribution of implementation rates among 
Table 4-2. Quartile-Based Statistics on Implementation Rates, Costs, and Payback Periods by Two-Digit ARC

\begin{tabular}{|c|c|c|c|c|c|c|c|c|c|c|c|c|}
\hline \multirow[b]{2}{*}{ ARC } & \multicolumn{2}{|c|}{$\begin{array}{c}\text { Number } \\
\text { of Measures }\end{array}$} & \multirow{2}{*}{$\begin{array}{c}\text { Imple- } \\
\text { mentation } \\
\text { Rate (\%) }\end{array}$} & \multicolumn{2}{|c|}{ Average Cost (S) } & \multicolumn{2}{|c|}{$\begin{array}{c}\text { Average } \\
\text { Payback Period (yr) }\end{array}$} & \multirow{2}{*}{$\begin{array}{c}\text { Quartile } \\
\text { Implementation } \\
\text { Rate (\%) }\end{array}$} & \multicolumn{2}{|c|}{$\begin{array}{c}\text { Quartile- } \\
\text { Weighted } \\
\text { Average Cost (\$) }\end{array}$} & \multicolumn{2}{|c|}{$\begin{array}{c}\text { Quartile- } \\
\text { Weighted } \\
\text { Average } \\
\text { Payback Period (yr) }\end{array}$} \\
\hline & $\begin{array}{l}\text { Imple- } \\
\text { mented }\end{array}$ & $\begin{array}{l}\text { Recom- } \\
\text { mended }\end{array}$ & & $\begin{array}{l}\text { Imple- } \\
\text { mented }\end{array}$ & $\begin{array}{l}\text { Recom- } \\
\text { mended }\end{array}$ & $\begin{array}{l}\text { Imple- } \\
\text { mented }\end{array}$ & $\begin{array}{l}\text { Recom- } \\
\text { mended }\end{array}$ & & $\begin{array}{l}\text { Imple- } \\
\text { mented }\end{array}$ & $\begin{array}{l}\text { Recom- } \\
\text { mended }\end{array}$ & $\begin{array}{l}\text { Imple- } \\
\text { mented }\end{array}$ & $\begin{array}{l}\text { Recom- } \\
\text { mended }\end{array}$ \\
\hline 61 & 248 & 334 & 74.3 & 541 & 863 & 0.27 & 0.27 & 68.4 & 2,316 & 2,492 & 0.90 & 0.95 \\
\hline 21 & 775 & 1,043 & 74.3 & 1,662 & 2,082 & 0.70 & 0.72 & & & & & \\
\hline 12 & 977 & 1,347 & 72.5 & 1,957 & 2,308 & 0.64 & 0.74 & & & & & \\
\hline 42 & 1,889 & 2,740 & 68.9 & 643 & 672 & 0.49 & 0.55 & & & & & \\
\hline 71 & 2,666 & 3,947 & 67.5 & 3,142 & 3,395 & 1.12 & 1.18 & & & & & \\
\hline 41 & 1,569 & 2,450 & 64.0 & 3,788 & 3,754 & 1.39 & 1.42 & & & & & \\
\hline 73 & 116 & 188 & 61.7 & 1,826 & 2,092 & 0.59 & 0.61 & & & & & \\
\hline 81 & 202 & 332 & 60.8 & 6,653 & 7,381 & 0.47 & 0.67 & 60.2 & 3,870 & 4,540 & 0.88 & 0.99 \\
\hline 62 & 931 & 1,532 & 60.8 & 1,156 & 1,117 & 0.46 & 0.48 & & & & & \\
\hline 27 & 17 & 28 & 60.7 & 4,291 & 5,205 & 1.05 & 1,24 & & & & & \\
\hline 74 & 618 & 1,018 & 60.7 & 6,072 & 6,384 & 1.51 & 1.64 & & & & & \\
\hline 72 & 1,233 & 2,055 & 60.0 & 3,304 & 4,874 & 0.84 & 0.99 & & & & & \\
\hline 22 & 31 & 54 & 57.4 & 2,889 & 2,189 & 0.65 & 0.60 & & & & & \\
\hline 32 & 184 & 322 & 57.1 & 11,075 & 10,645 & 1.66 & 1.79 & & & & & \\
\hline 25 & 640 & 1,216 & 52.6 & 2,240 & 2,371 & 1.02 & 0.97 & 50.6 & 3,727 & 4,382 & 0.95 & 0.92 \\
\hline 11 & 192 & 378 & 50.8 & 1,589 & 1,936 & 1.47 & 1.33 & & & & & \\
\hline 91 & 1 & 2 & 50.0 & $-24,000$ & 12,000 & 29.06 & 14.53 & & & & & \\
\hline 51 & 77 & 157 & 49.0 & 19,098 & 20,537 & 0.98 & 1.10 & & & $\cdot$ & & \\
\hline 31 & 373 & 772 & 48.3 & 3,021 & 4,767 & 0.49 & 0.52 & & & & . & \\
\hline 26 & 82 & 172 & 47.7 & 8,874 & 8,792 & 0.91 & 1.09 & & & & & \\
\hline 43 & 349 & 752 & 46.4 & 5,349 & 7,272 & 0.72 & 0.71 & 42.6 & 16,219 & 19,464 & 1.18 & 1.30 \\
\hline 33 & 3 & 7 & 42.9 & 21,169 & 66,258 & 2.63 & 2.11 & & & & & \\
\hline 24 & 664 & 1,567 & 42.4 & 9,180 & 12,368 & 1.34 & 1.50 & & & & & \\
\hline 14 & 185 & 446 & 41.5 & 21,545 & 17,832 & 1.23 & 1.36 & & & & & \\
\hline 35 & 22 & 57 & 38.6 & 16,445 & 18,620 & 1.36 & 1.97 & & & & & \\
\hline 13 & 14 & 43 & 32.6 & 117,293 & 90,406 & 1.66 & 2.22 & & & & & \\
\hline 34 & 14 & 67 & 20.9 & $448,200 \quad 6$ & 601,887 & 3.24 & 3.31 & & & & & \\
\hline
\end{tabular}




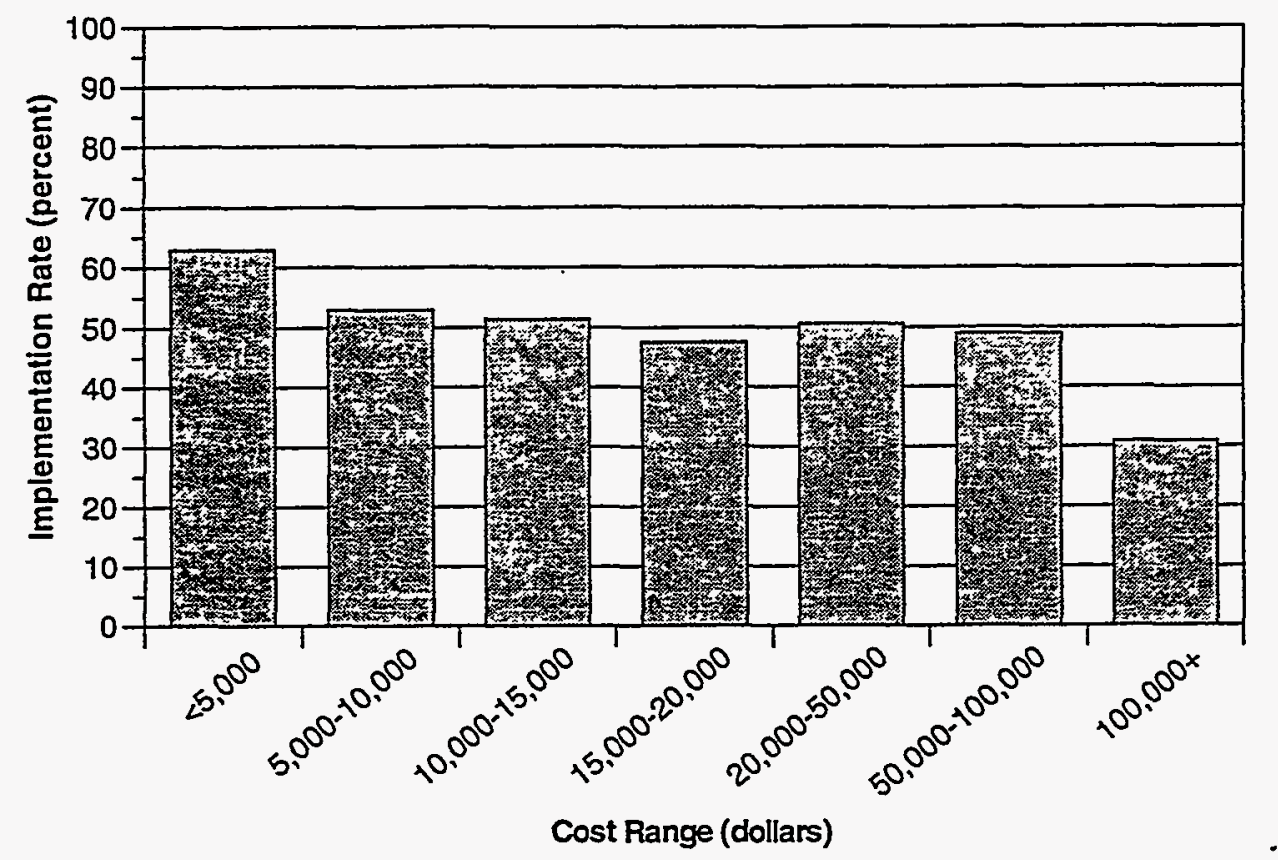

Figure 4-1. Implementation Rate Versus Implementation Cost

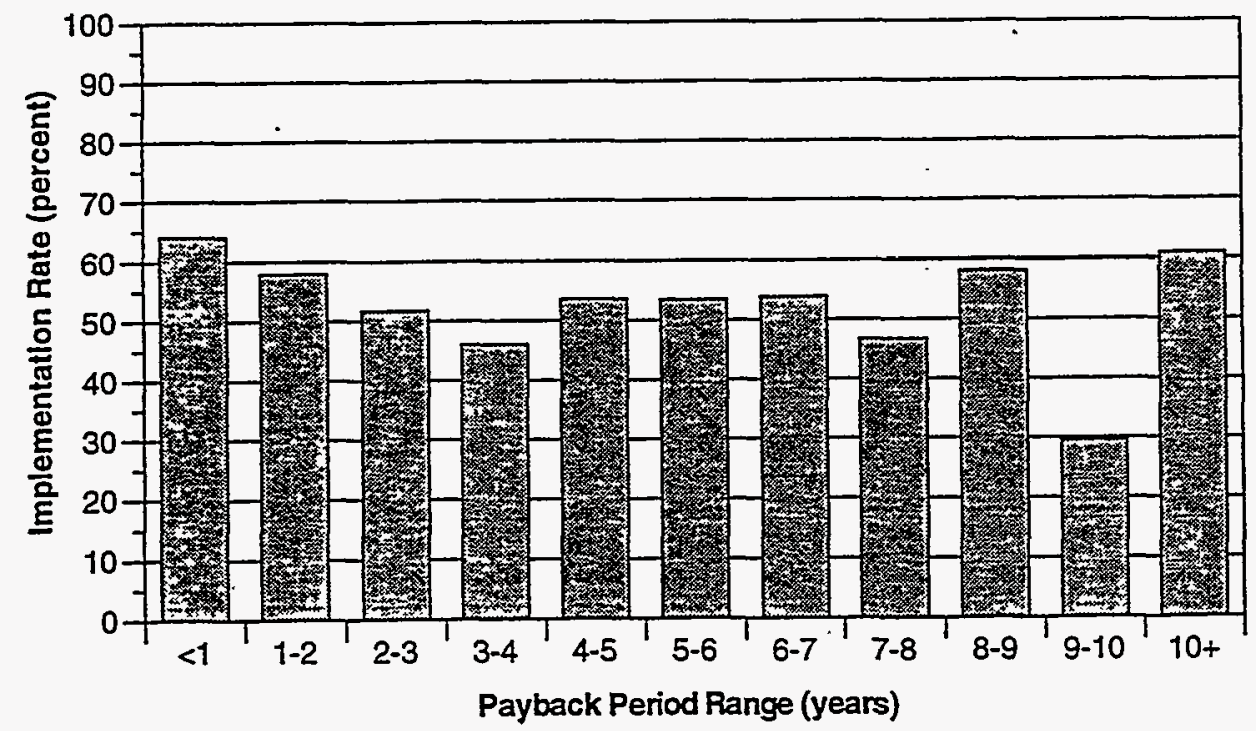

Figure 4-2. Implementation Rate Versus Payback Period 
Table 4-3. Number of Recommendations With Payback Periods in Given Ranges

\begin{tabular}{lrrr}
\hline \multirow{2}{*}{$\begin{array}{l}\text { Payback } \\
\text { Period Range } \\
\text { years) }\end{array}$} & \multicolumn{2}{c}{$\begin{array}{c}\text { Number of } \\
\text { Measures }\end{array}$} & $\begin{array}{c}\text { Implementation } \\
\text { Rate (\%) }\end{array}$ \\
\cline { 2 - 4 } $0-0$ & 3,061 & 5,274 & 58.0 \\
$0-1$ & 6,929 & 10,311 & 67.2 \\
$1-2$ & 2,379 & 4,105 & 58.0 \\
$2-3$ & 960 & 1,855 & 51.8 \\
$3-4$ & 325 & 705 & 46.1 \\
$4-5$ & 162 & 302 & 53.6 \\
$5-6$ & 84 & 157 & 53.5 \\
$6-7$ & 42 & 78 & 53.9 \\
$7-8$ & 21 & 45 & 46.7 \\
$8-9$ & 18 & 31 & 58.1 \\
$9-10$ & 8 & 27 & 29.6 \\
$>10$ & 83 & 136 & 61.0 \\
Total & 14,072 & 23,026 & 61.1 \\
\hline
\end{tabular}

specified payback periods, there is a slight downward trend in implementation rate as the payback period increases, but a lot of fluctuation. The more pronounced trend is associated with implementation cost (Table 4-4). That is, first cost appears more important than overall payback period in determining whether a measure will be implemented. The factors that underlie this phenomenon are discussed further later in this chapter. However, these findings make sense in light of the plant sizes targeted by the IAC program. Small and medium-sized plants are likely to be more capital-constrained than larger establishments and thus less able to invest in even those higher cost measures that have very short payback periods.

Table 4-5 explores the characteristics of plants that are willing to accept recommendations with higher payback periods. It would be expected that the 
Table 4-4. Number of Recommendations With Implementation Costs in Given Ranges

\begin{tabular}{lrrr}
\hline $\begin{array}{l}\text { Cost Range } \\
\text { (dollars) }\end{array}$ & \multicolumn{2}{c}{ Number of Measures } & $\begin{array}{c}\text { Implementation } \\
\text { Rate (\%) }\end{array}$ \\
\cline { 2 - 3 } 0 & Implemented & Recommended & 58.0 \\
$0-5,000$ & 9,059 & 5,271 & 64.8 \\
$5,000-10,000$ & 731 & 14,350 & 53.0 \\
$10,000-15,000$ & 287 & 1,380 & 51.5 \\
$15,000-20,000$ & 171 & 557 & 47.6 \\
$20,000-25,000$ & 113 & 359 & 49.3 \\
$25,000-30,000$ & 75 & 229 & 43.9 \\
$30,000-35,000$ & 68 & 171 & 59.7 \\
$35,000-40,000$ & 54 & 114 & 51.9 \\
$40,000-45,000$ & 32 & 62 & 51.6 \\
$45,000-50,000$ & 39 & 73 & 53.4 \\
$50,000-60,000$ & 30 & 74 & 40.5 \\
$60,000-70,000$ & 22 & 36 & 61.1 \\
$70,000-80,000$ & 18 & 34 & 52.9 \\
$80,000-90,000$ & 11 & 27 & 40.7 \\
$90,000-100,000$ & 19 & 33 & 57.6 \\
$>100,000$ & 47 & 152 & 30.9 \\
All Measures & 14,072 & 23,026 & 61.1 \\
\hline
\end{tabular}

average payback period would increase with plant size and with annual energy costs, because larger plants would be better able than smaller plants to afford such longer term investments, and plants with higher energy costs would be more motivated to undertake them than plants with lower energy costs. However, for this sample these expectations were not borne out. No strong trends emerge from these data. One possible explanation is that the IAC participants, by virtue of their desire to participate in the program, may be more attuned to and enthusiastic about possible energy savings (and related cost savings) than the general population of small and medium-sized manufacturing plants and so may implement more higher-payback-period measures than would be expected. 
Table 4-5. Variation of Plant Characteristics With Average Assessment Payback Period for Implemented Measures

\begin{tabular}{lccccc}
\hline $\begin{array}{c}\text { Number of } \\
\text { Assessments }\end{array}$ & $\begin{array}{c}\text { Average } \\
\text { Assessment } \\
\text { Payback } \\
\text { Period (yrs) }\end{array}$ & $\begin{array}{c}\text { Average } \\
\text { Annual } \\
\text { Sales (\$) }\end{array}$ & $\begin{array}{c}\text { Average } \\
\text { Employment }\end{array}$ & $\begin{array}{c}\text { Average } \\
\text { Annual } \\
\text { Energy Costs } \\
\mathbf{( \$ )}\end{array}$ & $\begin{array}{c}\text { Average } \\
\text { Energy Cost } \\
\text { as Percentage } \\
\text { of Sales }\end{array}$ \\
\hline 119 & 0 & $22,986,660$ & 154 & 380,843 & 1.7 \\
2050 & $0-1$ & $19,990,947$ & 163 & 367,725 & 1.8 \\
741 & $1-2$ & $21,767,215$ & 163 & 348,250 & 1.6 \\
138 & $2-3$ & $18,283,444$ & 168 & 289,372 & 1.6 \\
38 & $3-4$ & $19,023,684$ & 143 & 370,186 & 1.9 \\
20 & $4-5$ & $16,735,000$ & 148 & 242,852 & 1.5 \\
18 & $5-8$ & $17,338,889$ & 146 & 354,142 & 2.0 \\
18 & $>8$ & $21,047,778$ & 169 & 425,016 & 2.0 \\
\hline
\end{tabular}

${ }^{o}$ These values represent the average payback period for all implemented measures in an assessment.

The range of average payback periods for two-digit AR groups was not very large. While one group (ARC 91-Alternative Energy) had a large average payback period (and only two recommended measures), all the rest of the twodigit ARC groups had payback periods ranging from 0.3 year to 3.31 years.

Table 4-6 shows the percentages of all implemented and recommended measures falling into five payback periods (zero, greater than zero to 1 year, 1 to 2 years, 2 to 3 years, and more than 3 years). Almost all of the implemented and recommended measures (95 and 94 percent, respectively) had payback periods of 3 years or less. About 88 percent and 86 percent of the implemented and recommended measures, respectively, had payback periods of 2 years or less. The typical (average) payback period is about 1 year for the small and medium-sized manufacturing plants that receive energy assessments.

The most frequently recommended and implemented measures had payback periods of up to 1.4 years. A significant fraction of the recommended measures (22.9 percent) had payback periods of zero-that is, zero cost but nonzero savings. Fifty-eight percent of these zero-cost measures were implemented. 
Table 4-6. 'Distribution of Recommended Measures Among Five Payback Period Ranges

\begin{tabular}{lcc}
\hline & \multicolumn{2}{c}{$\begin{array}{c}\text { Fraction of Recommendations } \\
\text { Falling Into Each Range (\%) }\end{array}$} \\
\cline { 2 - 3 } Payback Period Range & $\begin{array}{c}\text { Implemented } \\
\text { Recommendations }\end{array}$ & $\begin{array}{c}\text { All } \\
\text { Recommendations }\end{array}$ \\
\hline 0 (i.e., zero cost) & 21.8 & 22.9 \\
0 to 1 year & 49.2 & 44.8 \\
1 to 2 years & 16.9 & 17.8 \\
2 to 3 years & 6.8 & 8.1 \\
Over 3 years & 5.3 & 6.4 \\
& & \\
\hline
\end{tabular}

\section{Implicit Discount Rates}

From the analyst's perspective, implicit discount rates provide a useful way to model investment decisionmaking and provide a starting point for further inquiry about the factors that influence company investment decisionmaking. When looking at investment decisions after the fact, analysts characterize them using implicit discount rates, also known as behavioral discount rates. A behavioral discount rate is an observed value that characterizes the behavior of a consumer, a consumer group, or a market. Based on actual purchase decisions, it can be inferred that certain consumers or groups behave as though they have certain discount rates. Individuals may or may not perform life-cycle cost analyses as part of their investment decisionmaking process. The behavioral, or implicit, discount rate characterizes only the final, observed decision.

The specific discount rates associated with particular measures depend on the expected lifetimes of the measures. Table E-1 shows how implicit discount rates are related to payback periods for various investment lifetimes. Few of the measures described in the ARC system will have lifetimes of less than 10 years. For maintenance items, such as turning off lights, scheduling equipment efficiently, and adjusting boilers, an infinite lifetime can be assumed. Accordingly, for most ARs, a payback period of up to 2 years implies an implicit (real) discount rate of about 50 percent. This value is significantly higher than the 
discount rate that is normally used to characterize investment decisions in industrial energy models.

The implicit discount rate is a very aggregate measure that captures a number of factors that influence a decision to make an investment and, thus, may represent more than a company's tradeoff between capital and operating cost. For example, the total amount of capital available for investing and the operational risk posed by the technology in question often influence the amount that will be invested regardless of the annual energy and cost savings. The next section discusses how some of these factors may affect investment decisions.

\section{Why Some Energy Efficiency Measures Are Not Implemented}

Five recent studies provide some insight into why some recommended efficiency measures are not implemented and some implemented measures are not maintained. These studies are the following:

- An analysis of rejection codes assigned to the ARs in the EADC database

- A 1991 study in which companies that had undergone an energy assessment were interviewed via telephone about the longevity of company commitment to implemented measures

- EADC client interviews of 104 companies, focusing on issues concerning large investments

- Interviews with 355 companies that had received assessments between 1989 and 1992

- A series of industry roundtables for small and medium-sized companies held in 1994 to explore incentives and obstacles to investing in energy-efficiency improvements.

The remainder of this section reports on the key findings from these analyses, in turn.

\section{Analysis of Rejection Codes in the EADC Database}

Beginning in 1992-93, the rejection codes that are assigned to ARs to provide information on why recommended measures are not implemented were included 
in the publicly accessible EADC database. From the 1992-93 timeframe to the time of this analysis, a total of 735 AR records were assigned rejection codes. The findings discussed in this section refer to these $735 \mathrm{AR}$ records.

Although there are 22 codes, the findings presented here focus only on the first 9, which are listed in Table 4-7. (The complete table of results from the rejection code analysis can be found in Appendix D.) These 9 reasons cited for rejecting recommendations account for more than 94 percent of the 735 recommendations for which rejection codes are publicly available.

Table 4-8 shows the principal reasons why plants receiving energy assessments reject recommendations that would improve their energy efficiency. Almost 48 percent of the ARs were rejected for financial reasons (because they were considered to have an unsuitable return on investment or to be too expensive initially, or because cash-flow prevented implementation). ${ }^{I}$ As expected, these ARs tend to be the highest cost measures, with the average implementation cost of measures rejected for financial reasons 10 times the average cost of measures rejected for the remaining six reasons. The average payback period for measures rejected because of an unsuitable return on

\section{Table 4-7. Selected EADC Database Rejection Codes}

Rejection Code Reason for Rejection

Unsuitable Return on Investment

Too Expensive Initially

Cash-Flow Prevents Implementation

Unacceptable Operating Changes

Impractical

Process and/or Equipment Changes

Facility Change

Personnel Changes

Production Schedule Changes 
Table 4-8. Distribution of Recommendations by Reason for Rejection

\begin{tabular}{lcccc}
\hline Reason for Rejection & $\begin{array}{c}\text { Number } \\
\text { of Records }\end{array}$ & $\begin{array}{c}\text { Percent of } \\
\text { Total Records }\end{array}$ & $\begin{array}{c}\text { Average } \\
\text { Implementation } \\
\text { Cost (S) }\end{array}$ & $\begin{array}{c}\text { Average } \\
\text { Payback } \\
\text { Period (yr) }\end{array}$ \\
\hline Unsuitable Return on Investment & 83 & 11.3 & 141,294 & 1.62 \\
Too Expensive Initially & 86 & 11.7 & 17,919 & 0.91 \\
Cash Flow Prevents Implementation & 180 & 24.5 & 6,299 & 0.98 \\
$\quad$ Unacceptable Operating Changes & 74 & 10.1 & 6,934 & 0.31 \\
Impractical & 110 & 15.0 & 5,499 & 0.77 \\
Process and/or Equipment Changes & 38 & 5.2 & 2,806 & 0.91 \\
Facility Change & 56 & 7.6 & 3,510 & 1.16 \\
Personnel Changes & 40 & 5.4 & 2,921 & $1: 21$ \\
Production Schedule Changes & 25 & 3.4 & 1,334 & 0.41 \\
All Others & 43 & 5.9 & & \\
$\quad$ Total & 735 & & & \\
\hline
\end{tabular}

investment is indeed the highest payback period in Table 4-8. The average implementation cost of those measures rejected for either an unsuitable return on investment or a too-high initial cost was $\$ 77,449$ (or $\$ 107,527$ if zero-cost measures are excluded), while the highest average cost of the measures rejected for any other single reason was $\$ 6,934$ (or $\$ 15,601$ if zero-cost measures are excluded). ${ }^{2}$ Yet the average payback period for each rejection code category (except for category 20-see Appendix D) is less than 2 years. In fact, most payback periods are closer to 1 year. This suggests that first-cost and capital constraints may be key factors driving a company's decision not to implement recommended energy-saving measures.

About 47 percent of the recommendations were rejected based on concerns about required production-related changes (for example, process or equipment

\footnotetext{
IThe 735 AR records evaluated here represent a limited time period. Results obtained from an evaluation of all rejection codes assigned to ARs may differ from those presented here.

${ }^{2} \mathrm{~A}$ number of the rejection code records contain a zero implementation cost, or a blank, where it is not clear that the cost should be zero. The inclusion of these records generally has only a small effect on the results; where the effect is significant, it is noted in the text.
} 
changes, facility changes, schedule changes, and personnel changes). Among these ARs, about 25 percent of the recommendations were rejected because they would have caused unacceptable operating changes or were otherwise impractical. Another 21 percent of the recommendations were rejected because of production-related concerns-process or equipment changes, facility changes, personnel changes, or production-schedule changes.

\section{EADC Callback Interviews}

The findings in this section are largely excerpted from a 1991 study (Wilfert et al., 1991) that reviewed the long-term energy savings attributed to energy assessments. The purpose of the report, which was prepared for the Department of Energy's Office of Industrial Technologies by Pacific Northwest Laboratory, was to independently assess the accuracy of past energy-savings reporting, specifically (1) whether a 2-year evaluation for identifying implemented recommendations captures all the recommendations implemented under the program and (2) whether the number of implemented recommendations and thus, the energy-savings associated with program assessments, significantly decreases in years 3 through 7 after the assessment. (The initial followup calls to plants, which are made by the IACs, gather information on implementation activities and plans for a period of 2 years after each assessment.)

In 1991, a limited sample of recommendations (161) was reviewed through telephone interviews with manufacturing companies to evaluate the longevity of implemented recommendations. Manufacturing companies were contacted from 4 to 7 years after the initial assessment was performed and asked to identify which recommended measures had been implemented and when. They were also asked if any measures had been dropped.

The report's conclusions include the following:

- For 88 percent of the recommendations, the implementation status remained unchanged between the initial callback made from 6 months to 2 years following the assessment and the callback made 4 to 7 years after the initial assessment was performed. ARs originally implemented were still in operation, and ARs not implemented at the time were still not being implemented.

- The stream of benefits (annual energy savings) persisted throughout the 3- to 7-year period analyzed. It was uncommon for implemented recommenda- 
tions to be dropped. Only 4 percent of ARs implemented were discontinued from service. For example, plants did not return to purchasing conventional motors once the move to high-efficiency motors had been made. They also continued maintenance programs for boiler tuning, steam-line leak reduction, and compressed-air leak reduction. Although no actual measurements were conducted to verify the current energy savings associated with implemented measures, it appears that there was only a very small reduction in energy savings as the result of recommended measures being dropped or their efficiency being diluted during years 3 through 7 after the assessment. In addition, this reduction was offset somewhat by the fact that plants decided to implement some recommendations after the initial callback.

- The heightened awareness by companies of energy use resulting from energy assessments appears to lead to an important but not easily quantifiable benefit of the program: some companies implemented additional energyefficiency measures that were not a part of the assessment recommendations. A typical situation occurred when plants added new warehouse capacity and installed energy-efficient lighting in the new space. Placing efficient heating systems in new plant capacity was also typical. Many companies reported that the ongoing purchase of efficient equipment occurred partly because of a heightened awareness of energy use resulting from the assessment.

\section{EADC Client Survey of 104 Companies}

The findings discussed in this section are drawn from a survey of EADC clients, which was documented in a 1994 report and subsequent research paper (Muller, 1994b; Muller et al., 1995).

The survey of 104 manufacturing companies was carried out in the spring of 1994 and primarily focused on issues concerning large investments (in this survey, large investments were defined as ARs costing more than $\$ 5,000$ ). The survey covered plants that had undergone assessments and had received and failed to implement individual recommendations that would have cost more than $\$ 5,000$. The survey results provide some additional insight into decisionmaking practices for large and expensive investments and into the reasons why certain high-cost recommendations are not implemented. ${ }^{3}$

When asked to characterize a "large investment," respondents stated a range from $\$ 1,000$ to $\$ 20,000$, as shown in Table 4-9 (Column 1). Almost 30 percent 
of the companies interviewed felt that any recommendation costing more than $\$ 1,000$ was a large investment. For 58 percent of the companies, a recommendation costing more than $\$ 5,000$ was considered a large investment. About 81 percent of the companies felt that a recommendation costing more than $\$ 10,000$ was a large investment.

Table 4-9 also shows information about the survey respondents drawn from the EADC database (columns 3 through 6). Plants that reported a "large investment" threshold of $\$ 20,000$ averaged twice the sales of plants whose threshold was $\$ 1,000$. Also, average energy expenditures are about the same across the various investment threshold categories, which may suggest that capital expenditure decisions are more a function of plant size (that is, level of sales) than of energy expenditures. Thus, IACs may find higher implementation rates for "big ticket" items in larger plants, even if their energy costs are not high.

Decisions on the more costly recommendations were most frequently made by people higher in management, who were more removed from technical

\footnotetext{
${ }^{3}$ Analysis of the distribution of respondents by sales, energy costs, number of employees, and SIC code indicates that the industry profiles of the interview sample do not greatly differ from those of the whole population of plants in the EADC database. However, the findings from this survey should not be interpreted to apply to the entire population of IAC-ciass manufacturing plants represented in the overall EADC database. This is because the survey sample was not determined by a stratified random selection process.
}

Table 4-9. Response to Question on Large Investment

\begin{tabular}{lccccc}
\hline & $\begin{array}{c}\text { Percent of } \\
\text { Plants } \\
\text { "Large Investment" } \\
\text { Threshold }\end{array}$ & $\begin{array}{c}\text { Average } \\
\text { Sales (\$) }\end{array}$ & $\begin{array}{c}\text { Average } \\
\text { Number of } \\
\text { Employees }\end{array}$ & $\begin{array}{c}\text { Average } \\
\text { Energy } \\
\text { Costs (\$) }\end{array}$ & $\begin{array}{c}\text { Average } \\
\text { Energy Cost as } \\
\text { Percentage } \\
\text { of Sales }^{a}\end{array}$ \\
\hline Greater than $\$ 1,000$ & 28.2 & $20,606,897$ & 166 & 605,617 & 2.6 \\
Greater than $\$ 5,000$ & 30.1 & $27,936,367$ & 186 & 655,937 & 3.1 \\
Greater than $\$ 10,000$ & 22.3 & $24,354,545$ & 168 & 638,587 & 4.0 \\
Greater than $\$ 20,000$ & 19.4 & $41,901,250$ & 221 & 507,431 & 1.9 \\
\hline
\end{tabular}

${ }^{a}$ Computed as average of individual averages.

Source: Muller, 1994c. 
issues than plant-level personnel. Plant-level personnel (for example, plant managers and engineers) typically made the decisions on less costly recommendations.

Generally, what companies consider to be a large investment varies with the hierarchical position of the decisionmaker. When only plant-level personnel made investment decisions, a recommendation costing more than $\$ 5,000$ was always considered a large investment. When only upper management made decisions, 72 percent of companies considered any investment costing more than $\$ 5,000$ to be a large investment, whereas only 28 percent of companies considered a large investment to be $\$ 10,000$ or greater. When both plant-level personnel and upper management were involved in decisions, about 50 percent of companies considered a large investment to be anything more than $\$ 5,000$, while the remaining companies considered a large investment to be anything costing more than $\$ 10,000$. This finding suggests that, in general, recommendations costing $\$ 5,000$ or less are more favored when upper management alone or plant personnel alone make decisions. That is, investment decisions made by those in upper management or plant personnel may result in a higher portion of lower cost measures being implemented than is the case when both are involved in decisionmaking. In these instances, short-term cost considerations may be outweighing the long-term benefits of investing in energyefficiency improvements. The analysis earlier in this chapter indicated that first cost may be more important than payback period (or some other economic criterion that balances cost and benefit) in energy-efficiency investment decisionmaking at small and medium-sized manufacturing plants. On the other hand, when both upper management and plant-level personnel are involved, recommendations costing greater than $\$ 5,000$ are more likely to be implemented.

The implementation experiences reported in the EADC client survey support the findings of Wilfert et al. discussed in the previous section. Fully 69 percent of the plants interviewed indicated that every previously implemented measure was still in place. Overall, 83 percent of the previously implemented recommendations remained in place. Also, 12 percent of recommendations not initially implemented were eventually implemented. This latter result is consistent with findings from the study by Wilfert et al., and it indicates that the implementation rates reported after the initial 2 years may understate the actual rates because of delayed implementation of some energy-efficiency measures. 
In the survey, a specific recommendation that costs more than $\$ 5,000$ and that was not implemented by the plant was identified to focus the discussion. For the identified "target" recommendation, a full 76 percent of companies felt that such a recommendation would be considered a major financial undertaking. Among these companies, a payback period of 12 to 24 months was preferred. For those companies that felt a recommendation costing more than $\$ 5,000$ was not a major financial undertaking, the majority (76 percent) appeared to prefer a payback period of 24 months.

The majority of companies ( 75 percent) felt that cost issues, such as unsuitable return on investment or unavailability of financial resources, were the major reason for not implementing recommendations costing more than $\$ 5,000$. However, concern about cost issues does not appear to depend on whether or not the recommendation would be a major financial undertaking. When the recommendation was a major financial undertaking, 86 percent of the companies felt that important cost issues would prohibit investment. When the recommendation was not considered a major financial undertaking, 60 percent of the companies considered cost to be a critical factor. This suggests that, in general, unsuitable return on investment or the unavailability of financial resources is a key factor preventing energy-efficiency investments.

Technical concerns can also deter companies from implementing recommended measures. Almost half the companies interviewed cited technical doubts as an issue affecting implementation decisions for recommendations that cost more than $\$ 5,000$. Although the cost issue is the biggest concern for most companies (as noted earlier), in more than half of these cases technical doubts also were apparent.

Only a few companies (13 percent) reported concerns about unacceptable changes in personnel, production, or facilities as reasons for not implementing recommendations costing more than $\$ 5,000$. Of these companies, only 23 percent of them also had technical doubts.

Finally, the interviewed companies were asked where they obtained technical assistance (for example, supporting information) on evaluating costly recommendations before making a final decision. About 40 percent of the companies interviewed indicated that they completed their evaluation using "in-house" staff, while the remainder used vendors and consultants. This suggests that IACs, after issuing an assessment report, may wish to determine if the client needs followup services in pursuing the more detailed information or 
economic analysis upper management may require. Followup services by IACs or another third party may help minimize any period of delay in companies' arriving at investment decisions.

\section{Survey of 355 Companies}

The findings discussed in this section are drawn from a survey of 355 manufacturing companies conducted by the University City Science Center (Kirsch and Clark, 1994b).

This survey of companies serviced by the IAC program between 1989 and 1992 was conducted in the fall of $1994 .{ }^{4}$ In addition to determining the implementation rates of assessment recommendations, the survey examined reasons why recommendations are rejected and possible influences of certain groups (plant engineers or managers, corporate officers, or others) on implementation decisions.

According to the study, 59.8 percent of the recommendations were implemented for the 355 manufacturing plants surveyed. 5 This result is consistent with the 61-percent implementation rate reported from the analysis of the full EADC database discussed in Chapter 3.

The study also found seven groups of reasons for rejection of recommended energy savings that accounted for 86 percent of all reasons energy-saving measures were not implemented. Table 4-10 identifies these seven groups.

The five most frequently cited reasons for rejection were the same top five reported in the analysis of rejection codes earlier in this chapter. Both analyses confirm that a large majority of the reasons for rejection of recommended energy savings are financial concerns or concerns about production-related changes. ${ }^{6}$

In examining individual reasons for rejection by the type of individuals who read the energy assessment reports, the Science Center study offers insights into the possible influence that plant (engineering) managers, corporate officers, and others (for example, personnel who have little or no decisionmaking power,

\footnotetext{
4The sample of 355 companies is not statistically representative of the set of companies represented in the EADC database. See footnote 3 on page 40.

5 The data analysis for this study excluded one category of energy-savings measures-alternative energy sources (that is, fuel switching and cogeneration)-because of their limited range of applications, high initial cost, and infrequent implementation.
} 
Table 4-10. Reasons for Nonimplementation

\begin{tabular}{lcr}
\hline $\begin{array}{l}\text { Reasons for Not } \\
\text { Implementing }\end{array}$ & $\begin{array}{c}\text { Percent of All } \\
\text { Reasons }\end{array}$ & $\begin{array}{c}\text { Corresponding } \\
\text { Rejection Code }\end{array}$ \\
\hline Financial Risk & $a$ & $1,2,3$ \\
Impractical Change & 25.0 & 5 \\
Plant/Person Risk & 11.5 & $4,16,17,18$ \\
Process/Plant Change & 16.9 & 6,7 \\
Schedule Change & 7.2 & 8,9 \\
Postponed Change & 4.2 & 12,13 \\
Lack of Staff & 14.8 & 14 \\
$\quad$ Subtotal & 6.3 & \\
Other & 86.0 & \\
\hline
\end{tabular}

The financial risk category comprises the following three specific reasons:

- Unsuitable return on investment

- Too expensive initially

- Cash-flow preventing implementation

Source: Kirsch and Clark, 1994b.

such as a maintenance foreman) may have upon decisions not to implement recommended energy-saving measures. Table 4-11 shows the distribution of report readership by percent of recommended energy savings and type of reason. Similarly, Table 4-12 shows report readership by percent of recommended cost savings and type of reason.

The influences of different levels of plant personnel are revealed from an analysis of readership frequency for each of the rejection reasons.

The bolded areas in Tables 4-11 and 4-12 indicate where the strong influences appear to occur. For example, the data suggest that when the reason for rejection has to do with a concern about scheduling changes, the influence of

\footnotetext{
${ }^{6}$ The University City Science Center analysis of the approximately 970 recommendations that were rejected during the 1989-92 period showed that these top 5 categories accounted for roughly 65 percent of the recommended energy-saving measures that were rejected, while the analysis of the 735 rejected recommendations for the 1992-93 timeframe and beyond reports that these top 5 reason categories accounted for 95 percent of the reasons for rejection. Although these results are not entirely consistent, they do reveal that a large majority of rejections are attributed to the top five reason categories.
} 
Table 4-11. Reasons for Nonimplementation of Energy-Efficiency Measures, by Reader of Report (Energy Savings Basis) (percent)

\begin{tabular}{|c|c|c|c|c|c|c|}
\hline Reason & $\begin{array}{c}\text { Percent } \\
\text { of All } \\
\text { Reasons for } \\
\text { Rejection }\end{array}$ & $\begin{array}{c}\text { Corporate } \\
\text { Officer } \\
\text { and Plant } \\
\text { Manager }\end{array}$ & $\begin{array}{c}\text { Corporate } \\
\text { Officer } \\
\text { Only }\end{array}$ & $\begin{array}{c}\text { Plant } \\
\text { Manager } \\
\text { Only }\end{array}$ & $\begin{array}{c}\text { Neither } \\
\text { Officer or } \\
\text { Manager (e.g., } \\
\text { Maintenance } \\
\text { Foreman) }\end{array}$ & Total \\
\hline \multicolumn{7}{|l|}{ Unacceptable Financial } \\
\hline Risk & 25.0 & 36.8 & 16.9 & 38.8 & 7.4 & 100 \\
\hline Impractical Change & 11.5 & 42.0 & 15.2 & 35.7 & 7.1 & 100 \\
\hline \multicolumn{7}{|l|}{ Unacceptable Plant/Person } \\
\hline Risk & 16.9 & 32.9 & 17.7 & 35.4 & 14.0 & 100 \\
\hline Process/Plant Change & 7.2 & 34.3 & 22.9 & 32.9 & 10.0 & 100 \\
\hline Schedule Change & 4.2 & 55.0 & 10.0 & 35.0 & 0.0 & 100 \\
\hline Postponed Change & 14.8 & 38.9 & 21.5 & 33.3 & 6.2 & 100 \\
\hline Lack of Staff for Analysis & 6.3 & 27.9 & 45.9 & 11.5 & 14.8 & 100 \\
\hline $\begin{array}{l}\text { Subtotal } \\
\text { Other }\end{array}$ & $\begin{array}{l}86.0 \\
14.0\end{array}$ & 37.1 & 19.9 & 34.1 & 8.9 & 100 \\
\hline
\end{tabular}

Note: Totals may not add because of rounding.

Source: Kirsch and Clark, 1994b.

corporate officers and plant managers who jointly participate in evaluating reports (and make subsequent investment decisions) appears to be large.

The following general observations can be drawn from the tables.

- When corporate officers and plant managers jointly participate in evaluating and following up on the assessment recommendation report, concern over scheduling changes or financial risk, or a postponement of the change, is more likely to be a reason for rejection.

- When the corporate officer alone evaluates the assessment recommendation report, lack of staff analysis, unacceptable plant or personnel risk, or concern over scheduling changes is more likely to be a reason for rejection.

- When the plant manager alone evaluates the assessment recommendation report, unacceptable financial risk or impracticality is more likely to be a reason for rejection.

- When neither the corporate officer nor the plant manager, but instead a maintenance foreman (or someone else who has little or no decisionmaking 
Table 4-12. Reasons for Nonimplementation of Energy-Efficiency Measures, by Reader of Report (Cost Savings Basis) (percent)

\begin{tabular}{|c|c|c|c|c|c|c|}
\hline Reason & $\begin{array}{c}\text { Percent } \\
\text { of All } \\
\text { Reasons for } \\
\text { Rejection }\end{array}$ & $\begin{array}{l}\text { Corporate } \\
\text { Officer } \\
\text { and Plant } \\
\text { Manager }\end{array}$ & $\begin{array}{c}\text { Corporate } \\
\text { Officer } \\
\text { Only }\end{array}$ & $\begin{array}{c}\text { Plant } \\
\text { Manager } \\
\text { Only }\end{array}$ & $\begin{array}{l}\text { Neither } \\
\text { Officer or } \\
\text { Manager (e.g., } \\
\text { Maintenance } \\
\text { Foreman) }\end{array}$ & Totals \\
\hline Unacceptable Financial & & & & & & \\
\hline Risk & 23.9 & 38.5 & 10.4 & 46.2 & 4.9 & 100 \\
\hline Impractical Change & 12.1 & 25.7 & 16.2 & 37.5 & 20.6 & 100 \\
\hline $\begin{array}{l}\text { Unacceptable Plant/Persor } \\
\text { Risk }\end{array}$ & 22.1 & 20.8 & 57.0 & 17.8 & 4.5 & 100 \\
\hline Process/Plant Change & 8.2 & 32.5 & 14.1 & 32.1 & 21.3 & 100 \\
\hline Schedule Change & 4.8 & 45.8 & 36.5 & 17.7 & 0.0 & 100 \\
\hline Postponed Change & 13.8 & 38.6 & 11.3 & 32.0 & 18.2 & 100 \\
\hline Lack of Staff for Analysis & 5.3 & 14.0 & 31.7 & 29.4 & 24.9 & 100 \\
\hline Summary & 90.3 & 30.9 & 25.7 . & 32.1 & 11.3 & 100 \\
\hline
\end{tabular}

Note: Totals may not add because of rounding.

Source: Kirsch and Clark, 1994b.

power), evaluates the assessment recommendation report, lack of staff for analysis, unacceptable plant or personnel risk, impracticality, unacceptable process or plant change, or postponement of the change is more likely to be a reason for rejection.

These findings suggest that further improvements in the energy assessment process may be achieved when assessment teams ascertain which persons expect to review the assessment report and provide appropriate followup support where needed. For example, if a plant manager is not involved in reviewing the assessment recommendation report, it appears more likely that an AR will be rejected because of lack of technical staffing, uncertainties regarding the impact of process or plant changes on plant production, or personnel risk. In these instances, implementation rates may be improved if a plant can be provided with followup technical assistance to help it complete the engineering analysis needed to make an informed decision, either through the IAC program or a third-party engineering contractor. Energy assessment teams 
may wish to make this an explicit recommendation to plant manage-ment in their assessment report and exit interview. On the other hand, when the plant manager alone, or in combination with a corporate officer, reviews the assessment report, potential concerns about financing may be allayed by presenting additional information in the assessment report on financing opportunities, perhaps through a regional financing registry developed by each individual IAC.

\section{Observations From Industry Roundtables}

As pointed out earlier, a plant typically implements about 50 to 61 percent of the recommendations resulting from an energy assessment. In 1994, the Alliance to Save Energy conducted a series of industry roundtables with representatives of small and medium-sized companies to identify the reasons behind the "efficiency gap" between energy-efficiency investments that are technically cost-effective and those that businesses actually implement (Jones and Verdict, 1995).

The Alliance held the three industry roundtables in Boston, Massachusetts; Houston, Texas; and Portland, Oregon. The purpose of the roundtables was to explore the factors that affect industrial energy-efficiency investments (for example, market conditions, environmental regulations, and utility programs). The 26 industrial participants represented a broad range of company sizes, types of industries, geographic areas, and levels of authority in the decisionmaking process. Feedback was also provided by a variety of other industrial energy professionals, such as utility program personnel, equipment suppliers, consulting engineers, and IAC representatives. Each roundtable addressed seven major topics: origin of energy-efficiency projects, evaluation techniques, the role of risk and uncertainty, access to the right information, operations and maintenance training for new equipment, utility demand-side management programs, and environmental considerations. The findings on four of these topics are germane here and are summarized below.

\section{Origin of Energy-Efficiency Projects}

Within an industrial plant, energy-efficiency projects originated from all levels-from the chief executive officer to the line worker. Projects originating from sources outside the plant were most often recommended by consultants, utility personnel, vendors, and peers. Several industry representatives said that 
energy-efficiency projects were identified and evaluated on a "cost driven" basis. If energy prices are high or there is a spike in energy costs, the plant's comptroller will often be the one to focus plant resources toward controlling the increase through efficiency measures. For this reason, semimonthly and weekly reporting is important to identifying any irregularities in energy consumption. Several companies mentioned that regular energy monitoring and reporting were useful tools in identifying energy efficiency projects.

\section{Evaluation Techniques}

Simple payback analysis was the most common analysis technique among the roundtable participants. Projects were generally limited to 2-year payback periods, although larger companies considered 3-year payback periods to be acceptable. In addition to payback analysis, a few companies mentioned that they also used internal rate-of-return calculations to help evaluate discretionary investment opportunities. Companies rarely used sophisticated life-cycle cost analysis to investigate energy-saving investments and viewed discretionary improvements (production process changes) quite differently from nondiscretionary improvements (in response to equipment failures). Several roundtable participants also said that energy-efficiency projects requiring large investments must be approved on a capital budgeting basis - that is, funds must be identified prior to the budget cycle, the budget for the item or items must be approved, and the project must be initiated during the fiscal cycle.

\section{Role of Risk and Uncertainty}

A major consideration for most industrial companies regarding whether to investigate an energy-efficiency project was the potential impact (real or perceived) of the project on product quality, cost, and production time. For instance, when a critical piece of equipment breaks down, there is frequently little time to evaluate an alternative investment adequately. Process-related energy-efficiency improvements were rarely undertaken exclusively to save money, primarily because of concerns about adverse impacts on production. Most companies agreed that having better access to accurate performance information on energy-saving equipment is a good way to reduce the risk and uncertainty associated with these capital investments. IAC program participants indicated that the assessment recommendations they received were very useful in providing the type of performance information they needed to make decisions, thus removing a great deal of uncertainty. 


\section{Access to the Right Information}

The sources of information used to evaluate an energy-efficiency improvement varied dramatically among the roundtable participants and were based largely on the size of the company. Smaller companies typically had limited access to product information, to dedicated in-house engineering staff, and to their peers to exchange insights and experiences. The roundtables revealed that the source of efficiency information often affects its credibility. Many companies told of their difficulties in getting the right information to make good decisions on whether to implement energy-efficiency projects. They simply did not have the time to adequately investigate new technologies. If they did manage to find the time, they often did not know where to start looking.

Many roundtable participants reported that they found it difficult and expensive to find efficiency projects that were worth serious investigation. In addition, smaller companies typically lack the resources to adequately research energy-efficiency opportunities to the point where an investment decision can be made by management. When they do investigate projects, plant personnel must often sort out conflicting answers. For instance, one energy manager told of investigating a cogeneration system and receiving very different advice from equipment vendors and the company's local utility representative. As a result, he did not know whom to believe. 


\section{Conclusions}

\section{Findings and Observations}

\section{A Typical Energy Assessment}

The Industrial Assessment Center (IAC) program provides assessment services to small and medium-sized manufacturing plants. A plant will meet this definition if it has less than 500 employees at the plant site, has less than $\$ 75$ million in sales, and spends less than $\$ 1.75$ million on energy in a year. An additional requirement to meet the criteria of the program is that the plant not have a full-time energy manager. While these criteria must be met to qualify, these limits do not characterize the population of plants that agree to energy assessments. Nearly two-thirds of all assessments are conducted at plants with less than $\$ 20$ million in sales and less than 200 employees.

Manufacturing industries with Standard Industrial Classification (SIC) codes 20 through 39 are covered by the program, but a characteristic energy assessment would occur in those four industries in which a disproportionate share of small and medium-sized plants fall: food and kindred products, rubber and miscellaneous plastics, metal fabrication, and industrial and commercial machinery and computer equipment (SIC codes 20, 30, 34, and 35, respectively).

When an industry assessment is conducted for a plant, the recommendations most likely to be made apply to building lighting, heating, and airconditioning; the building envelope; heat recovery and containment; and motors and compressors. The plant is most likely to implement the recommendations that apply to boilers and steam systems, motors and compressors, and lighting. Typically, a plant accepts about 61 percent of the recommendations made to it, saves about 4.4 billion Btu of energy per year, and reduces energy costs by about 10 percent. The plant typically pays for these measures within 2 years of the change.

Table 5-1 summarizes the observations from the EADC database on which measures are the most frequently recommended, which have the highest implementation rates, and which save the most energy and money. 
Table 5-1. Ranking of Measures by Frequency

\begin{tabular}{|c|c|c|c|}
\hline $\begin{array}{l}\text { Most Frequently } \\
\text { Recommended Measures }\end{array}$ & $\begin{array}{c}\text { Measures with } \\
\text { the Highest } \\
\text { Implementation Rate }\end{array}$ & $\begin{array}{l}\text { Measures Saving } \\
\text { the Most Energy }\end{array}$ & $\begin{array}{l}\text { Measures Saving } \\
\text { the Most Money }\end{array}$ \\
\hline Lighting & Steam Systems & $\begin{array}{l}\text { Heat Recovery } \\
\text { and Containment }\end{array}$ & $\begin{array}{l}\text { HVAC Systems and } \\
\text { Building Envelope } \\
\text { Changes }\end{array}$ \\
\hline $\begin{array}{l}\text { HVAC Systems and } \\
\text { Building Envelope } \\
\text { Changes }\end{array}$ & Boilers & Boilers & $\begin{array}{l}\text { Heat Recovery } \\
\text { and Containment }\end{array}$ \\
\hline $\begin{array}{l}\text { Heat Recovery } \\
\text { and Containment }\end{array}$ & Air Compressors & $\begin{array}{l}\text { HVAC Systems and } \\
\text { Building Envelope } \\
\text { Changes }\end{array}$ & Lighting \\
\hline Air Compressors & Lighting & Operational Changes & Boilers \\
\hline Motors & Motors & Steam Systems & Operational Changes \\
\hline Operational Changes & Operational Changes & Lighting & Motors \\
\hline
\end{tabular}

Note: Only the measures ranked first through sixth (in that order) are listed in each column.

A plant least likely to be the beneficiary of an energy assessment is one with more than 500 employees with annual sales of between $\$ 40$ million and $\$ 50$ million. Very few assessments occur in the petroleum refining industry (SIC 29) and the leather and leather products industry (SIC 31); no assessments have been made in the tobacco industry (SIC 21). The measures least likely to be recommended are in cogeneration, drying, and heating and heat treatment.

\section{Longevity of Implemented Savings}

Both the 1991 callback study and the 1994 EADC client survey conducted by Rutgers confirmed that the savings originally achieved via implementation of assessment recommendations persist. The former study found that, 4 to 7 years following an assessment, 88 percent of the implemented energy savings continued to be achieved and only 4 percent of implemented measures were taken out of service. Similarly, the 1994 survey indicated that 83 percent of 
implemented measures remained in place at the time of the survey. Both studies found that some recommendations that were not originally implemented were eventually adopted. The 1994 client survey reported that about 12 percent of these recommendations were implemented. Finally, the 1991 study identified an important but not easily quantifiable benefit of the IAC program: a heightened awareness of energy use as a result of the assessments led plants to adopt additional energy-efficiency measures that were not a part of the assessment recommendations.

\section{Implementation Experience at Smaller Versus Larger Plants}

Smaller plants (fewer employees and smaller sales) receive a higher number of assessments and, hence, receive a higher number of recommendations and implement a larger number of recommendations than larger plants. However, the implementation rates for all size plants are roughly the same, as are the number of recommendations and implementations per assessment.

\section{Payback Period and Discount Rate Results}

The typical payback period of less than 2 years that was found in the payback period analysis and the analysis of the rejection code data is echoed in the findings of other studies that have addressed the implementation experience of small and medium-sized manufacturing companies. Both the 1994 EADC client survey and the Alliance to Save Energy (ASE) industry roundtables indicate that a payback period of 2 years or less is generally required for implementation. For most assessment recommendations, this transiates to an implicit discount rate of about 50 percent or more. In addition, the payback period analysis found that first cost appears to be more important than overall payback period in implementation decisions. This is confirmed by the 1994 EADC client survey and the industry roundtables. The former found that a recommendation of more than $\$ 5,000$ was typically considered a "large investment" regardless of payback period. Even when a high cost measure was not considered a "major financial undertaking," companies still felt that cost was the major issue in deciding whether to implement the measure. The industry roundtables found that higher cost measures (for example, more than $\$ 10,000$ ) were subject to increased scrutiny, as they must be approved on a capital 
budgeting basis rather than funded out of engineering, production, and maintenance budgets. Similarly, the 1994 EADC client survey found that decisions on higher cost measures were typically made by those higher up in management, while decisions on lower cost measures could be made by plant-level personnel.

The findings on payback periods and the importance of initial cost make sense in light of the plant sizes targeted by the IAC program. Small and medium-sized plants are likely to be more capital-constrained than larger establishments and thus less able to invest in even those higher cost measures that have very short payback periods. In fact, larger companies that are not so capital-constrained are typically characterized as requiring a payback period of 3 years or less, which is slightly longer than that found for the small and medium-sized plants examined here. The industry roundtables confirm this, reporting that larger companies were willing to consider slightly longer payback periods (up to 3 years). However, the detailed analysis of the EADC database revealed no relationship between plant size or energy costs and willingness to invest in recommendations with longer payback periods.

The implicit (real) discount rate of 50 percent computed for small and medium-sized plants exceeds the values typically used to characterize industrial investment decisions in manufacturing companies. The majority of companies are typically modeled using a discount rate of 25 percent, a value that reflects less flexible companies with more capital constraints. The findings of this study indicate that another tier of companies exists-the small and mediumsized manufacturing companies-for which a discount rate of about 50 percent is probably more appropriate.

\section{Information Provision}

The IAC program operates without a profit motive or relationships with vendors, so plants receiving an energy assessment know they can trust the recommendations and the energy and cost savings data provided by the IAC. The importance of this was highlighted by the industry roundtable participants, who emphasized the importance of accurate information on technology reliability, equipment purchase price, and cost recovery. The IAC program thus fills an important niche by providing objective information at no cost to companies that otherwise might not have the resources to identify potential energy-saving projects or to evaluate them to the point where a decision on implementation can be made. 


\section{Recommendations}

Several policy options for enhancing the support that the Department of Energy and others provide to small and medium-sized manufacturing companies are recommended based on the analysis presented in this report and on the findings of the studies reviewed herein. Some of these options apply specifically to the IAC program, while others are more general.

\section{Helping Small Companies Access and Evaluate Energy-Efficiency Information}

Local utilities, State energy offices, and regional Department of Energy offices should work together to provide accurate cost and performance information on energy-efficiency process technologies and to demonstrate these technologies at the request of smaller manufacturing companies. Proactive information and cooperative demonstration programs are needed to help smaller companies make wise investment decisions. This may be accomplished through the expansion of existing programs, such as the Department of Energy's IAC program and utility industrial demand-side management (DSM) programs, or the creation of regional energy information centers.

Utilities should greatly expand their efforts to work directly with small companies in their service territories, helping them establish energy-use monitoring systems. This can be accomplished through assistance for enhanced metering and submetering programs that would help smaller companies measure, analyze, and manage their process energy flows.

\section{Enabling Investments Through Technical and Financing Assistance}

States should establish energy manager personnel pools to share "hands-on" assistance for identifying and implementing energy-efficiency improvements. Smaller companies (within or across industries) desperately need greater access to higher levels of energy-efficiency expertise. Unfortunately, few can afford to hire a dedicated energy manager. This situation could be remedied if the States made this expertise available to companies in a particular region on a "shared" basis. Under this scenario, an energy-efficiency expert could be hired and shared among a number of smaller companies-eventually covering the cost 
entirely from the energy savings. Initially, the project could be subsidized by a local utility, a State energy office, or a local IAC supported by the Department of Energy.

Energy assessment reports should also contain information on sources of financing, such as vendor and energy service companies specializing in process improvements. Seminars and workshops similar to those provided by the Federal Energy Management Program (FEMP) should be conducted by the Department of Energy or local utilities to educate industrial decisionmakers on energy service companies and vendor financing opportunities. Alternatively, small industries could be included as invited participants in FEMP workshops. Financing referrals could also be incorporated into the IAC program.

\section{Reaching the Ultimate Decisionmaker}

An important aspect of reaching the ultimate decisionmaker with energy assessment recommendations is ascertaining who in the organization will determine whether specific investments will be made. Further improvements in implementation rates could occur if the energy assessment team can determine which recommendations can be acted upon by the plant manager and which recommendations require the decision of higher management. The team could then make different kinds of presentations to different plant representatives.

It would also be beneficial for assessment teams to establish at the exit interview whether additional technical assistance (for example, from vendors or consultants) is needed by the plant to complete an evaluation of any particular recommended measure. Followup project-evaluation services could be provided by either the IACs or another third-party entity to help minimize lost investment opportunities arising from a plant's management delay in getting the detailed evaluation information it requires.

\section{Fostering Energy-Efficiency Networks}

The IACs or others should develop individual and regional programs to increase peer-to-peer exchanges within industry by (1) encouraging participation in local energy-related associations, (2) developing energy engineer program groups or chapters of these national organizations in regions where they do not exist, and (3) fostering industry-specific local energy engineering groups. 
Smaller manufacturing companies need more opportunities to exchange information on energy-efficiency projects. Regional clearinghouses for energy efficiency should be established to (1) serve as information clearinghouses for energy-efficiency technologies, (2) provide a single point of contact to locate people who are knowledgeable about energy-efficient equipment, and (3) serve as regional technology demonstration and training sites for IAC participants, utility DSM program personnel, and plant engineers. These centers could be provided through expanded utility DSM program efforts, expanded missions for the IACs, or a partnership effort among these and other programs.

\section{Expanding the Technical Resources Available to the IACs}

One way to help the IACs better serve their client plants is to provide the IAC staff with enhanced tools and energy assessment (audit) aids. There are a number of such tools and aids that the Department of Energy could make available to IACs that would be useful as educational tools and as living documents that provide the staff with a picture of the state of the art in improving the energy efficiency of industrial production process and plants. What tools would have value to the IACs is an issue that the IAC Directors should discuss with the Department of Energy. Some tools that could be considered in these discussions are as follows:

- Provide Industry-Specific Information. Provide industry-specific guides, similar to the previous "Industrial Market and Energy Management Guides" (for example, American Consulting Engineers Council, 1985), containing industry information and energy-efficiency ideas. Provide information on potential process improvements, perhaps in the form of anonymous case studies. Such information would help the IAC staff prepare for energy assessments in specific industries and help them provide even more information to client plants during or after an assessment that conveys the potential savings associated with implementing specific assessment recommendations.

- Provide an Electronic Energy Assessment (Audit) Aid. Have a tool developed that downloads a set of data applicable to a given assessment onto a personal computer that walks an assessment team through a typical plant within a specific SIC code. This would follow much the same style as the management guide identified above, but would provide, through the use of a 
comprehensive database, specific information about plants and potential energy-efficiency measures.

\section{Enhancing Assessment Data Collection}

The collection, during an assessment, of information on Census Bureau reporting would be very useful to those who use the EADC database for analysis. The IAC teams should, if possible, identify what, if any, reporting to the Census Bureau has been completed in the recent past. The census reports considered should include the Census of Manufactures, the Annual Survey of Manufactures, and the Manufacturing Energy Consumption Survey. This additional information could greatly expand the use of the EADC database for analytical purposes, such as for plant-level analysis by certified census agents, by enabling the data to be integrated with the available repository of information from the census surveys. 


\section{APPENDIX A. DESCRIPTION OF THE ENERGY ASSESSMENT PROCESS}

\section{The Energy Assessment Process}

While the energy assessments conducted by the Industrial Assessment Centers (IACs) provide a high-quality service to the manufacturing plants served, it is likely that use of the data developed through the program will have more of an impact on manufacturing productivity. However, to appreciate the data one must have a clear idea of the assessment process: what is done, what measurements are taken, and how recommendations are arrived at. This appendix details the various components of an energy assessment performed by an IAC. ${ }^{l}$

\section{Client Selection and Solicitation}

Selecting clients to serve involves weighing several competing goals of the program. Over a reasonable period of time, an IAC is expected to serve a diverse range of clients. This includes covering all of the geographical areas assigned to a center and auditing a broad array of manufacturing operations as categorized by Standard Industrial Classification (SIC) code.

From an operational perspective, it is also advantageous to select clients that will result in the most successful assessments. Historically, the two factors leading to the most effective assessments are plant size and interested management, which are discussed further below.

- Plant Size. If plants are too small, there are neither the opportunities nor the resources to employ many of the assessment recommendations (ARs) that may be suggested.

- Interested Management. The successful implementation of some ARs can cost substantial amounts of money. This requires that management get involved. Therefore, the best assessment clients are ones where high-level managers either get involved or otherwise indicate their support.

The material in this appendix is adapted from Muller, $1994 \mathrm{c}$. 
In practice, clients are solicited in a number of ways, such as through direct mailings, interaction with State organizations and manufacturing associations, and cold calling. Normally there is not a backlog, and plants expressing an interest usually can be served within a few weeks. The centers operate throughout the year, but because students are a large part of the program, exam periods and other times of competing student interest can result in brief periods of low activity.

\section{Preassessment Information Gathering}

Great effort is expended to find out as much information as possible about a client before the site visit. There are several reasons for this. First, the client needs to qualify for the program. It is a waste of resources for a team to travel 100 miles to perform an assessment only to determine that the plant does not qualify. Second, receiving copies of energy bills and details about manufacturing processes allows the team to gather necessary background information from the database or other resources to aid in the assessment. However, it is not always easy to get such information from plants. In many cases, they are not sure what level of study will be carried out and are skeptical until the team arrives. Still, the more successful assessments start with a reasonable amount of information concerning the physical plant and manufacturing operations.

\section{Site Visit}

The site visit normally consists of five segments, as described below.

\section{Initial Interview}

Upon arriving at the plant, the assessment team meets with a designated member of plant management for an extended interview. Goals for this interview are the following:

- Introductions

- Description of the IAC program

- Detailed discussion of plant operations

- Detailed discussion of plant hardware 
This segment of the assessment is critically important. A successful assessment requires that plant management be convinced of the competence of the assessment team. Great effort is taken to reassure the client about any concerns, whether technical, relating to proprietary technologies, or procedural. Confidentiality, insurance issues, and safety policies of the assessment team are reviewed. In addition, a review is made of plant management philosophy, training, and educational level to assess its commitment to energy efficiency. The assessment team leader normally uses a standard outline for this discussion with the plant personnel.

It is important to remember that the operation of a plant involves both machines and people, and there is a great deal more consistency in machines than in people. So, while it may appear that the most essential skills for conducting assessments are technical, the ability to communicate successfully with plant managers, understand their operational philosophies, and customize technical information to best fit their philosophies and needs are skills of equal or greater importance.

\section{Plant Tour}

Following the initial interview, the assessment team is escorted on a detailed tour of the plant. Normally the major focus is on manufacturing processes, but the tour also involves heating, ventilation, and air-conditioning (HVAC) systems and any other ancillary systems that consume energy. Where possible, the tour through the plant operations is sequenced to begin with the intake of raw materials and progress to the output of the finished product. The assessment team's goals for the tour are a global view of plant operations and an initial impression of possible recommendations for energy conservation. Getting the "big picture" is essential to the team's ability to place energysaving ideas into the correct context for presentation to plant management.

\section{Evaluation}

After the plant tour, the assessment team members meet by themselves to review the information gained so far and to determine a plan or strategy for the time remaining in the day. Normally a meeting is held in the plant cafeteria.

There are three purposes for this meeting:

- Student Training. Every plant is different and there are always operations, hardware, and processes that are new to the students. The initial interview is often too fast-paced to allow much in the way of student training, and the 
plant tour takes place in noisy environments that allow only for shouted conversation. Therefore, the first part of the plant evaluation meeting involves answering students' questions.

- Identification of Potential Recommendations. Based on a review of energy bills, discussions during the initial interview, and study of energy bills, a preliminary list of potential ARs can be assembled. Students are encouraged to participate in idea generation, and there is a direct relationship between student experience and ability to contribute at this point.

- Plan for Remainder of Visit. As the list of ARs is generated, another list is started that details additional information needed from management to allow the ARs or other aspects of the assessment report to be developed. A list is also made of the additional data needed to evaluate the potential ARs, as well as other measurements and studies that could lead to additional ARs.

\section{Measurements and Data Gathering}

This aspect of the assessment is crucial to its successful outcome. Ideas for energy savings beyond "motherhood and apple pie" need appropriate engineering data to support them. The approach is normally to obtain the obvious information first. Then, with time permitting, the team is able to explore additional ARs that have been identified. Typical measurements include the following:

- Temperature measurements of various types

- Flow-rate measurements of various types

- Flue-gas composition

- Lighting levels

- Air leaks

- Vibration levels

- Kilowatt demand

Gathering most of the other necessary information involves measuring lengths and distances, counting, and identifying qualitative insights that provide support for ARs (for example, "the steam plume was observed to rise several feet above the clogged steam trap resulting in unnecessary energy loss"). 


\section{Exit Interview}

The data-gathering phase of the assessment continues until near the end of the working day. At this point a final interview is held with plant management. The primary purpose of the interview is to go over the ARs that are being considered. One purpose is to determine if the energy-saving ideas presented by the assessment team could be implemented. In some cases, there are constraints of which the assessment team is not aware. Discussion of this in the exit interview can save unnecessary work in the report writing. The most important purpose, however, is to "sell" management on the ideas that will be contained in the report. If the correct foundation for the ideas can be presented during this interview, then plant management knows what to expect from the report and, in many cases, is immediately ready to commence with changes upon receipt of the report. If concerns are raised about any of the potential ARs, these concerns can be addressed in detail in the assessment report.

\section{Assessment Report Preparation}

The assessment report is prepared in four steps.

\section{Descriptive Writeups}

As soon as possible after the site visit, work commences on the assessment report. The report includes detailed descriptions, such as a writeup on the plant layout, on the HVAC system, and on the manufacturing processes. This part of the report can normally be written without waiting for vendor information.

\section{Vendor Information}

Very often, information in addition to that acquired during the site visit is needed to complete the engineering analyses for ARs. Examples of such information are rate schedules for utilities and information from a boiler manufacturer about economizers available for a certain model. This step turns out to be the most time-consuming aspect of the process.

\section{Assessment Recommendation Calculations}

The AR calculations, which are the "meat" of the report, must be clear and concise such that plant management can easily follow the logic. However, care 
must also be taken to present enough information to justify the judgments that are often part of the engineering analysis.

\section{Report Assembly and Proofreading}

The quality of the final report can affect the ultimate decisions made on implementing recommended measures, so ensuring high quality is essential. This may appear easy, but with many different people contributing to the effort, ensuring quality requires great diligence.

\section{Implementation}

At a point between 6 and 9 months after the submission of the assessment report, a followup interview is done with plant management, usually by phone. Here the ideas presented in the report are reviewed to identify the actions either already undertaken or planned for implementation. If an AR is not to be implemented, reasons are sought.

There are three important reasons for timely and accurate evaluations of the implementation of ARs. The first is as a check on the work of the assessment team. If an idea has been rejected, it is important to determine why and to try and make a stronger case when it next comes up. The second reason is as a motivational tool for the center staff. When an AR is implemented, especially one that requires the plant to invest a sizable amount of money, there is a real feeling of accomplishment. For the students, this may be one of the first times their engineering work has made an impact anywhere. The third reason is that the program needs to demonstrate its effectiveness, both on the programmatic level and at the individual IAC level. Implemented ARs show policymakers that the funds spent in the program are making a difference. At the center level, knowledge that a particular $\mathrm{AR}$ has been implemented provides strong leverage when approaching another client with the same energy-saving idea. 


\section{APPENDIX B. BENEFITS OF THE IAC PROGRAM}

The benefits of the Industrial Assessment Center (IAC) program include increased efficiency of energy use, the training of staff, the accessibility to the public of a rich database of end-use data on energy use in small and mediumsized plants, and workshops and other activities that have become part of the operation of the IACs.

These results have been achieved at a total cumulative Federal cost of $\$ 27$ million.

\section{Energy and Cost Savings}

On average, individual manufacturing plants participating in the IAC program implement within 2 years 50 to 60 percent of the recommendations made, and each generates energy savings of about 4.4 billion Btu per year. Each plant averages about $\$ 38,000$ in annual cost savings.

In addition, the IAC program has proven to be extremely useful in providing plants with a heightened awareness of energy management issues. The assessment teams bring new technologies and procedures to the attention of management. By evaluating energy-saving ideas to the point of predicting savings, the assessment teams illustrate the connection between conservation and profit. Although small and medium-sized manufacturing companies generally recognize the benefits of energy conservation, they may remain woefully unaware of the dollar savings involved unless they go through the process of evaluating actual energy- and cost-saving opportunities. Finally, the very act of reviewing energy use with the staff in charge of production heightens their awareness regarding energy efficiency, which can result in better informed decisionmaking for years following the assessment. This is supported by findings from a recent survey of 355 companies for which energy assessments had been conducted by IACs. Companies' perceptions of program benefits reported in the survey suggest five primary benefits (Kirsch and Clark, 1994b):

- Fostering company awareness of energy inefficiency and waste

- Confirming company suspicions about energy inefficiency and waste

- Helping companies identify ways to lower costs 
- Helping companies in deciding to install new equipment

- Convincing company management of profitable recommendations by quantifying savings

\section{Energy Management Training}

The program's benefits go beyond the clients served. Each center provides energy management training to 4 to 12 students per year. The students involved in the program have a unique opportunity to see a range of manufacturing operations first hand. Students participate in every aspect of the program, from selecting clients to preparing implementation reports. Since 1976, more than 1,000 students have received energy management training.

Operation of IACs is a dramatically effective tool for bringing the fascinations and the challenges of energy engineering to the attention of students. For example, at Rutgers University, more than half the students involved with IAC activities to any significant degree have taken employment in some form of energy engineering after graduation. In addition, faculty have developed ideas for research from their studies of manufacturing processes and have taught courses using experiences gained through their energy-assessment work.

\section{End-Use Data}

An additional benefit of the program is the information generated by the assessments, which provides a unique opportunity to quantify the state of energy management in small and medium-sized manufacturing plants and the potential of energy assessments to improve efficiency. Data from the energy assessments have been formally compiled since 1980 . The EADC database provides a source of empirical information on energy-saving measures, adoption rates, energy and dollar savings, and payback periods that can provide input to future energy-economic modeling efforts. ${ }^{1}$

\footnotetext{
${ }^{I}$ The database is available for download from the Office of Industrial Productivity and Energy Assessment at Rutgers University. It is accessible at http://oipea-www.rutgers.edu/ through the World Wide Web. It is also available via FTP, CompuServe, and dial-up. Guest accounts (not needed for World Wide Web access) and more information can be obtained by sending e-mail to database@camp.rutgers.edu or by calling $908-445-5540$.
} 


\section{Other Benefits}

IAC personnel conduct many other activities that provide both direct and indirect support to manufacturing plants. These include running workshops, speaking at seminars, writing books, doing research on energy-related problems, and participating in the development of a host of decisionmaking aids.

The work done by the IACs is viewed as a complement to other programs run by State energy offices, utilities, vendors, and other universities. The IACs interact regularly with these other organizations. Staying current with rebate programs, participating in State programs, holding seminars with vendors, and collaborating with other universities are all routine practices at IACs. 



\section{APPENDIX C. UNIVERSITY PARTICIPATION IN THE IAC PROGRAM}

Table C-1 lists all of the Industrial Assessment Centers (IACs) and their years of operation.

Table C-1. University Participation in the IAC Program

University

Texas A\&M University (College Station)

Arizona State University (Tempe)

North Carolina A\&T

Bradley University (Peoria)

Colorado State University (Fort Collins)

South Dakota State University (Brookings)

Georgia Institute of Technology (Atlanta)

Hofstra University (Long Island)

Iowa State University (Ames)

Texas A\&M (Kingsville)

University of Kansas (Lawrence)

Louisiana Tech

University of Massachusetts (Amherst)

University of Maine (Orono)

University of Missouri (Rolla)

Mississippi State University

North Carolina State University (Raleigh)

Notre Dame University

University of Nevada (Reno)

Old Dominion University (Norfolk)

Oklahoma State University (Stillwater)

Oregon State University (Corvallis)

Prairie View A\&M

Rutgers, The State University of New Jersey

San Diego State University

San Francisco State University

Stevens Institute of Technology
First-Last Fiscal Years

$87-95$

90-95

85-89

94-95

84-95

94-95

$82-95$

91-95

91-95

94-95

81-95

84-89

80-95

93-95

90-95

94-95

93-95

91-95

94-95

94-95

82-95

$87-95$

$\cdot 85-85$

$86-92$

91-95

93-95

84-86 
Table C-1. University Participation in the IAC Program (continued)

University

University of Tennessee (Knoxville)

Tri-Cities University

University of Dayton (Ohio)

University of Florida (Gainsville)

University of Louisville

University of Michigan (Ann Arbor)

University of Wisconsin (Milwaukee)

West Virginia University (Morgantown)

University of Arkansas (Little Rock)
First-Last Fiscal Years
$81-95$
84-90
81-95
91-95
94-95
94-95
87-95
93-95
93-95

Note: The years indicated are fiscal years, which start on October 1 of the year in question (for example, fiscal year 1995 begins on October 1, 1994, and ends on September 30, 1995). 


\section{APPENDIX D. REJECTION CODE RESULTS}

The rejection codes used in the EADC database are shown in Table D-1. The database contains 735 records for which a rejection code is entered. A number of the records contain an implementation cost of zero, or a blank, where it is not clear that the cost should be zero. The inclusion of these results has only a small effect on the results; where a difference is significant, it is noted in the text. These records represent recommendations from assessments conducted after the 1991-92 timeframe. The full set of data results is provided in Table D-2.

Table D-1. EADC Database Rejection Codes

\begin{tabular}{ll} 
Rejection Code & \multicolumn{1}{c}{ Description } \\
\hline 1 & Unsuitable Return on Investment \\
2 & Too Expensive Initially \\
3 & Cash Flow Prevents Implementation \\
4 & Unacceptable Operating Changes \\
5 & Impractical \\
6 & Process and/or Equipment Changes \\
7 & Facility Change \\
8 & Personnel Changes \\
9 & Production Schedule Changes \\
10 & Material Restrictions \\
11 & Bureaucratic Restrictions \\
12 & To Be Implemented After Two Years \\
13 & Considering \\
14 & Lack of Staff for Analysis and/or Implementation \\
15 & Not Worthwhile \\
16 & Disagree \\
17 & Risk or Inconvenience to Personnel \\
18 & Suspected Risk or Problem with Equipmert or Product \\
19 & Rejected After Implementation Failed \\
20 & Unknown \\
21 & Could Not Contact Plant \\
22 & Other \\
& \\
\hline
\end{tabular}


Table D-2. Distribution of Recommendations Among Rejection Codes

\begin{tabular}{|c|c|c|c|c|}
\hline $\begin{array}{l}\text { Rejection } \\
\text { Code }\end{array}$ & $\begin{array}{l}\text { Number } \\
\text { of Records }\end{array}$ & $\begin{array}{l}\text { Percent of } \\
\text { Total Records }\end{array}$ & $\begin{array}{c}\text { Average } \\
\text { Implementation } \\
\text { Cost (\$) }\end{array}$ & $\begin{array}{c}\text { Average } \\
\text { Payback } \\
\text { Period (year) }\end{array}$ \\
\hline 1 & 83 & 11.3 & 141,294 & 1.62 \\
\hline 2 & 86 & $11.7^{\circ}$ & 17,919 & 0.91 \\
\hline 3 & 180 & 24.5 & 6,299 & 0.98 \\
\hline 4 & 74 & 10.1 & 6,934 & 0.31 \\
\hline 5 & 110 & 15.0 & 5,499 & 0.77 \\
\hline 6 & 38 & 5.2 & 2,806 & 0.91 \\
\hline 7 & 56 & 7.6 & 3,510 & 1.16 \\
\hline 8 & 40 & 5.4 & 2,921 & 1.21 \\
\hline 9 & 25 & 3.4 & 1,334 & 0.41 \\
\hline 10 & 0 & $\mathrm{NA}$ & $\mathrm{NA}$ & $\mathrm{NA}$ \\
\hline 11 & 2 & 0.3 & 0 & 0 \\
\hline 12 & 0 & NA & NA & $\mathrm{NA}$ \\
\hline 13 & 22 & 3.0 & 5,724 & 1.48 \\
\hline 14 & 2 & 0.3 & 180 & 1.13 \\
\hline 15 & .6 & 0.8 & 1,317 & 1.45 \\
\hline 16 & 1 & 0.1 & 0 & 0 \\
\hline 17 & 2 & 0.3 & 1,128 & 0.24 \\
\hline 18 & 2 & 0.3 & 6,945 & 0.29 \\
\hline 19 & 2 & 0.3 & 2,199 & 1.16 \\
\hline 20 & 1 & 0.1 & 480 & 3.43 \\
\hline 21 & 0 & $\mathrm{NA}$ & NA & $\mathrm{NA}$ \\
\hline 22 & 3 & 0.4 & 0 & 0 \\
\hline Total & 735 & & & \\
\hline
\end{tabular}




\section{APPENdIX E. METHOdOlOGY For PAYBACK PERIOd AND IMPLICIT DISCOUNT RATE ANALYSIS}

This appendix provides details on the methodology used for the payback period and implicit discount rate analysis described in Chapter 4.

\section{Database Analysis}

For this analysis, as well as for the analysis of assessment recommendations and implementation rates in Chapter 3, only those records that had an implementation status of $1,2,3,4$, or 5 coded in the database were used. An implementation status of 1 through 4 indicates that the plant receiving the assessment implemented or planned to implement the assessment recommendation within 2 years of the assessment. A status of 5 indicates that the plant did not plan to implement the recommendation within 2 years (although it may have implemented it at a later date). In this analysis, all recommendations with an implementation status of 5 were treated as not implemented.

A number of records did not have a code entered for implementation status-that is, the field was blank or coded as zero. These records were not considered in this analysis.

For those records that were coded, the implementation rate, implementation cost, and payback period were analyzed by two-digit assessment recommendation code (ARC) group. In addition, for the database as a whole, the distribution of implemented and recommended measures among implementation cost ranges and payback period ranges was determined.

For each two-digit ARC group and for the database as a whole, the following methodology was used:

- The implementation rate was measured as the number of assessment recommendations coded with implementation statuses 1 through 4 divided by the total number with implementation statuses 1 through 5 .

- The implementation cost and payback period were computed as the averages for all implemented and recommended measures in each ARC group. The payback period was calculated as a simple payback period, equal to the implementation cost divided by the cost savings. 
- The total cost savings were taken from the PSAVED, SSAVED, and OTHERSAVED fields, which contain either client-reported savings or estimated savings.

For several records, the payback period computed using the cost and savings data in the database was indeterminate. This occurred when the cost and savings were both zero and when the cost was nonzero but the savings were zero. Such records could reflect errors in the database or data that have not yet been entered or findings after the fact about whether a recommendation would indeed save money. In the first case, the payback period was changed manually to zero. In the second case, the payback period was changed manually to 25 years.

\section{Determining Implicit Discount Rates From Payback Periods}

The implicit real discount rate that is equivalent to a given payback period may be determined by setting the present value equation equal to zero and solving for the internal rate of return. An investment lifetime must be assumed to perform the calculation. For this calculation, it is assumed that the initial investment results in a uniform series of benefits (as opposed to benefits that vary from year to year). Simple (discrete) discounting is used.

It is assumed that an initial investment $C$ is made at the beginning of year one and that annual savings accrue at the end of each year, beginning in year one. The annual savings are equal to the initial investment divided by the payback period. The net present value (NPV) of the investment is therefore calculated as shown below. When the NPV equation is set equal to zero, the internal rate of return that is equivalent to a given payback period can be derived.

$\begin{array}{lll}\text { Initial investment: } & C & (\$) \\ \text { Annual savings: } & A & \text { (\$/year) } \\ \text { Payback period: } & P B & \text { (years) }=\mathrm{C} / \mathrm{A} \\ \text { Investment life: } & T & \text { (years) } \\ \text { Real discount rate: } & r & \text { (fraction/year) }\end{array}$




$$
\begin{gathered}
\text { Benefits }- \text { Costs }=N P V=\sum_{t=1}^{T} \frac{A}{(1+r)^{t}}-C=0 . \\
C=A \sum_{t=1}^{T} \frac{1}{(1+r)^{t}}=\frac{A}{C R F}
\end{gathered}
$$

where

$$
\text { Capital Recovery Factor }=C R F=\frac{r(1+r)^{T}}{(1+r)^{T}-1} .
$$

Now,

$$
A=\frac{C}{P B} \Rightarrow \mathrm{C}=\frac{C / P B}{C R F} \Rightarrow P B=\frac{1}{C R F} \text {. }
$$

The last equation above is used to calculate the internal rate of return for assumed payback periods and investment lifetimes. Note that, as $T$ becomes very large, $r$ approaches $1 / P B$ :

$$
P B=\frac{1}{C R F}=\frac{(1+r)^{T}-1}{r(1+r)^{T}}=\frac{1}{r}-\frac{1}{r(1+r)^{T}} .
$$

Thus,

$$
\text { as } T \rightarrow \infty, P B \rightarrow \frac{\cdot 1}{r}
$$

The internal rates of return that are equivalent to given payback periods are shown in Table E-1. 
Table E-1. Implicit Real Discount Rates as a Function of Payback Period and Investment Lifetime (percent per year)

\begin{tabular}{|c|c|c|c|c|c|c|c|c|c|}
\hline \multirow{2}{*}{$\begin{array}{l}\text { Payback } \\
\text { Period (yr) }\end{array}$} & \multicolumn{9}{|c|}{ Investment Lifetime (yr) } \\
\hline & 3 & 5 & 7 & 10 & 15 & 20 & 25 & 30 & Infinite \\
\hline 1 & 83.9 & 96.6 & 99.2 & 99.9 & 100 & 100 & 100 & 100 & 100 \\
\hline 2 & 23.4 & 41.0 & 46.6 & 49.1 & 49.9 & 50.0 & 50.0 & 50.0 & 50.0 \\
\hline 3 & 0 & 19.9 & 27.1 & 31.1 & 32.9 & 33.2 & 33.3 & 33.3 & 33.3 \\
\hline 4 & 0 & 7.93 & 16.3 & 21.4 & 24.0 & 24.7 & 24.9 & 25.0 & 25.0 \\
\hline 5 & & 0 & 9.20 & 15.1 & 18.4 & 19.4 & 19.8 & 19.9 & 20.0 \\
\hline 6 & & & 4.01 & 10.6 & 14.5 & 15.8 & 16.3 & 16.5 & 16.7 \\
\hline 7 & & & 0 & 7.07 & 11.5 & 13.1 & 13.7 & 14.0 & 14.3 \\
\hline 8 & & & & 4.28 & 9.13 & 10.9 & 11.7 & 12.1 & 12.5 \\
\hline 9 & & & & 1.96 & 7.19 & 9.20 & 10.1 & 10.6 & 11.1 \\
\hline 10 & & & & 0 & 5.56 & 7.75 & 8.78 & 9.31 & 10.0 \\
\hline 12 & & & & & 2.93 & 5.45 & 6.68 & 7.34 & 8.33 \\
\hline 15 & & & & & 0 & 2.91 & 4.39 & 5.22 & 6.67 \\
\hline 20 & & & & & & 0 & 1.80 & 2.84 & 5.00 \\
\hline
\end{tabular}




\section{REFERENCES AND BIBLIOGRAPHY}

American Consulting Engineers Council, Industrial Market \& Energy Management Guide: Standard Industrial Classification 20, Food andKindred Products Industry, Washington, D.C.: American Consulting Engineers Council, 1985.

Clinton, W.J., and A.G. Gore, The Climate Change Action Plan, White House Office of Environmental Policy, Washington, D.C., October 1993.

Hopkins, M., and T. Jones, Getting in Gear: How Energy Efficiency Can Help Smaller Manufacturers Compete in the Global Marketplace, Alliance to Save Energy, January 1995.

Jones, $\mathrm{T}$., and $\mathrm{M}$. Verdict, Understanding the Energy Efficiency Investment Decisions of Smaller Manufacturers: A Report on a Series of Energy Efficiency Industry Roundtables. Report prepared by the Alliance to Save Energy for the U.S. Department of Energy, April 1995.

Kirsch, F. W., and W. J. Clark, "And the Survey Said: Energy Conservation Audits Help Most Manufacturers Save Money, Reduce Inefficiencies," Plant Engineering, September 1994a,pg. 80.

Kirsch, F. W., and W. J. Clark, "Why Some Manufacturers Conserve Energy and Save Money and Some Do Not," University City Science Center, Industrial Technology and Energy Management Division, September, 1994b.

Muller, M.R., The DOE Industrial Assessment Database: User Information, Version 4.0b, Office of Industrial Productivity and Energy Assessment, Rutgers University, October 1994a.

Muller, M.R., "Client Follow-up Survey Report," Office of Industrial Productivity and Energy Assessment, Rutgers University, 1994b.

Muller, M.R., "Industrial Support Through the U.S. DOE's EADC Program." Presented at the International Workshop on Industrial Energy Efficiency: Policy and Programmes, May 26-27, Washington, D.C., 1994c.

Muller, M.R., and P.P. Polomski, "Insights Into Industrial Energy Auditing from the EADC Program: An Academic Perspective." In Proceedings of the Fifteenth National Industrial Energy Technology Conference. Houston, March 24-25, 1993, pp. 278-285. 
Muller, M.R., P.P. Polomski, and D.J. Kasten, The Assessment Recommendation Code System (ARC), Version 4.0, Office of Industrial Productivity and Energy Assessment, Rutgers University, November 1994.

Muller, M.R., T. Barnish, and P.P. Polomski, "On Decision Making Following an Industrial Energy Audit." Presented at the Seventeenth National Industrial Energy Technology Conference, April 8-10, Houston, TX, 1995.

Wilfert, G.L., B.R. Kinzey, and P.S. Kaae, "Discussion Paper: A Preliminary

Review of Energy Savings from EADC Plant Audits." Pacific Northwest

Laboratory, Richland, Washington. June 1991. 


\section{Distribution}

No. of

Copies

Offsite

2 DOE/Office of Scientific and

Technical Information

5 J. Dowd

U.S. Department of Energy

Office of Policy/PO-64

1000 Independence Avenue, SW

Washington, D.C. 20585

6 M. R. Muller

Rutgers University

Department of Mechanical and

Aerospace Engineering

Piscataway, NJ 08855-1179

C. Glaser

U.S. Department of Energy

Office of Energy Efficiency

and Renewable Energy/EE-223

1000 Independence Avenue, SW

Washington, D.C. 20585

L. Ambs

University of Massachusetts

Department of Mechanical Engineerin:

Energy Analysis and Diagnostic Cent:

Amherst, MA 01003

W. J. Clark

University City Science Center

Industrial Technology and Energy

Management Division

3624 Market Street

Philadelphia, PA 19104
No. of

Copies

N. Elliott

American Council for an

Energy-Efficient Economy

1001 Connecticut Avenue, NW

Suite 801

Washington, DC 20036

W. M. Heffington

Texas A\&M University

Department of Mechanical Engineering

Energy Analysis and Diagnostic Center

College Station, TX 77843-3123

T. W. Jones

The Alliance to Save Energy

$1725 \mathrm{~K}$ Street, NW, Suite 509

Washington, DC 20006

F. W. Kirsch

University City. Science Center

Industrial Technology and

Energy Management Division

3624 Market Street

Philadelphia, PA 19104

G. Wheeler

Oregon State University

Energy Analysis and Diagnostic Center

Batcheller Hall 344

Corvallis, OR 97331-2405

Onsite

DOE Richland Operatiens Office

J. Turner

$\mathrm{K} 8-50$

Distr.1 
PNL-11175

UC-1400

No. of

Copies

17 Pacific Northwest National Laboratory

J. M. Roop (6)

K8-17

M. G. Woodruff (6)

BWO

Technical Report Files (5) 


\section{DISCLAIMER}

This report was prepared as an account of work sponsored by an agency of the United States Government. Neither the United States Government nor any agency thereof, nor any of their employees, makes any warranty, express or implied, or assumes any legal liability or responsibility for the accuracy, completeness, or usefulness of any information, apparatus, product, or process disclosed, or represents that its use would not infringe privately owned rights. Reference herein to any specific commercial product, process, or service by trade name, trademark, manufacturer, or otherwise does not necessarily constitute or imply its endorsement, recommendation, or favoring by the United States Government or any agency thereof. The views and opinions of authors expressed herein do not necessarily state or reflect those of the United States Government or any agency thereof. 